\title{
TRUCK NOISE I-C
}

\section{PAVEMENT SURFACE EFFECTS ON THE GENERATION OF TRUCK TIRE NOISE}

\author{
R. D. Kilmer \\ W. A. Leasure, Jr. \\ D. E. Mathews
}

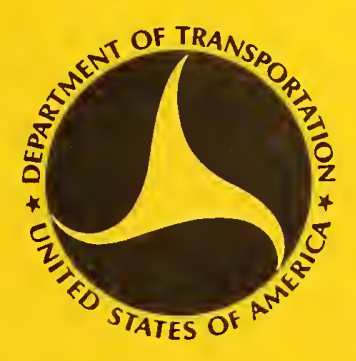

\section{FINAL REPORT OCTOBER 1975}

Availability is unlimited. Document has been released to the National Technical Information Service, Operations Division, Springfield, Virginia 22151 , for sale to the public

\section{U.S. DEPARTMENT OF TRANSPORTATION Office of the Secretary \\ Office of Noise Abatement \\ Washington, D.C. 20590}



TECHNICAL REPORT STANDARD TITLE PAGE

\begin{tabular}{|c|c|c|c|}
\hline & $\begin{array}{l}\text { Repart No } \\
\text { DOT-TS }\end{array}$ & 2. Government Accession No. & 3. Recipient's Cotolog No. \\
\hline \multirow{2}{*}{\multicolumn{3}{|c|}{$\begin{array}{l}\text { 4. Title and Subtitle } \\
\text { Truck Noise I-C } \\
\text { Pavement Surface Effects on the Generation of } \\
\text { Truck Tire Noise }\end{array}$}} & $\begin{array}{l}\text { 5. Report Dote } \\
\text { October } 1975\end{array}$ \\
\hline & & & 6. Performing Orgonization Cade \\
\hline \multirow{2}{*}{\multicolumn{3}{|c|}{$\begin{array}{l}\text { 9. Performing Organizotion Nome ond Address } \\
\text { National Bureau of Standards } \\
\text { Department of Commerce } \\
\text { Washington, D.C. } 20234\end{array}$}} & \multirow{2}{*}{\begin{tabular}{|l|} 
10. Work Unit No. \\
11. Contract ar Grant No. \\
DOT-AS-10004
\end{tabular}} \\
\hline & & & \\
\hline \multirow{2}{*}{\multicolumn{3}{|c|}{$\begin{array}{l}\text { 12. Sponsoring Ageney Nome and Address } \\
\text { U. S. Department of Transportation } \\
\text { Office of the Secretary } \\
\text { Office of Noise Abatement } \\
\text { Washington, D.C. } 20590\end{array}$}} & 13. Type of Repart and Period Covered \\
\hline & & & 14. Sponsaring Agency Code \\
\hline
\end{tabular}

15. Supplementory Nates

16. Abstract

This report presents data showing the effect that pavement surface has on the generation of truck tire noise. Three different tread designs -- rib, cross-bar and pocket -- were tested at speeds of 40,50 and $60 \mathrm{mph}(64.4,80.5 \mathrm{and} 96.5 \mathrm{~km} / \mathrm{hr})$ while coasting on eight different pavement surfaces at the Texas Transportation Institute. These surfaces represent a wide range of surface texture. Also presented are the results of one method of quantitatively characterizing pavement surface texture; namely, the mean square value of the macrotexture profile, obtained utilizing a macrotexture profile tracer. Plots of tire noise versus this particular measure of surface texture show that up to a certain macrotexture the generated noise is tire dependent while above this value the pavement macrotexture appears to be the controlling parameter. Because of the wide variation in noise level with changes in surface texture for the pocket retread, this tire is investigated as a possible simple calibrator of surface texture. These investigations serve as the basis for evaluation of the effect of surface texture on the generation of tire noise.

\section{Key Words}

Acoustics; noise measurement; noise (sound); tire noise; transportation noise; truck.

19. Security Clossif. (of this repart) Unclassified
20. Security Clossif. (of this poge)

Unclassified

18. Distribution Stotement

Availability is unlimited. Document may be released to the National Technical Information Service, Operations Division, Springfield, VA 22161, for sale to the public.
(1) 

1. Introduction . . . . . . . . . . . . . . . . . . . . . . . . . . . I

2. Field Test Program (Data Acquisition) . . . . . . . . . . . . . 2

2.1. Field Test Site . . . . . . . . . . . . . . . . 2

2.2. Test Tires... . . . . . . . . . . . . . . . 2

2.3. Test Vehicle . . . . . . . . . . . . . . . . . 7

2.4. Test Procedure . . . . . . . . . . . . . . . . . . 7

2.5. Test Pavement Macrotexture . . . . . . . . . . . . . 15

a. Pavement Surface Characteristics. . . . . . . . . . 15

b. Measurement of Pavement Macrotexture. . . . . . . . . 16

c. Macrotexture Profile Tracer . . . . . . . . . . 16

3. Parametric Study . . . . . . . . . . . . . . . 18

3.1. Tread Design and Speed . . . . . . . . . . . . . . . 22

3.2. Pavement Surface . . . . . . . . . . . . . . . . . 25

3.3. Spectral Characteristics . . . . . . . . . . . . . . . 25

3.4. Surface Texture Measurement Results. . . . . . . . . . . . . 33

3.5. Conciusions. . . . . . . . . . . . . . . . . . 43

4. Appendix A. Truck Tire Noise Data . . . . . . . . . . . . . . . 45

5. Appendix B. Macrotexture Profile Measurement Results. . ... . . . . 67

6. Appendix C. Instrument Descriptions . . . . . . . . . . . . . . . . 84

7. Appendix D. Description of Macrotexture Profile Tracer. . . . . . . 87

8. Appendix E. Description of Test Pavements . . . . . . . . . . . . . 93

9. References . . . . . . . . . . . . . . . . . . . . 108 



\section{Introduction}

The National Bureau of Standards, under the sponsorship of the U. S. Department of Transportation, has over the past five years established an extensive data base of truck tire noise $[1,2,3,4,5]$. If As a result of this program and the work of other researchers $[6,7,8,9,10,11]$, pavement surface has been identified as a major factor which influences tire-road interaction noise. Although this dependence has been noted, the lack of an appropriate method for characterizing the pavement texture in a quantitative manner has hindered the understanding of the effect of surface texture on the generation of tire noise. This deficiency is troublesome ircm at least two standpoints. First, without a quantitative pavement texture description over the proper texture scale, it is very difficult to authenticate any of the currently proposed models of tire noise. Second, testing of tires to establish compliance with certification standards will require quantitative specification of pavement textures. The terms. "smooth" or "rough" and "asphalt" or "concrete" are obviously insufficiently preciser Also, the degree of compliance of motor vehicles with noise standards enforced by roadside monitoring is, and will be, subject to variability from texture differences until the textures of moritoring sites can be specified quantitatively in noise-related terms.

This report presents data showing the effect of different pavement surfaces -- representing a broad range of surface textures -- on tire noise. The data consist of maximum A-weighted sound levels and spectral information for truck coastbys over eight different pavement surfaces. The measurements were made utilizing two tripod mounted microphones at a height of 48 inches $(1.2 \mathrm{~m})$ above the roadway surface and located 25 and 50 feet $(7.6$ and $15.2 \mathrm{~m})$ from the centerline of the test pavement. Also presented are data resulting from one approach of quantitatively characterizing pavement surface texture. These data consist of $1 / 3$-octave band (spatial frequency) profile spectral information for the eight test pavements. These data are compared with the corresponding tire noise levels in an attempt to correlate pavement surface texture with tire noise. The results are presented in both tabular and graphical form as well as in the form of summary plots showing general trends.

$1 /$ Figures in brackets indicate the literature references at the end of this report. 


\section{Field Test Program (Data Acquisition)}

This test program was sinilar to previous DOT/NBS truck tire noise studies with the exception that a new field test site was utilized. A discission of the details associated with the test program for the evaluation of the effect of pavement surface on truck tire noise follows.

\subsection{Field Test Site}

The research runway of the Texas Transportation Institute (TTI) located at the Texas A \& M Research Annex, College Station, Texas, was selected as the test site for the data acquisition phase of the program. This test site, located on property previously used as a jet-trainer airfield, provided an adequate stretch of pavement [7c00 feet $(2133.6 \mathrm{~m})]$, a flat terrain providing a well-defined reflecting surface without any unusual reflection or attenuation effects, and most importantly, eight different pavement surfaces representing a broad range of surface textures.

The eight different pavements were one portion of a skid test facility. Each test pad was 24 feet $(7.3 \mathrm{~m})$ wide and 600 feet $(182.9 \mathrm{~m})$ long with a cross slope of about $1 / 8$ inch per foot $(1.04 \mathrm{~cm} / \mathrm{m})$. These test pads were located approximately midway along runway B which is 150 feet $(45.7 \mathrm{~m})$ wide and 7000 feet $(2133.6 \mathrm{~m})$ long. The overall layout of the Texas A \& M Research Annex showing the location of runway $B$ and the test pads is given in Figure 1 . Figure 2 is a detailed layout of the eight test paūs as constructed on runway B.

These test pads were designed as reference surfaces for the comparison of the skid characteristics of various tires and for the calibration and correlation of skid resistance measuring devices[12, 13, 14]. Since the skid characteristics are extremely dependent on the surface condition of the pavement, these test surfaces were carefully constructed and in certain cases polished or coated to achieve a uniform surface texture.

The test pads can be categorized into three groups based on their materials and mlethods of construction. Group 1 (test pads 3, 4, 5 ana 8 ) is comprised of hot-mixed asphaltic concrete courses which were surface finished by a variety of methods for developing a consistent surface texture. Group 2 (test paōs 1 and 2) consist of surfaces prepared by cleaning or surface coating previously constructed asphaltic concrete or portland cement courses. Group 3 (test pads 6 and 7) consist of asphait chip seal surfaces. Photographs showing the surfaces of these eight test pads are presented in Figure 3. Detailed descriptions of the pavement surfaces are given in Appendix $\mathrm{E}$.

\subsection{Test Tires}

Based on previous DOT/NBS studies, new tires representing three basic tread designs were chosen -- rib, cross-bar, and pocket retread. The characteristic tread element patterns for the three tires used in this study are shown in Appendix A. 


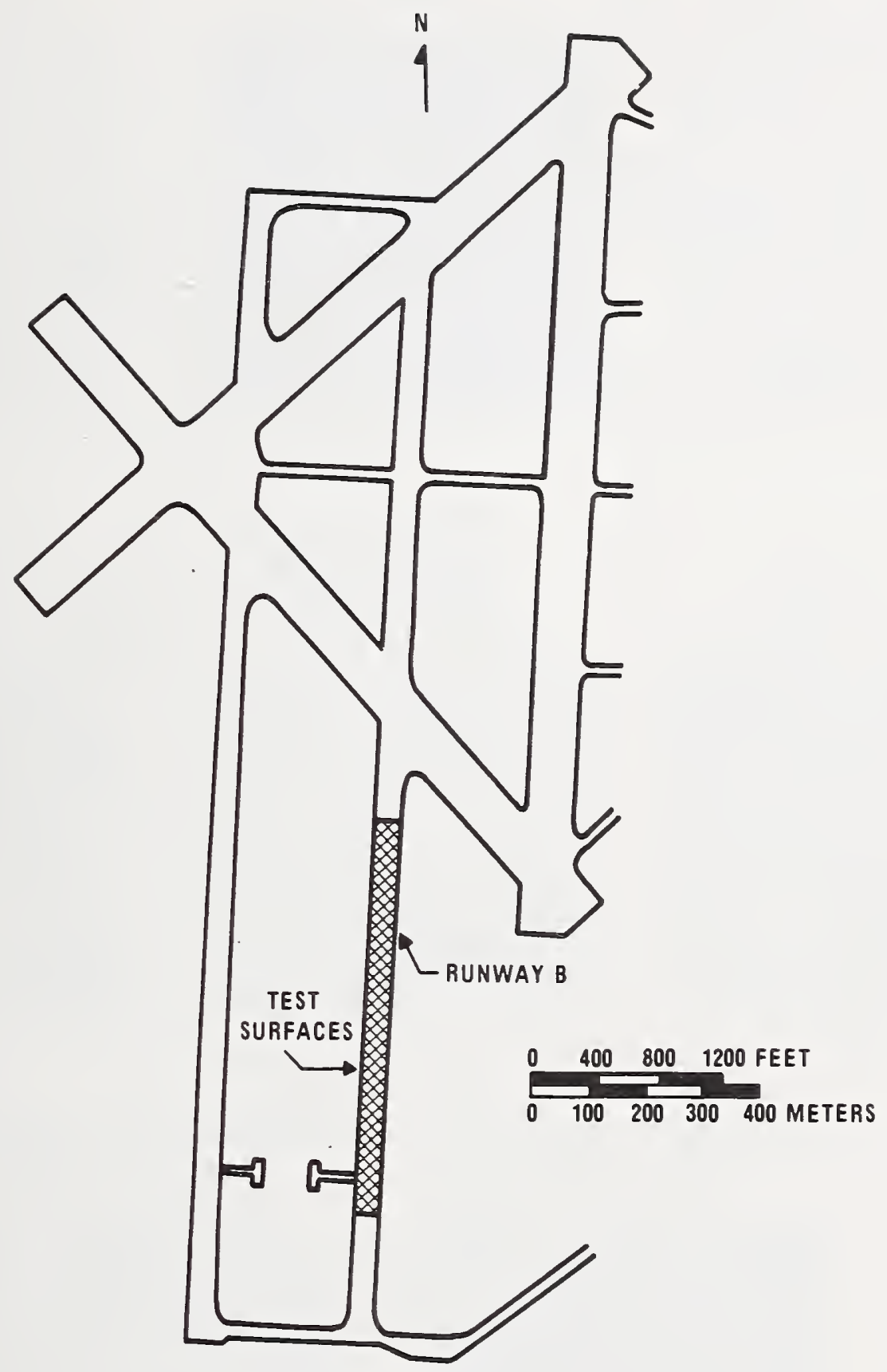

Figure 1. PIan of Texas A \& M Research Annex, College Station, Texas, showing the locations of the pavement test pads. 


\section{CEMTERHIPE}

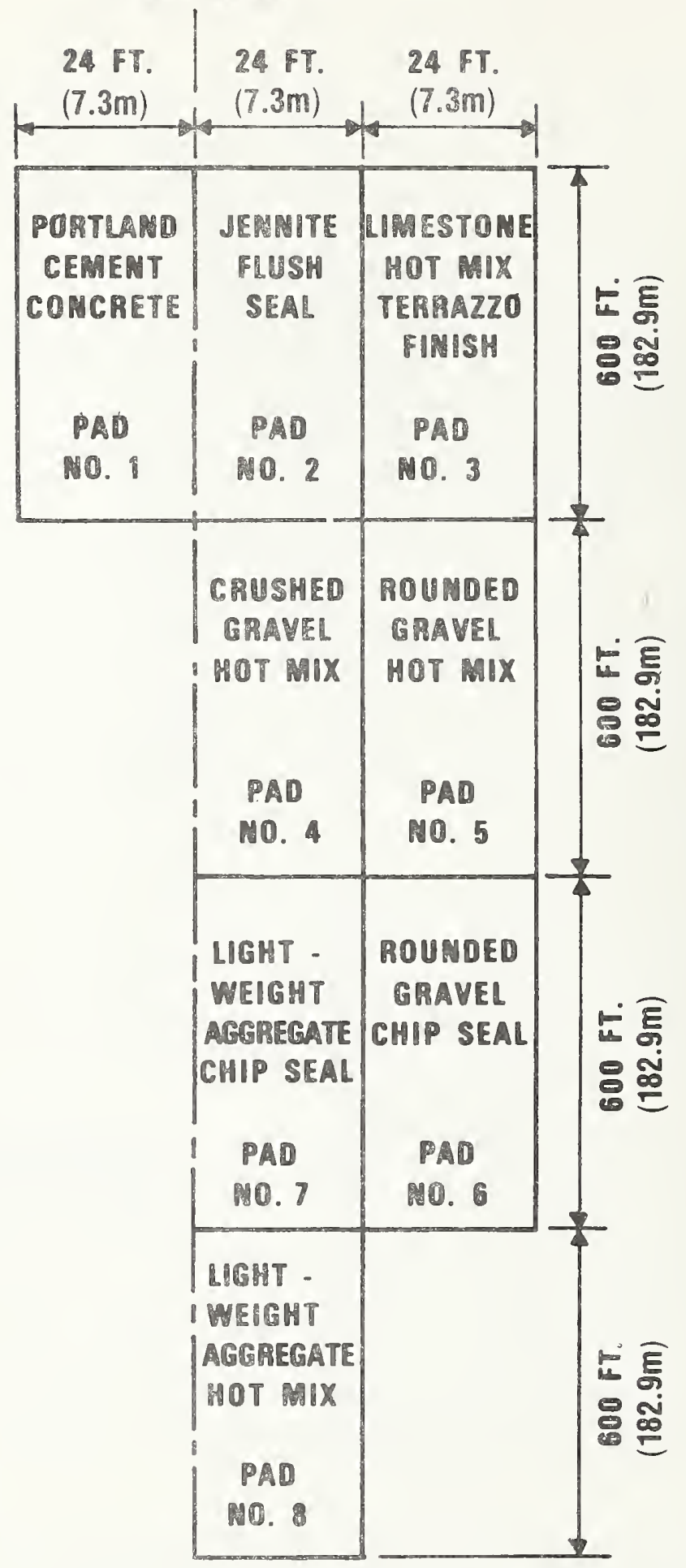

Figure 2. Plan of test pads on runway B. 


\section{PORTLAND CEMEMT CONCRETE, PAD.I}

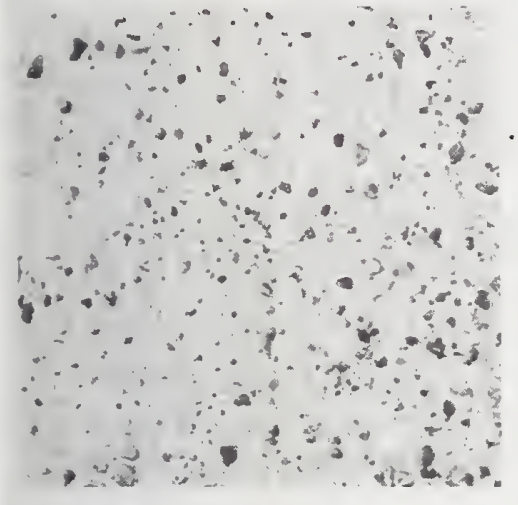

CRUSHED GRAYEL HOT MIX, PAD-4

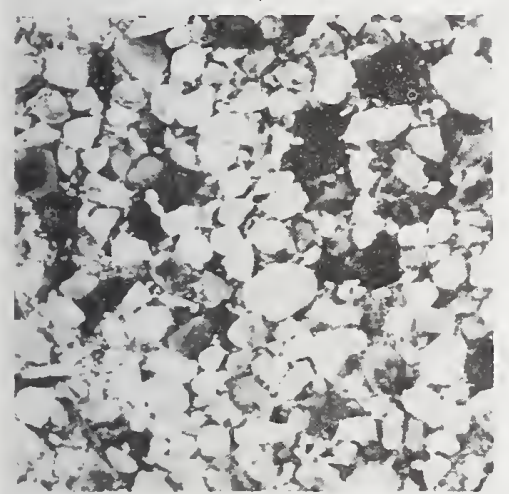

JEMHITE FLUSH SEAL,

PAD-2

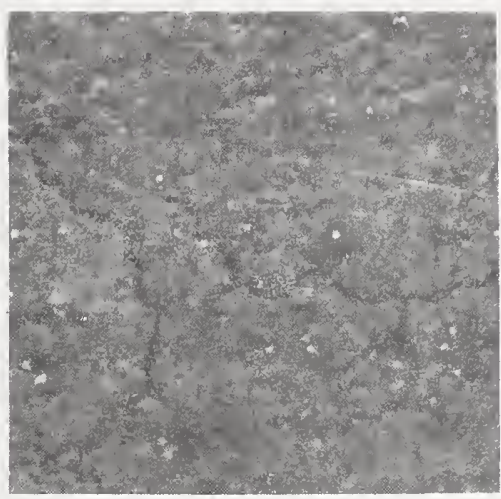

LIMESTOHE HOT MIX TERRAZZO FINISH, PAD-3

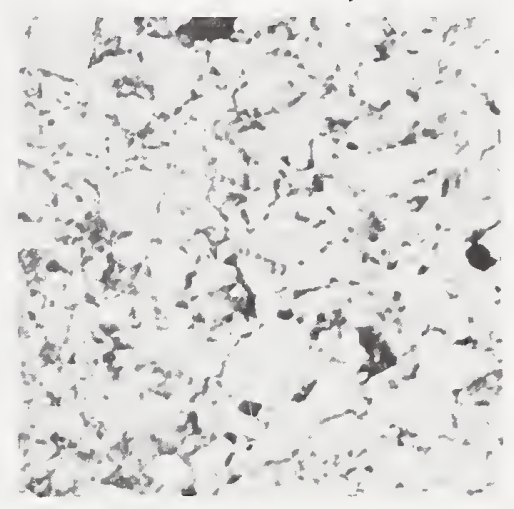

ROUNDED GRAVEL HOT MIX, PAD-5

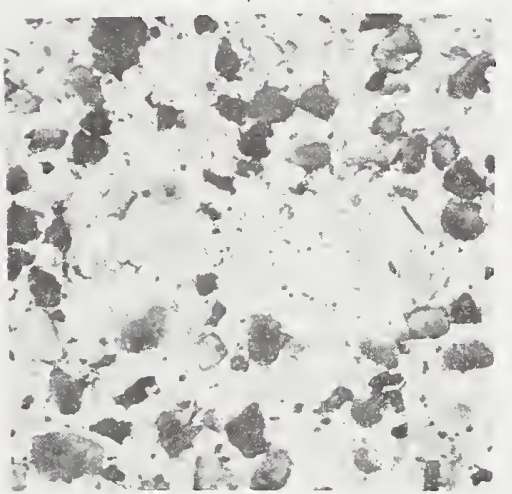

ROUHDED GRAVEL CHIP SEAL, PAD-6

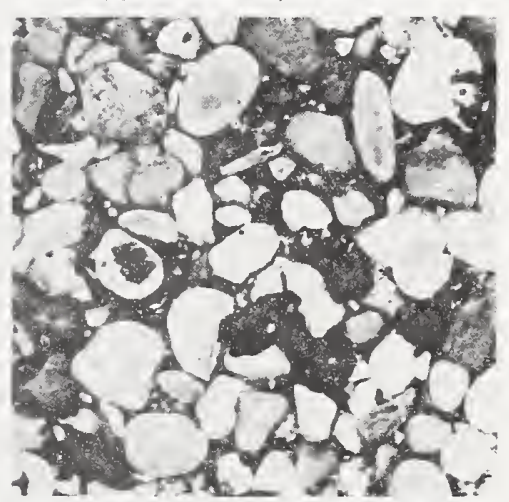

LIGHTWEIGHT AGGREGATE CHIP SEAL, PAD-7

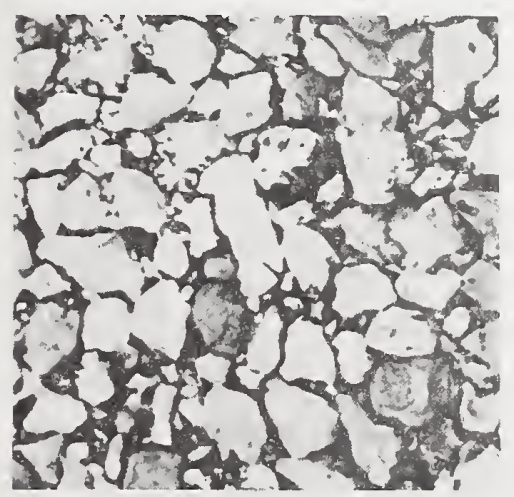

LIGHTWEIGHT AGGREGATE HOT MIX, PAD.8

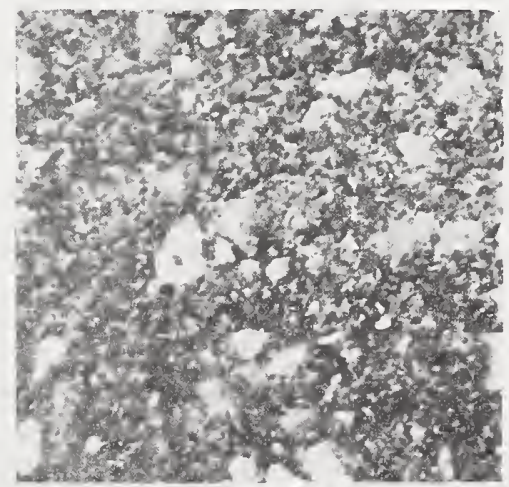

Figure 3. Pavement surface details of the eight test pads. Scale l:l. 
The rib tire (tire TB) has ribbed, multi-siped, rounded shoulders. It is representative of a type of tire primarily utilized on the steering and trailer axles.

The cross-bar tire (tire TD) has a circumferential tread, face center (central rib) for lateral traction with shoulders of laterally aligned bars with sipes for added traction.

The pocket retread pattern is not a design used by major tire manufacturers but represents the work of independent retread companies. For this reason, many varieties exist and the tire is known to different people under different titles. This design traps air in the pockets as it seals against the road surface and releases the entrapped air when the pocket unseals. The pocket retread (tire TI) was directional (should be mounted one way for most efficient operation), having slanted cups or pockets, with a bar across the center of the pocket, and a shoulder rib. The pocket retread tire was selected for testing because of its potential as a simple calibrator of pavement surface texture. Previous studies[1,2] have shown the pocket tread tire to be more sensitive to surface texture variation than tires with either a cross-bar or rib tread design. More is said about this in Section 3.

In accordance with standard operating procedure the tires utilized during this test program were not balanced. When new tires are installed on a truck, balancing is not performed unless there is a definite handling problem or severe vibration reported which might jeopardize the safety of the vehicle. When such a problem arises, the entire front end assembly, not just the tires, is checked. Unlike the normal practice with automobile tires, only front (steering) tires are ever balanced on trucks.

A tire was not considered acceptable as a test specimen for the tire noise investigation until it had undergone arbreak-in period of sufficient mileage under actual driving conditions to ensure the removal of all mold marks and manufacturing irregularities. Immediately prior to the actual noise testing of a given set of tires, a warm-up procedure was followed which normally required a minimum trip of approximately 10 miles $(16.1 \mathrm{~km}$ ).

Tread depth measurements for each test tire were taken at four equally spaced locations around the tire circumference. The device utilized for this measurement was a depth gage with $1 / 32$ inch $(0.8 \mathrm{~mm})$ graduations. The operator located the depth gage; over a major groove (not over the sipes or other small grooves), depressed the probe into the groove, and noted the tread depth directly from the instrument. The resulting data are given in Appendix A. 


\section{2.?. Test Vehicle}

The vehicle used throughout this test program was an International $2 /$ Mociel 1600 chassis equipped with a 20-foot stake body and hydraulic tail gate. This $4 \times 2^{-}$single-chassis vehicle (similar to that utilized in previous IOT/NeS[1, 2] truck tire noise programs) was equipped with a V-392 gasoline engine, 13-inch clutch, 5-speed transmission, 2-speed rear axie, and $11.00 \times 22.5$ tires. This vehicle had a gross weight capacity of 25,000 pounds $(11,364 \mathrm{k.g})$. Figure 4 provides an overall view of this test vehicle.

The truck was operated in the loaded condition. Figure 5 shows the loading arrangement. A variety of weights ( 4 concrete blocks, 2 scrap electrical motor casings and several bags of sand) were disitributed to develop a lcading equivalent to 75 percent of the rated tire load at $70 \mathrm{psi}\left(4.8 \times 10^{5}\right.$ $\mathrm{Pa}$ ) per Tire and Rim Association recommendetions. The weight distribution was as forlotis:

$\begin{array}{cr}\text { front axle } & 7,880 \text { pounds }(3582 \mathrm{~kg}) \\ \text { rear axle } & 17,730 \text { pounds }(8059 \mathrm{~kg}) \\ \text { gross vehicle weight } & 25,610 \text { pounds }(11641 \mathrm{~kg})\end{array}$

The test tires were always mounted on the drive axle and rib tires whose characteristic tire noise level was known to be low were always mounted on the steer.ing axle.

\subsection{Test Procedure}

Prior to a discussion of the test procedure, a few words of description are necessary to establish the placement of all instrumentation within the test section. Figure 6 shows the placement of the microphones, racio transmitters, and the path of the test vehicle.

The two microphones were located at 25 and 50 feet $(7.6$ and $15.2 \mathrm{~m})$ from the centerline of the lane in which the venicle travelled along a line perpendicular to the path of travel of the test vehicle. Radio transmitters, activated by the truck runing over a tape switch, were located along the test lane parallel to the path of the vehicle. Coaxial cables connected the microphones with the tape recording and monitoring equipment which was located more than 150 feet $(45.7 \mathrm{~m})$ back from the edge of the test pads.

$2 /$ The commercial vehicles utilized are identified in this report in order to adequately describe the vehicles on which the test tires were mounted throughout this program. In no case does such identification imply recommendation or endorsement by the National Bureau of Standards, nor does it imply that these vehicles were necessarily the best available for the purpose.

$3 /$ The nomenclature $4 \times 2$ relates to the number of wheel positions -- 4 , and the number of äriven positions - - 2, but has no relationship to the number of tires - - 6. Thus, a $6 \times 4$ would have 10 tires mounted at 6 wheel positions, 4 of which are driven. 


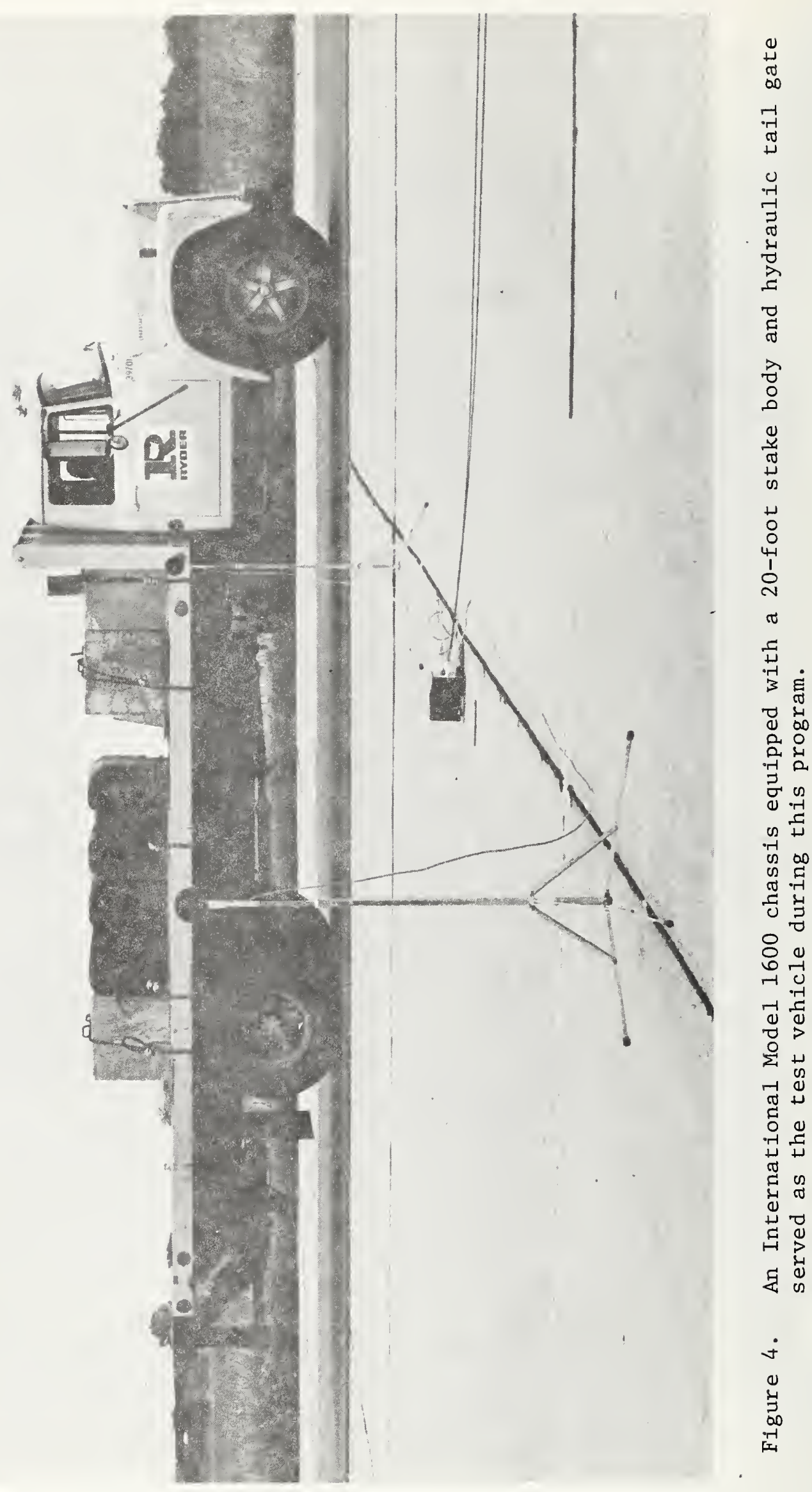




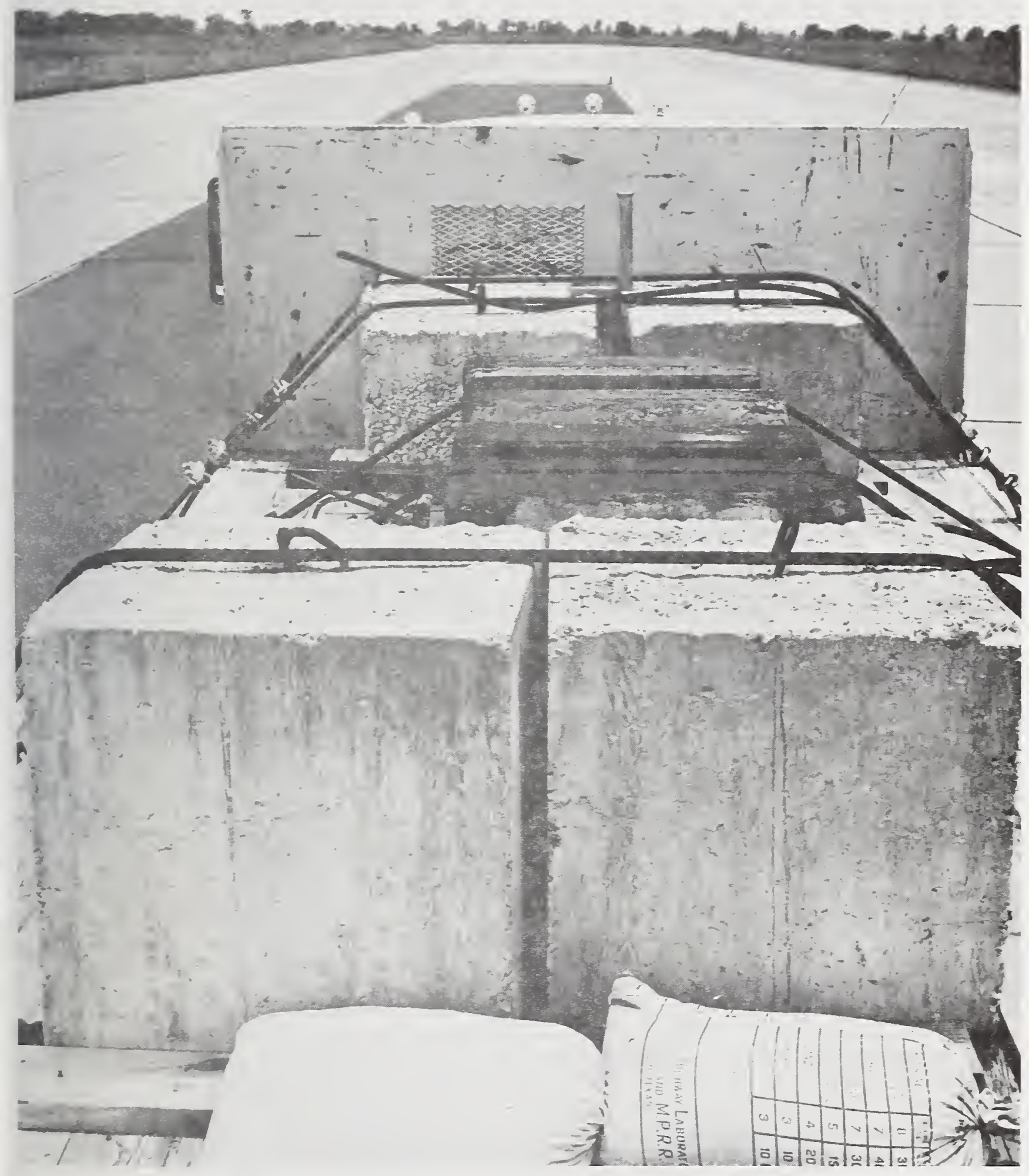

Figure 5. A view of the test vehicle body showing placement of the various weights used to provide tire loading. 


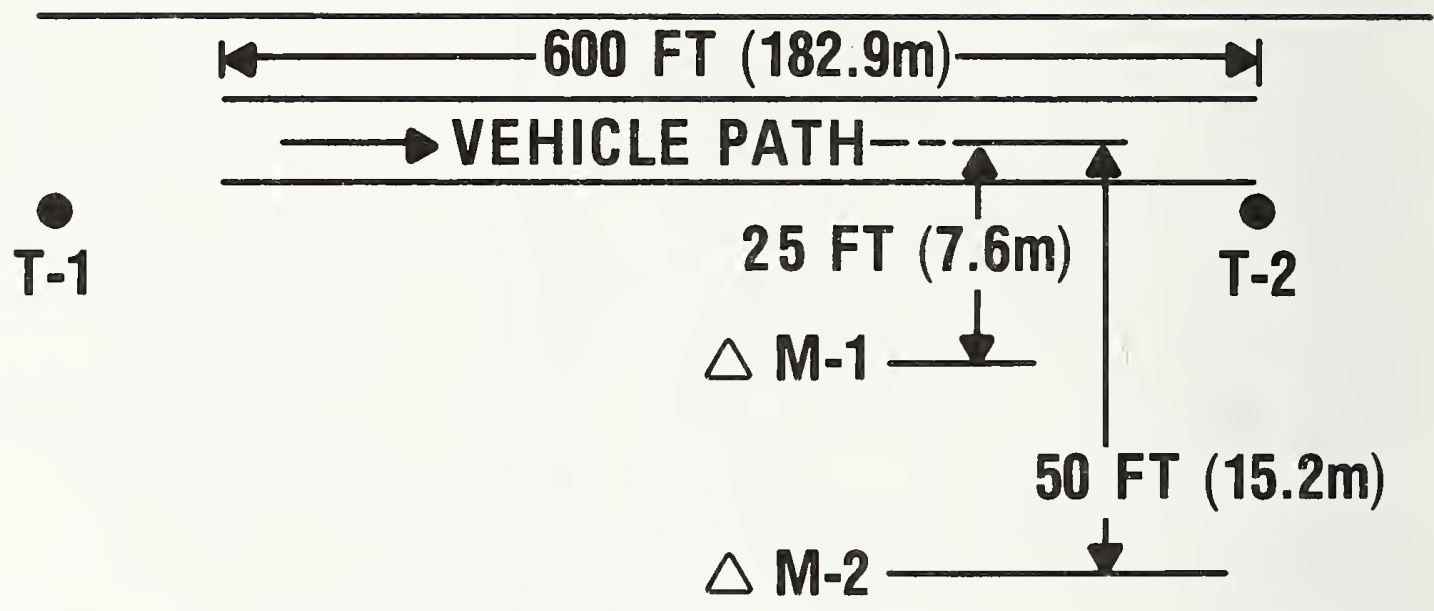

\section{- TRANSMITTER $\triangle$ MICROPHONES}

Figure 6. View of test section showing instrumentation placement plus vehicle path (not to scale). Microphones were placed at 25 and 50 feet $(7.6$ and $15.2 \mathrm{~m})$ from the centerline of the lane in which the vehicle travelled and along a line perpendicular to the path of travel. Radio transmitters (activated by tape switches) remotely controlled the on/off sequence of the tape recorder. 
For a nominal $50 \mathrm{mph}(80.5 \mathrm{~km} / \mathrm{hr}$ ) run (the vehicle should be travelling 50 mph $(80.5 \mathrm{~km} / \mathrm{hr})$ as it passed the microphone array) the driver of the test vehicle accelerated the truck to slightly more than the desired speed to compensate for the deceleration characteristics of the particular vehicle.

As the truck passed over the initial tape switch, the tape recorder was remotely commanded to turn on via the signal from the radio transmitter. The initial tape switch/radio transmitter system was located such that the tape recorder was up to speed by the time that the test vehicle entered the test section. (The location was selected based on the maximum test speed of the vehicle during the program.) Following a time delay a signal was recorded on the FM channel of the tape recorder which designated the start of data. As the truck left the test section, a second tape switch was activated. The radio transmitter sent a signal to the tape recorder identifying the end of data and then the tape recorder was remotely turned off. The data start and data end signals were transmitted to the receiver at different frequencies. An elapsed time clock indicated the time it took for the vehicle to cover the known distance between the tape switches from which the average speed of the vehicle was calculated.

Figure 7 identifies the components that constituted the data acquisition system -- a one-inch condenser microphone, a battery-operated microphone power supply (to supply the polarization voltage to the microphone), a step attenuator which provided the capability for selection of gain over a range of $60 \mathrm{~dB}$ in $10 \mathrm{~dB}$ steps, and a three-channel analog tape recorder. The system included both a flat frequency response hold capability -- which provided an indication as to whether or not a tape channel had saturated (saturated runs were repeated) - - and an A-weighting hold capability -- which provided a direct reading, in the field, of the maximum A-weighted sound level observed during a passby without having to return to the laboratory for the analysis of the tapes. The measurements were performed out-of-doors; therefore, windscreens were placed over the microphones to reduce the noise produced by wind passing over the microphone. A single point calibration utilizing a pistonphone which produced a $124 \mathrm{~dB}$ sound pressure level ( $\mathrm{re} 20 \mathrm{\mu Pa}$ ) at a frequency of $250 \mathrm{~Hz}$ was used for system calibration in the field. Calibration tones were recorded on the data tape once each hour as well as at the beginning and end of each data tape. Figure 8 shows the microphone array and associated instrumentation in the field at the Texas Transportation Institute test site.

Once the data had been recorded, the analog tapes were returned to the National Bureau of Standards for reduction and analysis. Figure 9 identifies the equipment which was utilized for analysis purposes. Each tape was played back a channel at a time through the real-time analyzer. An interface-coupler was necessary to make the real-time analyzer compatible with a mini-computer. When a timing signal appeared on the analog tape, the real-time analyzer was commanded to begin analysis. A time constant of 0.2 second above $200 \mathrm{~Hz}$ and one which below $2.00 \mathrm{~Hz}$ followed a straight line to 3.15 seconds at $12.5 \mathrm{~Hz}$ was utilized to obtain the root-mean-square ( $r m s$ ) value of the level in each one-third octave band at the output of the analyzer. Once all data had been 


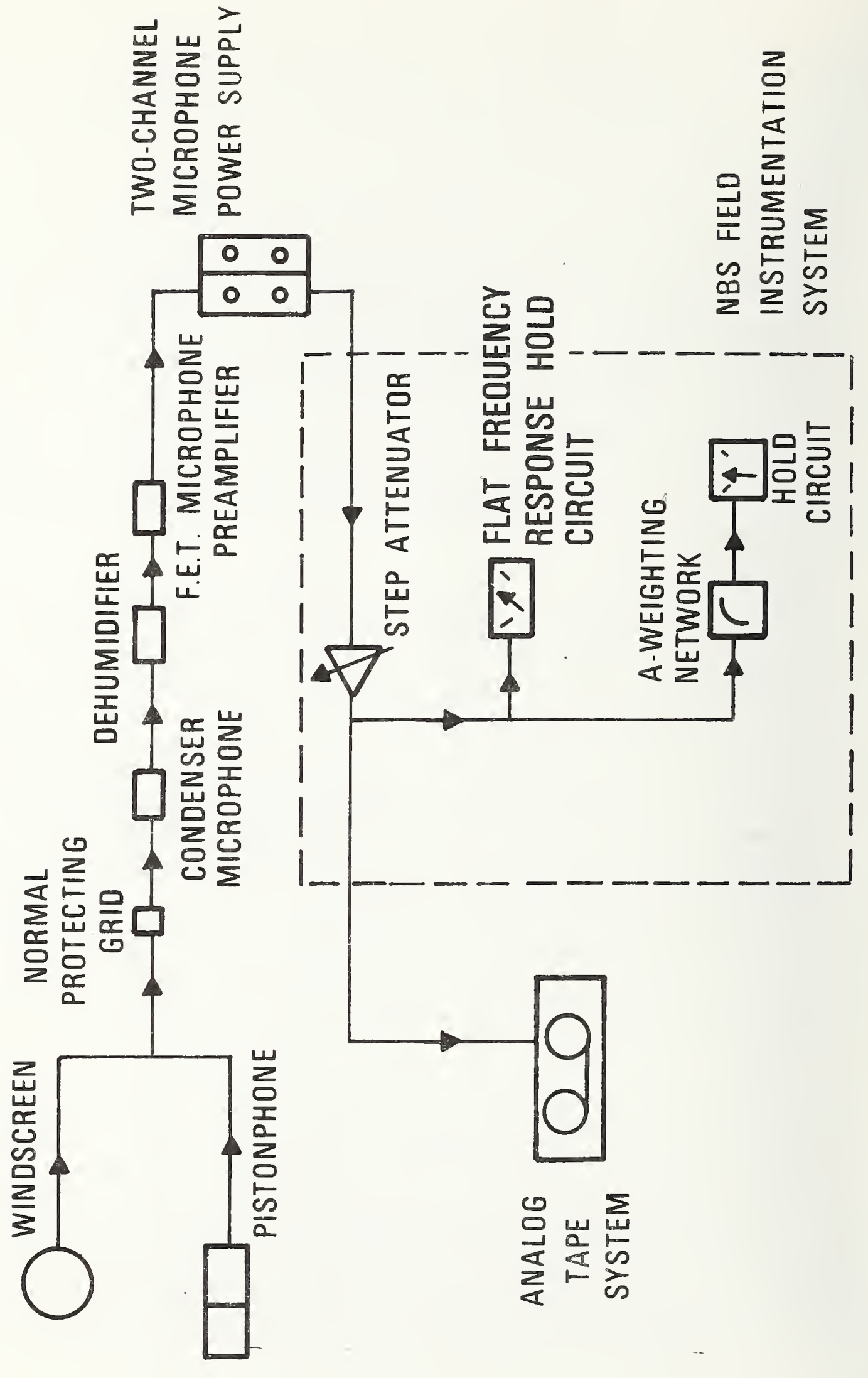




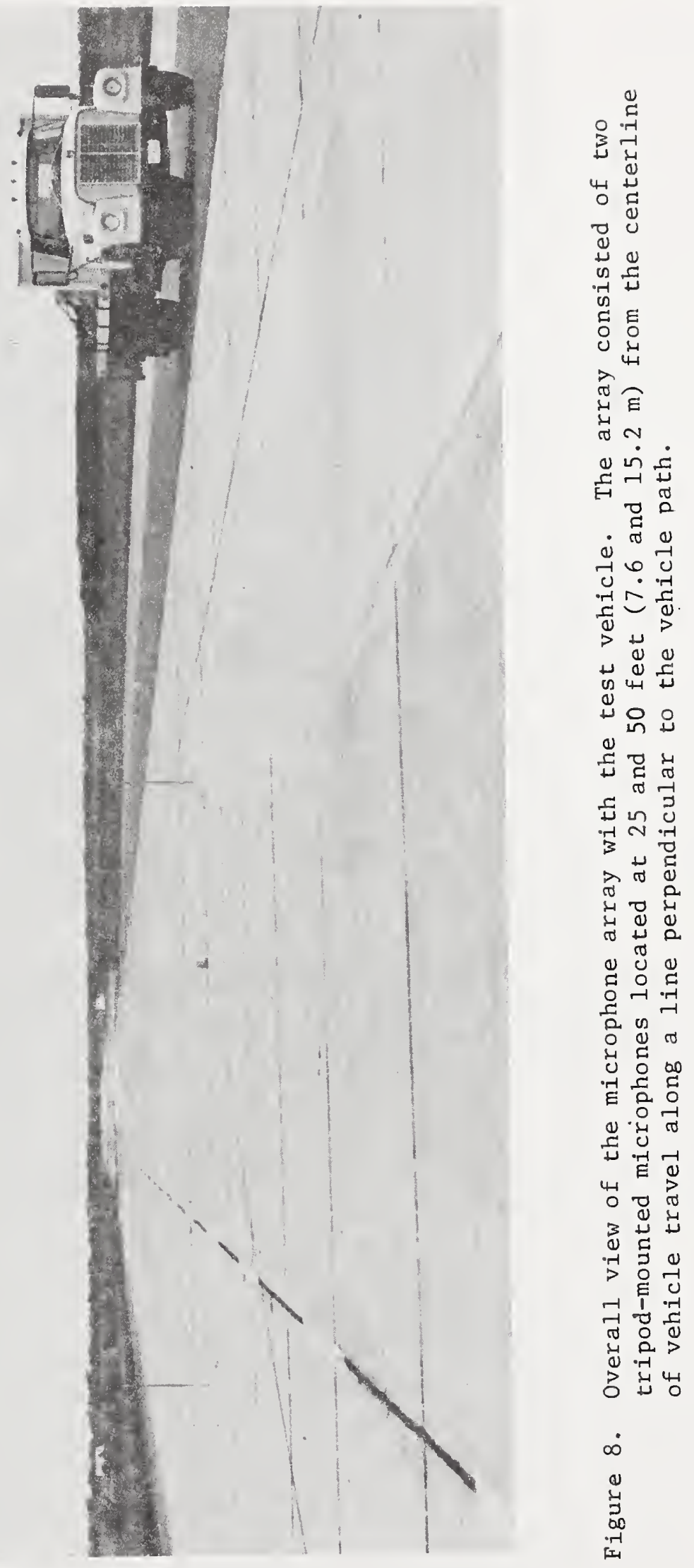




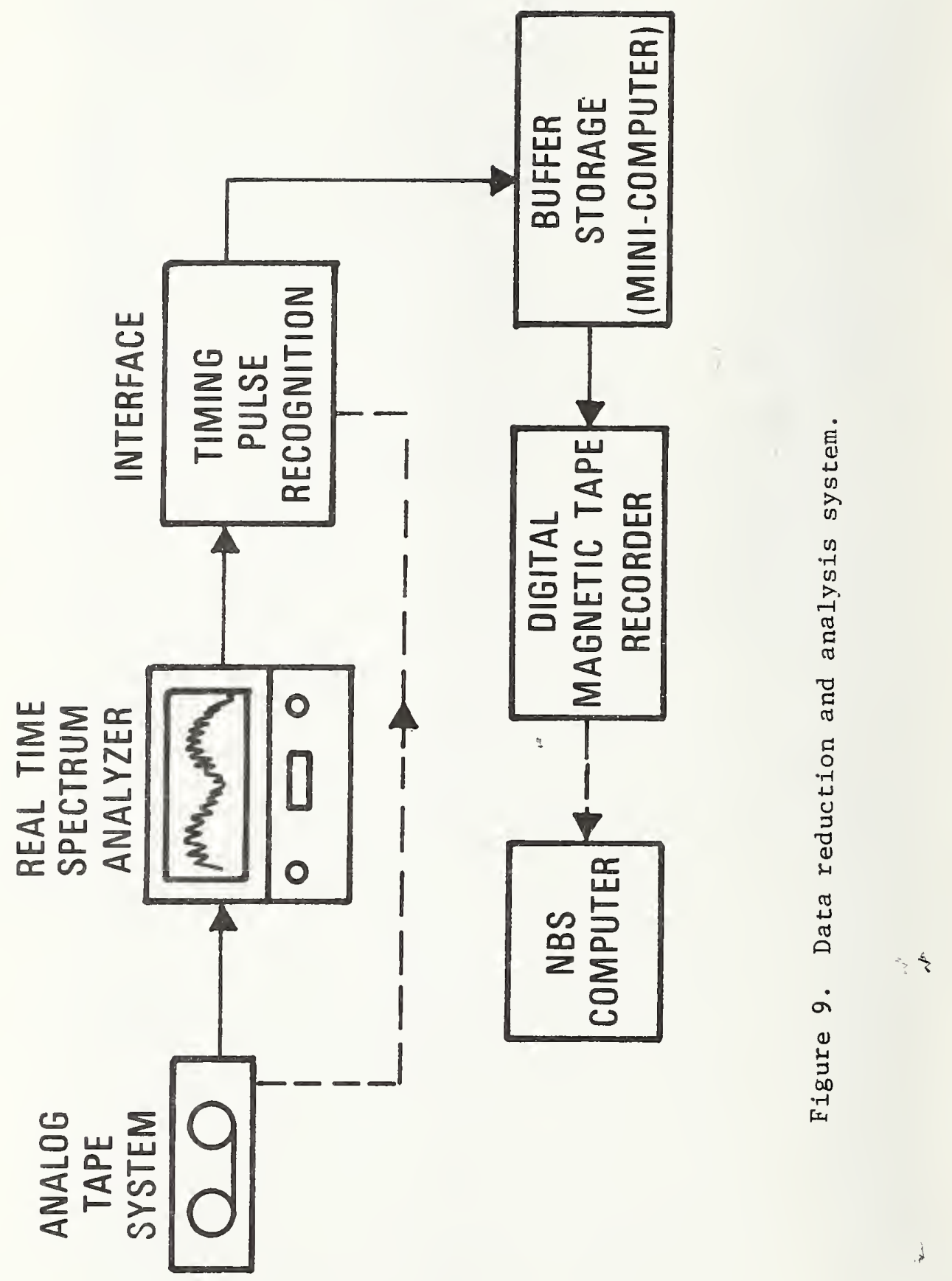


analyzed in one-thirà octave banàs, the computer stored the data and dumped it onto digital magnetic tape. Tnis tape was fomated to be acceptable to the large IBS computer which was utilizec for further analysis. This instrumentation system provicē for êfficient äata acquisition and data handing for the thousands of data points generated for each truck passby.

Appencix C contains a brief description of the instruments utilized for cata acquisition, reduction anc analvsis.

\subsection{Test Pevement Hacrotexture}

In orcer to correlate tire noise with pavement suriace, a technioue of characterizing the parement surface rariations is needed. A discussion of pavement surface texture and one metiod for quantitatively describing surface texture is discussec below.

\section{a. Pavement Suriace Characteristics}

The surface variations of a roabray can be classified into three regimes: roughness, macrotexture, and microtexture. These classifications are based on the size of the vaniations, and range from roughness which is the largest measure of surface variations to microtexture which is the smallest.

Roughness refers to the waves, pot holes, and surface aeterioration on the overall roaciry suriace. Such large scale irregularities are normally measurea. in inches per mile and have no relationship to irregularities as small as the individual pieces of aggregate. The pavement roughness is the roadray characteristic that determines vehicle ride quality. Previous studies hare shown that variations in the surface of less than $1 / 2-i n c h$ ( $1.27 \mathrm{~cm}$ ) in length do not materially affect the riding quality and have been classified as pavement texture[15].

Macroscopic texture, or macrotexture, refers to the large-scale texture of the pavement surface governed by the size and shape of the surface aggregate. The scale of macrotexture generaily spans the range of sizes of particies in the pavement aggregate -- approximately from 0.01 to 0.4 inches $(0.25$ to 10 mem) $[16]$.

licroscopic texture or microtexture refers to thé fine-scale texture contributed by individual small asperities on the individual aggregate particles. The scale of microtexture generally ranges below that for macrotexture with some overlap in the region separating the two regimes.

Of these three regimes of surface variations, macrotexture is believed to have the most infiuence on tire noise. This assumption is based on a consideration of the size of the tread element spacing relative to the texture variations (see Section 3.2). Since macrotexture is approximately on the same scale as the tread element spacing, it is this characteristic oi the pavement surface which is thought to be important in at least some tire noise source mechanisms. 
The macrotexture is due largely to the physical, mechanical, and chemical properties of the aggregate forming the surface of the roadway. The physical properties, which include the size, shape, and pore structure of the material, are the major controlling factors of pavement texture. The particle size is measured by the particle grading, which is the distribution of different particles of aggregate among various sizes; e.g., the relative amounts of $3 / 8$-inch to $1 / 2$-inch $(0.95 \mathrm{~cm}$ to $1.27 \mathrm{~cm})$ size, $1 / 4$-inch to 3/8-inch $(0.64 \mathrm{~cm}$ to $0.95 \mathrm{~cm})$ size, etc. The particle shape, generally classified as either uncrushed (rounded) or crushed,(angular or cubical), influences not only the macrotexture but also the microtexture of the pavement surface. The pore structure which is the size, volume and shape of the void spaces within the aggregate, is partially controlled by the maximum particle size and the material used for the pavement binder. The mechanical and chemical properties of the aggregate relate more to the wearing and erosion characteristics of the individual aggregate particles; but, these properties are also important since they will determine how the macrotexture changes with vehicle usage and weathering.

In addition to the aggregate properties, another important factor which affects the surface macrotexture of pavements is the method of surface finishing, including surface treating or coating.

\section{b. Measurement of Pavement Macrotexture}

To determine pavement macrotexture, a measuring technique which is capable of accounting for aggregate size, shape and pore structure and irregularities due to surface finishing is needed. The National Bureau of Standards, under the sponsorship of the U. S. Department of Transportation, supported a study by the Pennsylvania Transportation Institute (PTI), University Park, Pa., which investigated the feasibility of physically characterizing surface macrotexture by profile spectral analysis. The technique investigated by PTI characterizes pavement macrotexture through the use of space frequency spectrum analysis of the surface macrotexture profile as measured by a profile tracer recently developed by PTI[16]. The space frequency data represent a measure of the physical size distribution of the surface profile variations and as such are not a function of velocity. Correlation between pavement macrotexture spectra and tire-roadway interaction noise spectra requires a scale-up of the space frequency spectra to the tire passage speed, i.e., the space frequency is multiplied by, for example, $50 \mathrm{mph}(80.5 \mathrm{~km} / \mathrm{hr})$. Further discussion of space frequency and its relationship to the generated noise is presented in section 3.4. A general description of this device and how it operates follows.

\section{c. Macrotexture Profile Tracer}

The profile tracer developed by PTI and used in this study is shown in Figure 10. This device is designed to accurately measure the local variations in surface geometry by transversing a section of pavement and recording the changes of profile height as measured by a displacement transducer. 'More details of the profile tracer and its calibration are given in Appendix $D$. 


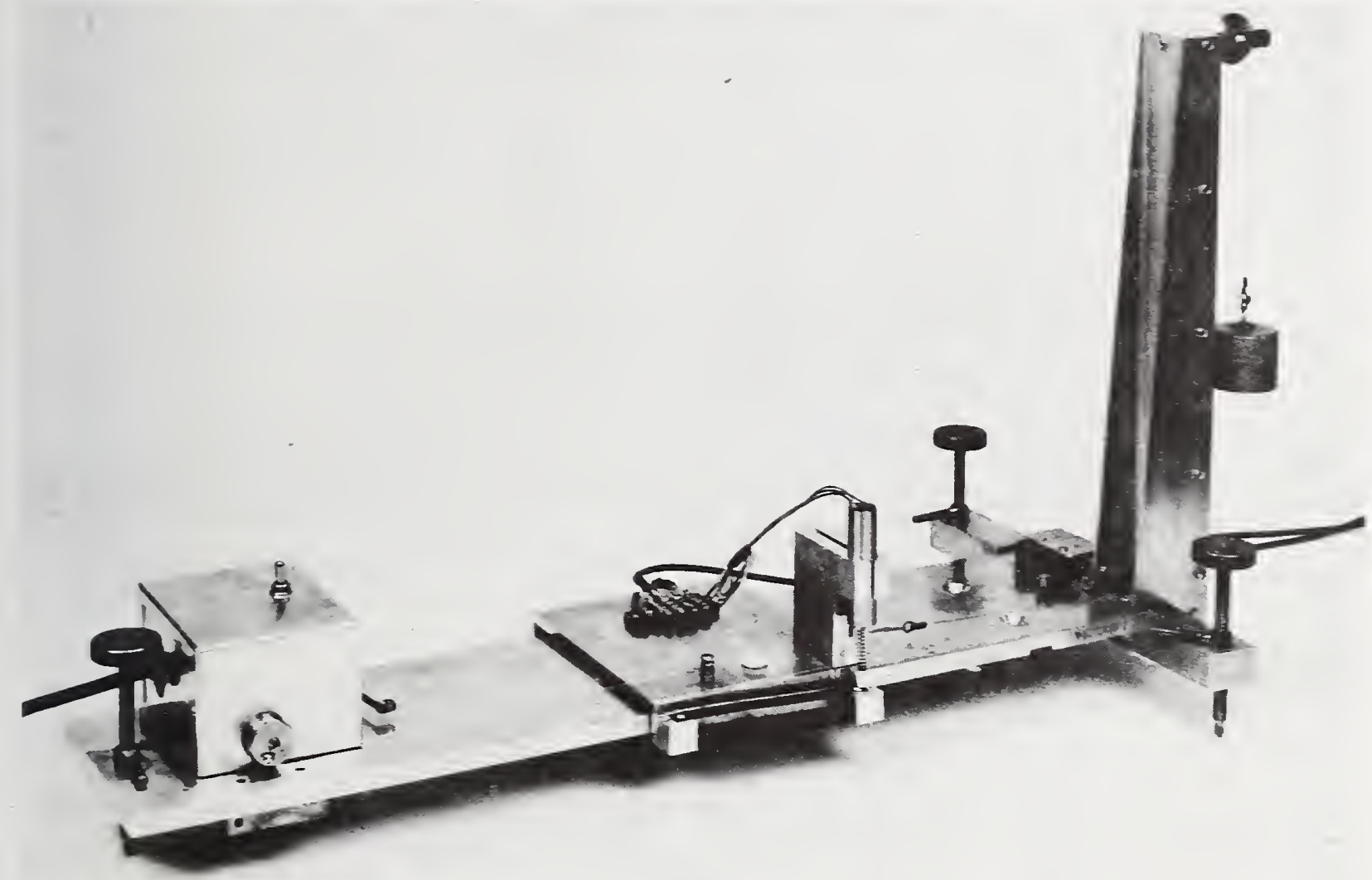

Figure 10. The macrotexture profile tracer. 
The general operating procedure consists of seiting the profile tracer on the pavement and adjusting the three legs so that the bed is parallel to the plane of the pavement. The sled is then made to traverse the bed at the rate of $0.0128 \mathrm{ft} / \mathrm{sec}(0.0039 \mathrm{In} / \mathrm{sec})$ by switching on the synchronous motor. The stylus, which follow's the profile of the pavement surface, displaces the cantilever spring suspended stylus holder which in turn moves the core of the linear variable differential transformer (LVDT). This motion of the core changes the dc-voltage output of the transicucer in a manner directly proportional to the stylus displacement. This variable dc-voltage output of the LVDT is then recorded on one track of an FM tape recorder. In each case, a minimum of five pavement traverses were made, each in the direction of vehicle trave1. (The study performed by PTI[16j showed that except where the surface had been intentionally brushed or fluted, the direction of traverse was not important for relatively new pavements. Similar data have not been coliected for sites which have undergone substantial polishing, so the important question of macrotexture dependence on direction of traverse for we11-traveled roads remains to be answered.) : The system used to obtain these profile data are shown in Figure 11.

The tapes of the recorded profile data were conveyed to the spectrum analysis facility at the Applied Research Laboratọy (ARL), University Park, $\mathrm{Pa}$., for playback and processing. The original tapes, recorded at a tape speed of 6.0 inches per second (ips) were copied with another FM recorder at $17 / 8$ ips and the analysis was then performed on the copy tapes. Analysis of the copy tapes rather than the original recordings introduces a potential $6 \mathrm{~dB}$. decrease in the signal-to-noise ratio, depending upon the dynamic range of the two FM recorders. Provided that the signal level is sufficiently above the noise floors of the recording, and analysis systems, this shculd not affect the validity of the dat.a. Figure 12 is a diagram of the tape copying equipment set-up.

A one-third ortave band analysis of the data on the copied tapes was performed. The tapes copied at $17 / 8$ ips were played back at 60 ips. This resulted in a time scale compression (playback to record ratio) of $32: 1$ that was required to match the slowly scanned profile signals to the ARL analysis equipment. The $32: 1$ ratio provided an apparent profile scan rate of 0.41 $\mathrm{ft} / \mathrm{sec}(0.125 \mathrm{~m} / \mathrm{sec})$, which greatly reduced the required analysis time.

The level in each of the one-thirc octave bands was obtained utilizing a time constant of 2 seconds (equivalent to 64 seconds at the original time scale). These one-third. octave band daia were then plotted using both an $x-y$ recorder and a digital printer. Figure 13 identifies the equipment which was utilized for the spectral analysis.

\section{Parametric Study}

The data acquisition program was designed to address the following questions:

What is the effect of roadway surface texture on the noise level generated by truck tires? 

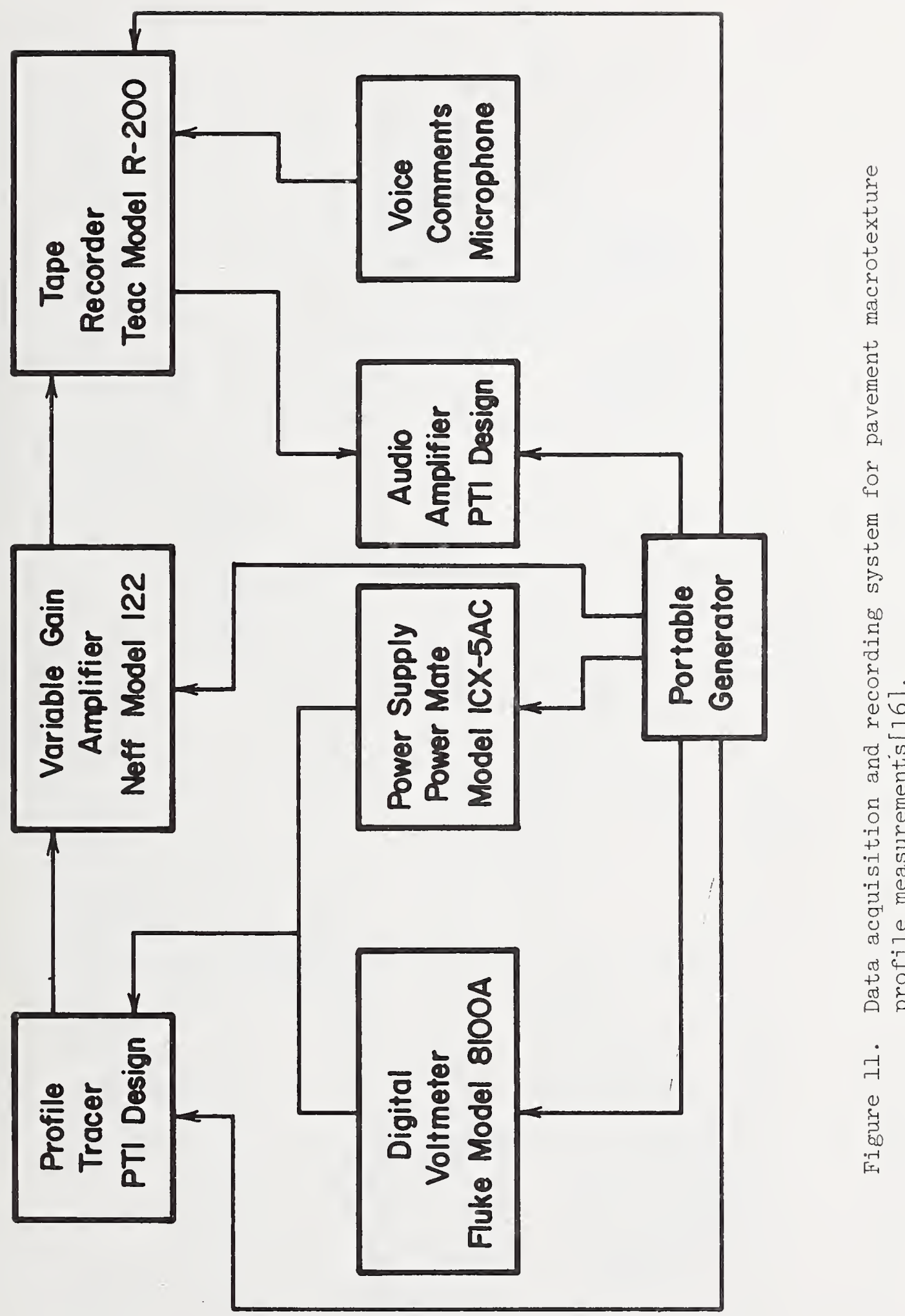


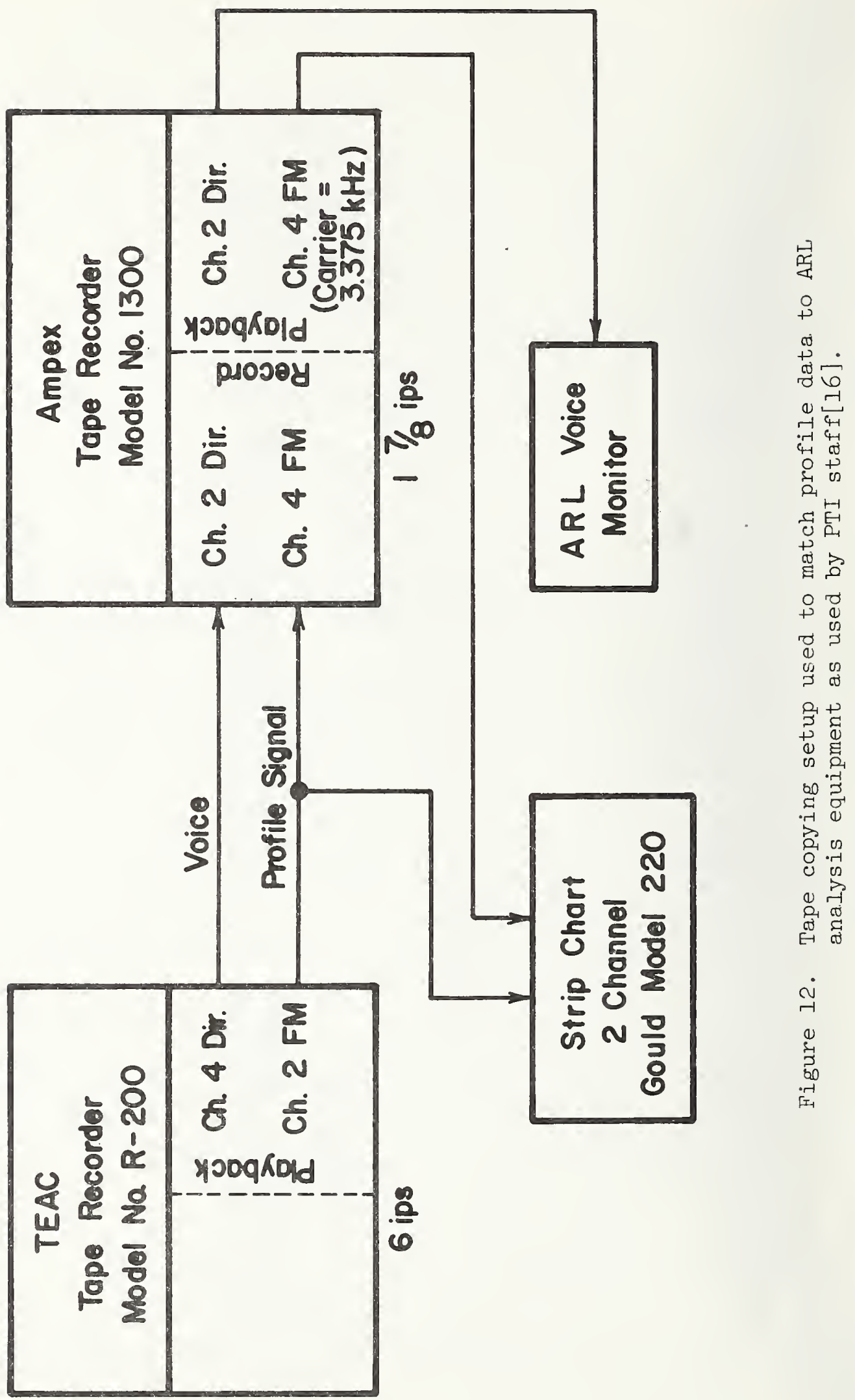




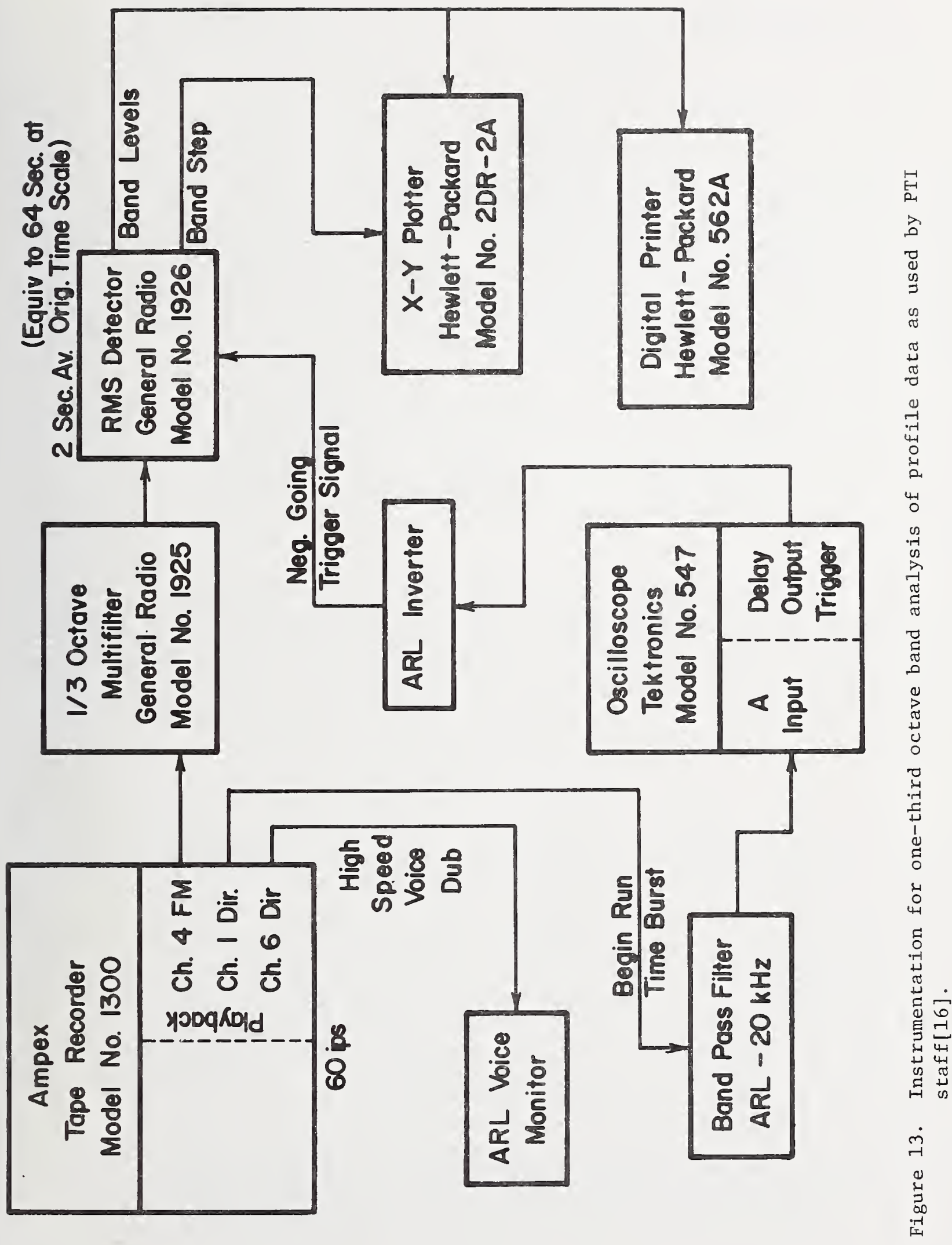


Can pavement surface texture be quantitatively measured and correlated with truck tire noise levels?

Can a given tire design be used as a simplified calibrator of pavement surface texture?

In order to develop the data base necessary to address these questions, two coastbys each at nominal speeds of 40, 50, and $60 \mathrm{mph}(64.4,80.5$, and 96.5 $\mathrm{km} / \mathrm{hr}$ ) over each of the eight test pads were made. Sound level measurements were performed at both 25 and 50 feet $(7.6$ and $15.2 \mathrm{~m})$ from the centerline of each of the test pads. The maximum A-weighted sound level data for all test runs are tabulated in Appendix A, along with the corresponding spectral data and the decrease in A-weighted sound level observed from 25 to 50 feet (7.6 to $15.2 \mathrm{~m})$. Also included are photographs showing characteristic tread design patterns of the test tires and the associated tread depth.

Profile measurements of the eight test pads 'were made by PTI personnel using the macrotexture profile tracer. These data are presented in Appendix B in terms of individual profile band levels for the one-third octave bands corresponding to the space frequency from 25 to 10,000 cycles per meter. The space frequency is related to temporal frequency through the velocity of the vehicle, i.e., the temporal frequency equals the velocity times the spacial frequency.

In this section, the sound level data for the 50 foot (15.2 m) microphone location are the basis for summary plots which are presented to show the effect of tread design, speed, and pavement surface' on the noise level generated by truck tires. Also presented are selected spectral data to show the variations in frequency content of truck tire noise for the varipus test pads. Finally, profile data for the eight test pads are given and the correlation between truck tire noise level and the pavement texture is discussed.

\subsection{Tread Design and Speed}

In order to investigate the effect of tread design and speed on generated noise levels, plots of maximum A-weighted sound level versus speed with tread design as a variable were developed (Figures 14 and 15). These data represent measurements at 50 feet $(15.2 \mathrm{~m})$ for coastby runs of the loaded $4 \times 2$ single-chassis vehicle on the eight test pads. An increase in speed resulted in an increase in the maximum $A$-weighted sound level. The increases were on the order of 4-7 $\mathrm{dB}$ for; test tire TB, 3.5-7 $\mathrm{dB}$ for test tire $\mathrm{TD}$ and 5-10 $\mathrm{dB}$ for test tire TI for speed changes from 40 to $60 \mathrm{mph}(64.4$ to $96.5 \mathrm{~km} / \mathrm{hr})$. On the average, the increases were $5-8 \mathrm{~dB}$. This corresponds to the sound level increasing as the third to fourth power of speed. The only exceptions to this general trend were for test tire TB on pads 2, 3 and 4 . For these three cases, the maximum A-weighted sound level decreased by $1 / 2$ to $1 \mathrm{~dB}$ for a speed increase from 50 to $60 \mathrm{mph}(80.5$ to $96.5 \mathrm{~km} / \mathrm{hr})$.

In every case, tire TI (pocket retread) was the noisiest of the three tire tread designs; followed by tire TD (crossbar); with tire TB (rib) the least 

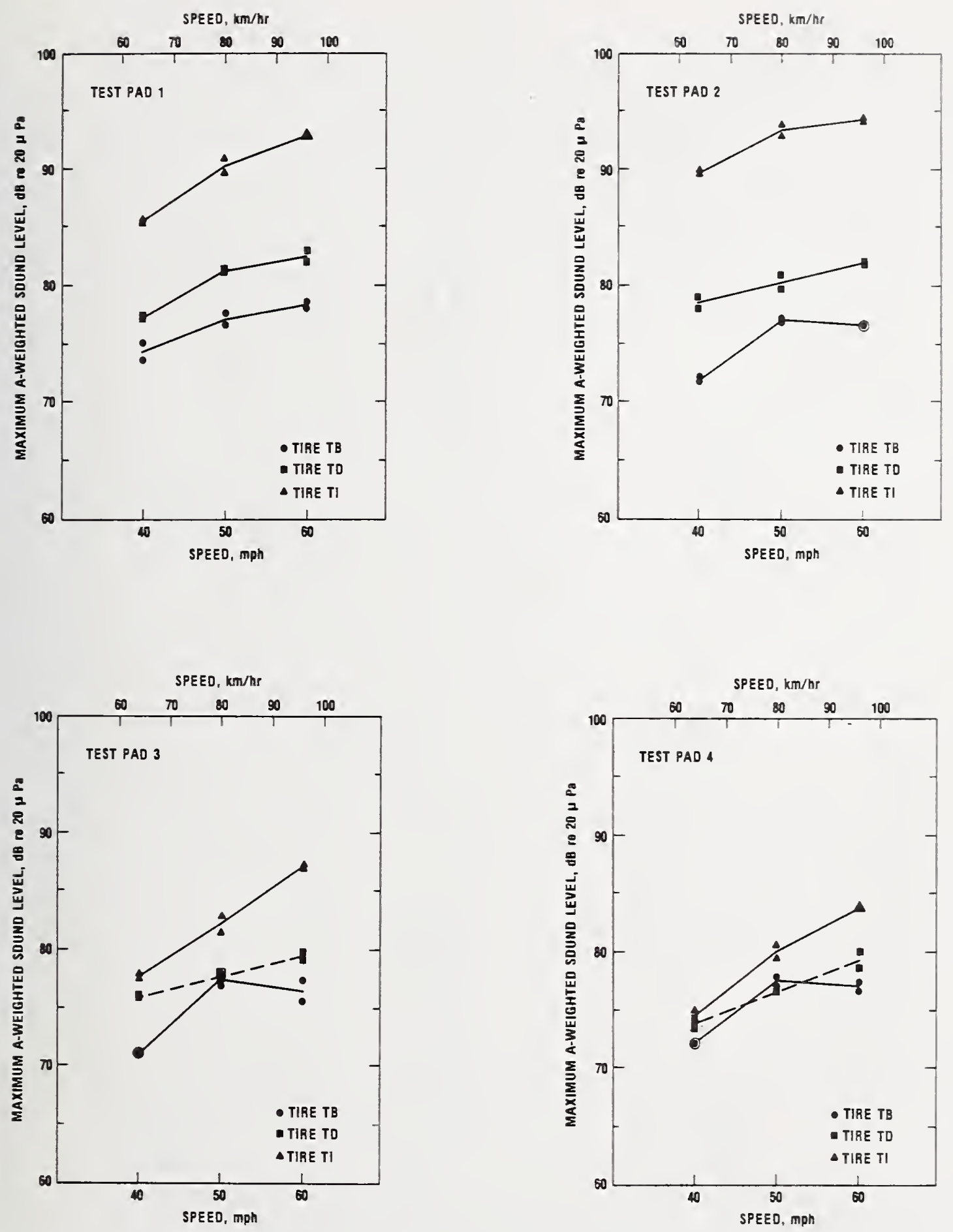

Figure 14. Maximum A-weighted sound levels, as measured at 50 feet ( $15.2 \mathrm{~m}$ ), versus speed with tire tread design as variable for vehicle coastbys on the indicated test pad. New rib tires were mounted on the steering axle and the test tires on the drive axle. 

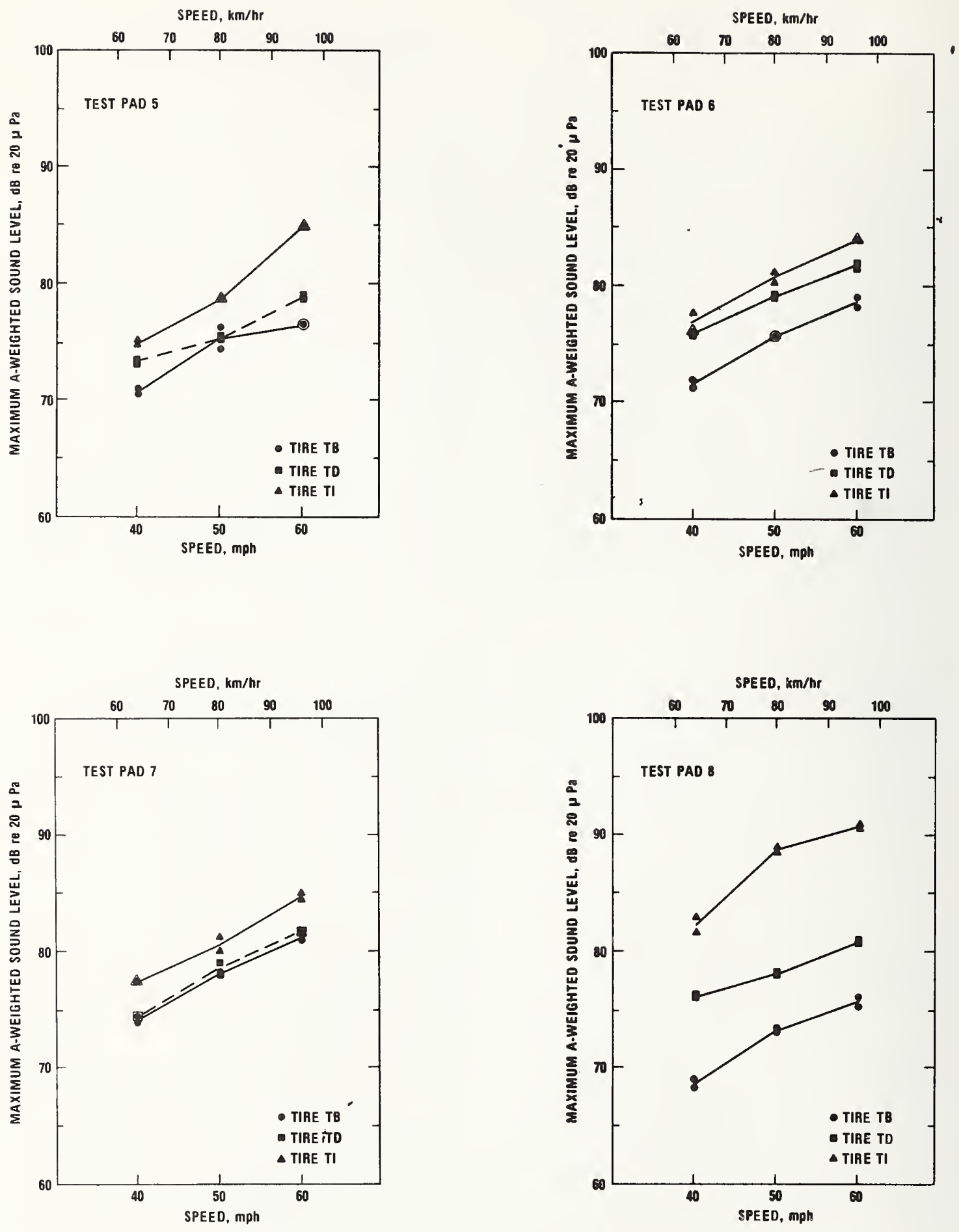

Figure 15. Maximum A-weighted sound levels, as measured at 50 feet ( $15.2 \mathrm{~m}$ ), versus speed with tire tread design as a variable for vehicle coastbys on the indicated test pad. New rib tires were mounted on the steering axle and the test tires on the drive axle. 
noisy of the tires tested. The difference in ncise level between the three tires was strongly influenced by the pavement surface. In general, the widest spread of noise levels occured on the smooth pavements (pads 1, 2, and 8); whereas on the rough surfaces (pads 4 and 7) there was a much smailer variation between the different tread designs. As shown in the previous figures, the spread of noise levels between tire TB and tire TI was 11-18 dB on pads 1,2 and 8, but only 2-7 dB on pads 4 and 7. Thus, as expected, the noise generated by truck tires is dependent not only on the tread design and speed range over which the vehicle is operated, but also on the type of pavement suriace.

\subsection{Pavement Surface}

The exact dependence of the generated noise level upon pavement surface is difficult to determine since other factors such as tread design and speed also come into play. To investigate the effect of pavemert surface on the generation of truck tire noise, plots of maximum A-weighted sound level versus speed with pavement surface as a variable were developed (Figures 16 to i8). These data represent the arithmetic average of the two measurements at 50 feet $(15.2 \mathrm{~m})$ for coastby runs of the loaded $4 \times 2$ single-chassis vehicle for the three types of tires tested. As expected, paverient surface has a greater effect on the noise generated by tire TI than by tires IB and TD. The nayimum A-weighted sound levels at any onf particular speed have a range of $10-20 \mathrm{~dB}$ for tire TI, but only $4-6 \mathrm{~dB}$ for tires $T B$ and $T D$.

\subsection{Spectral Characteristics}

To better understand the influance of pavement surface texture on tire-road interaction noise, the data measured at the 50 foct ( $15.2 \mathrm{~m}$ ) microphone at the time corresponding to the occurrence of the maximum

A-weighted sound level have been analyzed in one-third octave bands. One-third octave band data are not fine enough to distinguish many spectral

characteristics of tire-road interaction noise; however, it does allow the identificaticn of a range of frequencies associated with certain tire noise generation mechanisms. These data, for a vehicle coastby at 50 mph ( 80.5 $\mathrm{km} / \mathrm{hr}$ ) over each of the test pads, are plotted in Figures $A-4$ to $A-11$ in Appendix A.

These spectral data can be best explained by considering the mechanisms by which tire-road interaction noise is generated. As sumarized in references $[3,17]$, at present three generic types of tire noise source techanisms have been postulated -- aerodynamic, air pumping and vibration.

In addition, it may be helpful to introuce the concept of hoise floors". With today's technology in the area of tire structural design, the apparent limit -- i.e., the quietest tire -- is a smocth tire (nc tread) operating on a smooth road (no texture). This case represents the thinimum noise floor! I either tread is added to the tire (tire with tread/smcoth surface) or texture is added to the pavement surface (smooth tire/surface with texture), the noise level will increase and a. "Second level noise floor" will exist. Finally, in 
SPEED, $\mathrm{km} / \mathrm{hr}$

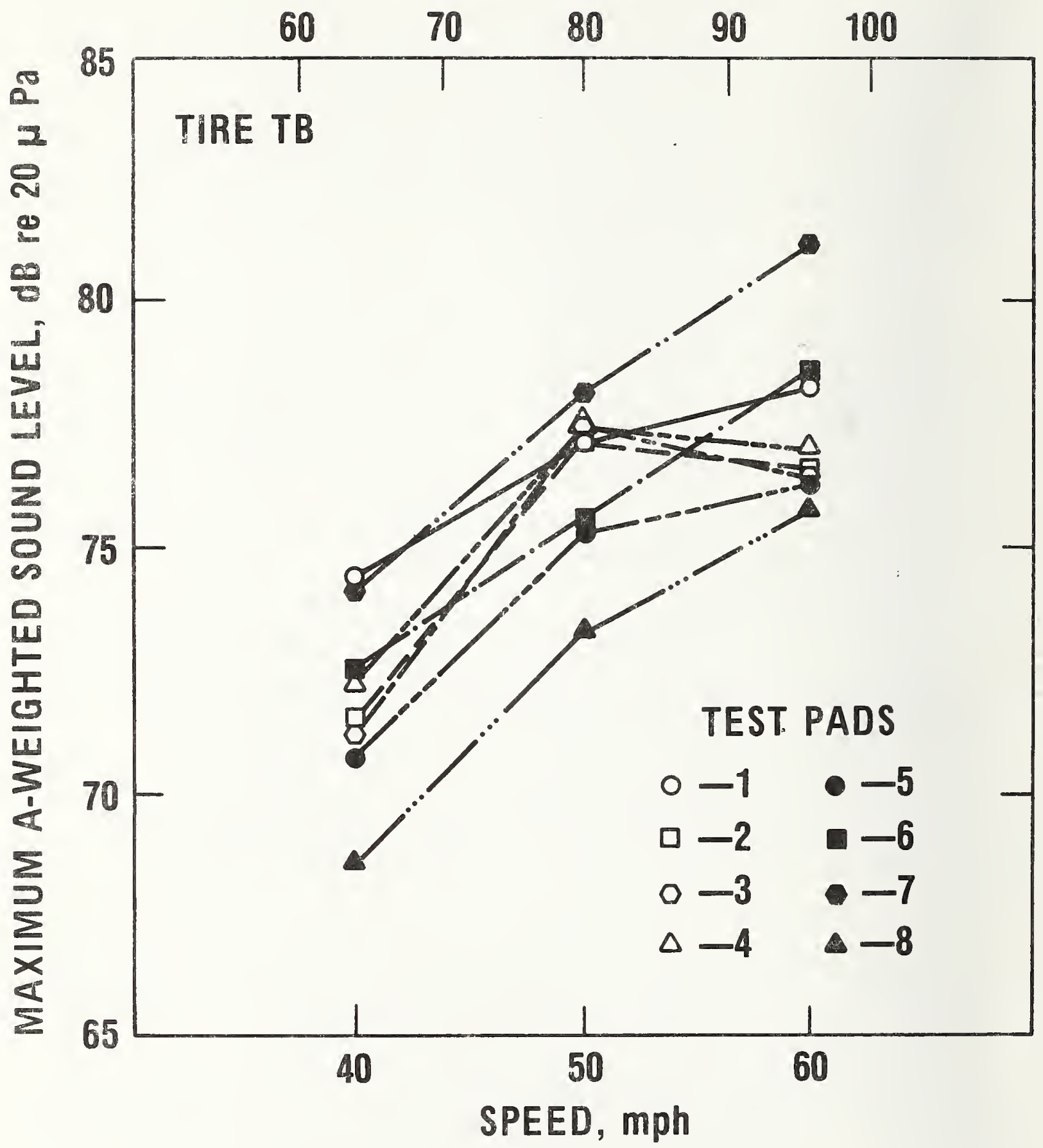

Figure 16. Maximum A-weighted sound levels, as measured at 50 feet ( $15.2 \mathrm{~m}$ ), versus speed with pavement surface as a variable. These plots correspond to vehicle coastbys with new rib tires mounted on the steering axle and test tires $T B$ on the drive axle. 
SPEED, $\mathrm{km} / \mathrm{hr}$

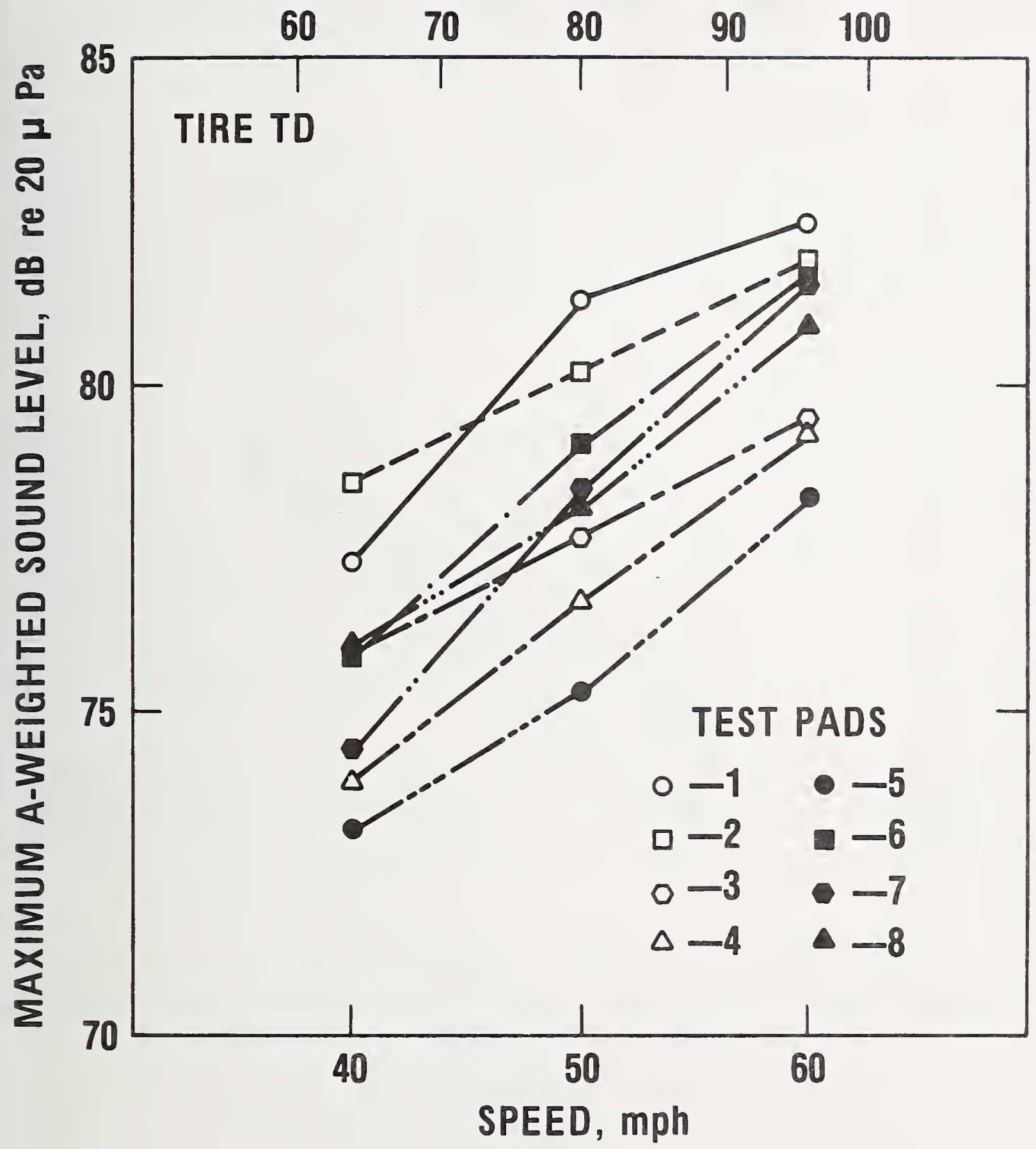

Figure 17. Maximum A-weighted sound levels, as measured at 50 feet ( $15.2 \mathrm{~m}$ ), versus speed with pavement surface as a variable. These plots correspond to vehicle coastbys with new rib tires mounted on the steering axle and test tires TD on the drive axle. 
SPEED, $\mathrm{km} / \mathrm{hr}$

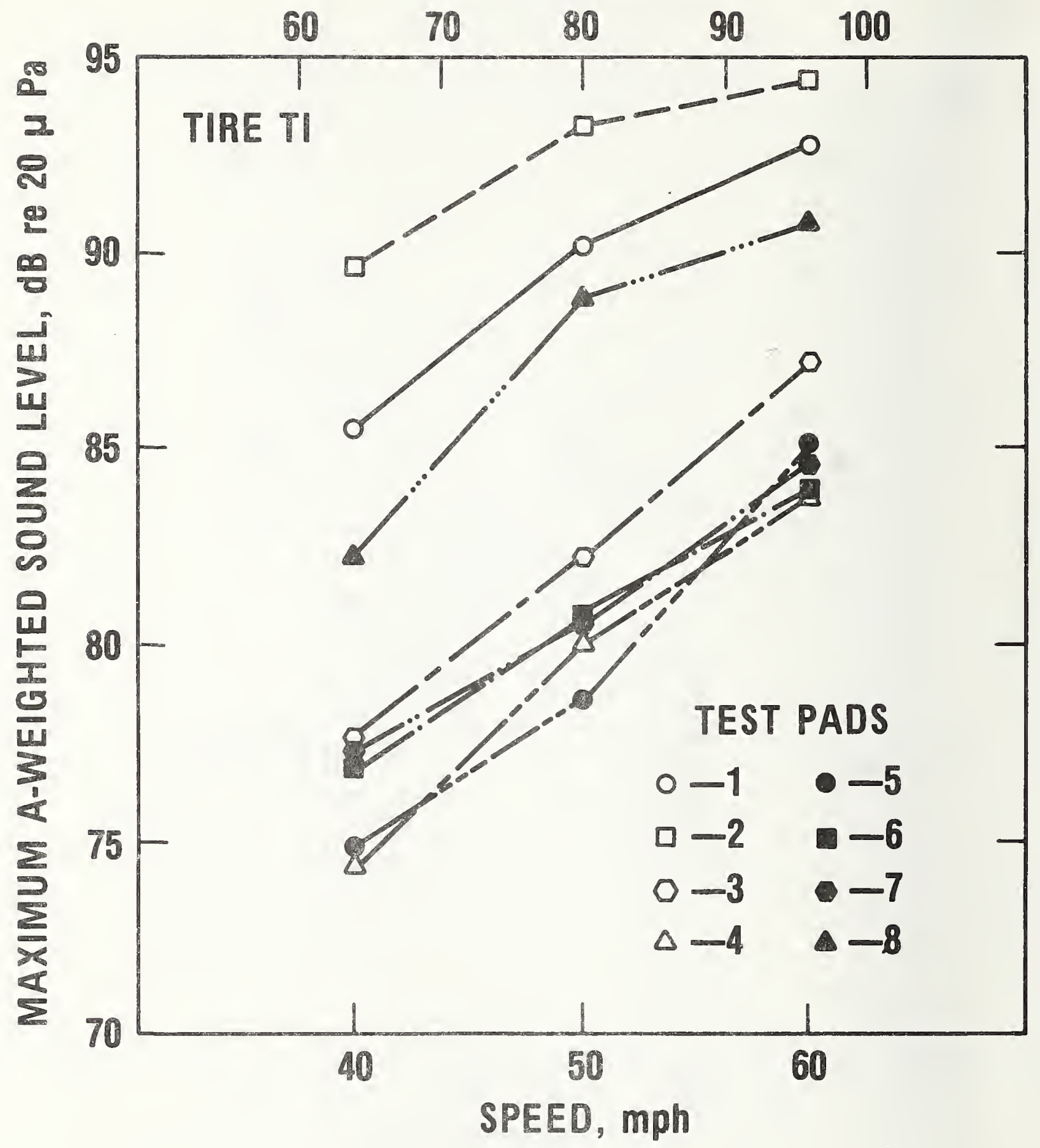

Figure 18. Maximum A-weighted sound levels, as measured at 50 feet ( $15.2 \mathrm{~m})$, versus speed with pavement surface as a variable. These plots correspond to vehicle coastbys with new rib tires mounted on the steering axle and test tires TI on the drive axle. 
the real world situation -- tire with tread operating on a surface with texture -- the noise level will increase further and a "third level noise floor" will be present. The noise level which characterizes any "noise floor" is determined by the complex interaction of the vibration, air-pumping and aerodynamic tire noise source mechanisms.

Aerodynamic sources refer to unsteady flow over the tire, attributable largely to the whole-body motion of the tire through nearly-stationary air. Siddon [18] speculates that fluctuating pressures from vortices generated at the trailing edge of a tire near the road are sufficient to contribute substantially to roadside noise. While this may be a factor in determining the "minimum noise floor", it hardly seems likely to be a major source in view of the overwhelming data demonstrating a dependence of tire noise on road roughness and tread design.

Investigators are in general agreement that air pumping can be a major contributor to tire noise. As a tire tread segment contacts the road surface, air is squeezed out of the small depressions in the road and tire interstices in sufficient volume to create significant noise. As the tread segment leaves the surface, air rushes back to fill the voids. Hayden [7] modeled this oscillating flow by assuming a compact array of monopole sources of noise associated with the leading and trailing parts of the contact area and developed an empirical expression for estimation of the overall sound pressure radiated by a single tire as:

$$
\begin{aligned}
\text { SPL } & =68.5+20 \log \left(\frac{\delta w}{S}\right)+40 \log v \\
& +20 \log \mathrm{f}+10 \log \mathrm{n}-20 \log \mathrm{r}
\end{aligned}
$$

Where, $\delta=$ tread depth, w = width of a single cavity or groove in the tread, $S$ = circumferential distance between tread grooves, $\mathrm{v}=$ vehicle velocity, $\mathrm{f}^{\prime}=$ fractional change in cavity volume, $\mathrm{n}=$ cavities per tire width and $\mathrm{r}=$ distance from tire to observation point. A similar concept is said to be applicable when one treats the roadway depressions in the same manner as the tread interstices.

Vibration of the tire carcass (caused by tire-road interaction) is believed to be a third source of noise. There exist numerous possible excitation and radiation mechanisms as well as types of tire response that could characterize tire vibration and attendant sound generation.

The primary excitation mechanisms are the periodic deflection of the toroid in the contact patch area (tire-road interaction zone) as the tire rolls along and the interaction of the tread elements with roadway-surface irregularities. Roadway-surface irregularities may be thought of as a continuous process at low frequencies, where the lengths of waves associated with the roadway wavenumber spectrum are long compared with the length of the tire-contact patch (e.g., $<100 \mathrm{~Hz}$ for automobile tires at highway speeds). At higher frequencies, however, the process becomes discontinuous as segments of the tire impact individual roadway surface asperities. 
Another potential excitation mechanism results from tire nonuniformities -- both of the tire itself (not really round or a flaw in construction) and the tread (uneven wear) -- which give rise to force variations in the tire. The fundamental component of this mechanism is related to the ire rotation rate (i.e., a variation of the force each time the nonuniformity impacts the roadway) which wquld correspond to about 10-20 Hz for automobiles operating at highway speeds. - It is unlikely that harmonics of this will be significant in the f'requency regime of substantial solund radiation ( $2300-500 \mathrm{~Hz}$ ). Nonuniformity of mass distribution (tire balance), however, can cause significant modulation of tire noise.

Based on the results of several laboratory studies[10, 20, 21], tire vibrational characteristics and mechanisms of sound generation may be evaluated in three frequency regimes -- low frequency, mid frequency and high frequency.

The low frequency regime covers the range from $20 \mathrm{~Hz}$ (below $20 \mathrm{~Hz}$ the tire responds approximately as a rigid mass on a spring) to frequencies just below the first carcass mode, which can vary from $8 \mathrm{C}$ to $180 \mathrm{~Hz}$ depending on the tire size, construction and inflation pressure. In this frequency range the tire responds only in the vicinity of the contact area. Sound radiation is likely to be monopole in nature, with an equivalent volume velocity corresponding to the change in tire volume accompanying a fluctuating load. However, because these frequencies are so low and because human hearing is largely insensitive to low-frequency sound, this range of tire vibrations is not likely to be of consequence.

The mid frequency regime extends from the first carcass mode ( $80-180 \mathrm{~Hz}$ ) to about $400 \mathrm{~Hz}$, again depending upon the size, construction and inflation pressure of the tire. In this frequency range, the carcass responds in a modal manner, which causes the tire to behave like a dipole sound source. The efficiency of sound radiation depends on the distance between the contracting and expanding parts of the tire and on the frequency of vibration, or, equivalently, the wavelength of sound $\lambda$ corresponding to a given frequency. Since $\lambda$ is much greater than the distance between the contracting and expanding parts of the tire, tire modes are inefficient sound radiators.

In trie high frequency regime $(>400 \mathrm{~Hz})$, waves are generated in the carcass at the tire-road interface, however, these waves are damped rapidly in the tire as they propagate away from the contact area. If the phase velocity of these waves is above critical (i.t., above the speed of sound in air) the waves will radiate very efficiently. However, even subcritical waves may radiate significant sound levels owing to low wavenumber components associated with the excitation point.

The frequency of the force variation and resultant tire vibration due to the impact of the tire nonuniformity with the roadway is approximately equal to the speed divided by the tire circumference. For example, an automobile tirk with a circumference of 25 inches $(63.5 \mathrm{~cm})$ traveling at $50 \mathrm{mph}(80.5 \mathrm{~km} / \mathrm{hr})$ corresponds to a frequency of about $11 \mathrm{~Hz}$. 
Tire tread and carcass vibration as sources of tire noise are actively being investigated by researchers at North Carolina State University[22]. This on-going analytical and experimental program, under the sponsorship of the office of Noise Abatement, Department of Transportation, should provide considerable insight into the role of tire vibration as a tire-noise source mechanism.

The tire noise spectrum is composed of two parts: a periodic variation due to the tread pattern and tire nonuniformities and an aperiodic variation due to the road surface features. The periodic component exhibits spectral peaks at discrete frequencies and the aperiodic component exhibits a more continuous spectrum. The frequencies of the spectral peaks are associated with the tire design (tread spacing) and the tire rotational rate. The fundamental frequency can be predicted by calculating the number of tread elements which pass through the footprint per second. If the distance between consecutive tread elements is uniform, the sound produced is nearly a pure tone whose frequency is given by [23]:

$$
\mathrm{f}=\frac{27.8 \mathrm{~V}}{\mathrm{a}}
$$

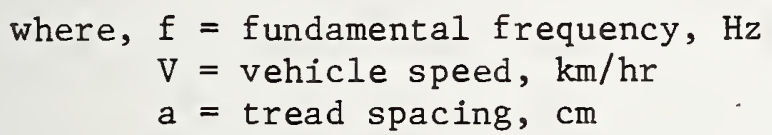

Most tire manufacturers, however, do not utilize a uniform element spacing. The pitch lengths are usually varied in some manner so as to produce a less intrusive sound than a pure tone. While this serves to reduce the perceived noisiness of tires, it raises the difficulty for researchers of defining an equivalent tread spacing. Modern tires are produced by molding into the tread major grooves (in the case of rib tires major grooves are oriented in the circumferential direction while for cross-bars the grooves are oriented in the lateral direction) and secondary grooves or slots called siping, all of which contribute in some unknown way to the complex acoustic signature of the tread pattern.

Table 1 shows the major tread spacing for the tires tested, the predicted frequency of the fundamental based on major tread spacing, and the one-third octave frequency band in which the fundamental was actually measured (see Figures A-4 to A-11 in Appendix A). The calculations are based on a vehicle speed of $50 \mathrm{mph}(80.5 \mathrm{~km} / \mathrm{hr})$. Although present understanding of tire noise source mechanisms does not allow one to identify the mechanism -- air pumping and/or vibration -- excited by the tread elements interacting with the road surface, in most cases the one one-third octave band in which the maximum signal level could be found was predictable on the basis of tread spacing considerations. Tread element spacing appears to be an important variable in either noise generation mechanism as presently postulated. 
Table 1. Predicted and measured fundamental tire noise frequencies based on major tread spacing considerations corresponding to a vehicle speed of $50 \mathrm{mph}(80.5 \mathrm{~km} / \mathrm{hr})$.

\begin{tabular}{|c|c|c|c|}
\hline Tire & $\begin{array}{l}\text { Major Tread } \\
\text { Spacing, } \\
\text { in. }(\mathrm{cm})\end{array}$ & $\begin{array}{c}\text { Predicted Fundamental } \\
\text { Frequency, } \\
\text { Hz }\end{array}$ & $\begin{array}{l}\text { Band Limits } \\
\text { of One-Third Octave } \\
\text { Band(s) Containing the } \\
\text { Measured Fundamental } \\
\text { Frequency, Hz }\end{array}$ \\
\hline $\begin{array}{l}\text { Tire TB } \\
\text { (Rib) }\end{array}$ & $\begin{array}{l}2.00-2.37 \\
(5.08-6.02)\end{array}$ & $371-440$ & $355-447$ \\
\hline $\begin{array}{l}\text { Tire TD } \\
\text { (Cross-Bar) }\end{array}$ & $\begin{array}{l}3.35 \\
(8.51)\end{array}$ & 263 & $224-355$ \\
\hline $\begin{array}{l}\text { Tire TI } \\
\text { (Pocket Retread) }\end{array}$ & $\begin{array}{l}2.48 \\
(6.30)\end{array}$ & 355 & $282-355$ \\
\hline
\end{tabular}

The sound generated by the rib tire (tire TB) contained only one spectral peak, which corresponded approximately to the predicted fundamental frequency $(371-440 \mathrm{~Hz})$ based on the major tread spacing. This was true in general, except for test pads 6 and 7 which did not exhibit this spectral peak (Figures A-9 and A-10). This indicated that for these two test surfaces, the pavement texture has more influence on the generated noise than does the tread element pattern of this particular tire.

The same general results were true for the cross-bar tire (tire TD). There was in general one dominant spectral peak corresponding to the fundamental tread spacing frequency $(263 \mathrm{~Hz})$, but there was also a secondary plateau which included the apparent second and third harmonics. Again, the results for test pads 6 and 7 did not show any spectral peak at the fundamental frequency, thus indicating the dominance of the pavement texture. 
For the pocket retread (tire TI) there were three types of distinguishable frequency spectra. For test pads 1, 2, 3, and 8, there were three well-defined spectral peaks which corresponded approximately to the frequencies of the fundamental $(355 \mathrm{~Hz})$, the second harmonic $(710 \mathrm{~Hz}$ ) and the third harmonic (1065 $\mathrm{Hz}$ ) predicted on the basis of the major tread spacing. For test pads 4, 5, and 6 , there was one dominant spectral peak corresponding to the fundamental frequency, and a secondary plateau in the range of the second harmonic. The level of this plateau was approximately $10 \mathrm{~dB}$ below that of the fundamental. For test pad 7, there was no distinctive spectral peak which indicated that the pavement texture was the controlling factor in the noise generated on this surface as it was for the rib and cross-bar tires. These results might be expected since the primary mechanism of sound generation for tire TI (pocket retread) is believed to be air pumping. The effectiveness of the air pumping is dependent on how well the tire and roadway seal. This obviously depends on the tread pattern of the tire and the texture of the pavement surface. For the pocket retread and pavements with a smooth surface texture, a good seal is possible, which results in both higher sound lévels and more well-defined spectral peaks than for pavements with a coarse surface texture.

Based on the spectral data for tire TI, the eight test surfaces could be roughly classified into three ranges of pavement texture: test pads $1,2,3$, and 8 as smooth; test pads 4, 5, and 6 as intermediate; and test pad 7 as coarse. This crude classification does not solve the problem of quantitatively relating pavement texture to truck tire noise, but it does indicate that there should be a relationship between these two quantities.

\subsection{Surface Texture Measurement Results}

In order to physically relate pavement surface to tire noise, a quantitative measure of the surface macrotexture is needed. The quantity used in this study to characterize macrotexture is the mean square value of the variation of the pavement profile, computed from the data obtained with the macrotexture profile tracer. The profile data, given in Appendix B, 5 gonsist of individual profile band levels in decibels referenced to 1 meter rms for the one-third octave bands corresponding to the space frequency from 25 to 10,000 cycles per meter. The data are given in terms of an arithmetic mean and

The authors realize that the profile band levels defined in this report should be expressed in units of decilogs since the logarithmic ratio is one of displacement rather than power. This usage, however, is not common and might create confusion; therefore, the profile band levels will be expressed as decibels with the added note that this logarithmic ratio is referenced to 1 meter rms.

$$
\mathrm{dB} \text { re } 1 \mathrm{~m} \mathrm{rms}=20 \log _{10}\left[\frac{\text { measurement band rms displacement }(\mathrm{m})}{1.0(\mathrm{~m})}\right]
$$


standard deviation based on five profile measurements. These arithmetic mean values of the one-third octave band levels are plotted versus the space frequency in Figures B-1 through B-8. Using this information, the mean square value of the profile displacement can be computed by taking the antilog of the profile band levels divided by ten and summing these values over the twenty-seven one-third octave bands from 25 to 10,000 cycles per meter.

$$
\begin{aligned}
& \text { Mean Square Value }=\left(1 \mathrm{~m}^{2}\right) \sum_{i=1}^{27} 10^{\mathrm{PBL}_{\mathrm{i}} / 10} \\
& \text { of Pavement Macrotexture }
\end{aligned}
$$

where $\mathrm{PBL}_{i}$ is the profile band level in $\mathrm{dB}$ re $1 \mathrm{~m}$ rms. This summation defines a single number descriptor of macrotexture which is equivalent to the area under the curve of a semi-log plot of the one-third octave band profile displacement squared $\left(\mathrm{m}^{2}\right)$ versus space frequency.

The resultant mean square values of the macrotexture for the eight test pads are given in Table 2. On the basis of these data, a relative rank ordering of the surfaces from smooth (identified as a) to coarse (identified as h) is established.

'Two alternative techniques for calculating the mean square value of the pavement macrotexture were also investigated. First the space frequency data were converted to temporal frequency data by multiplying by the vehicle speed. For instance, a space frequency of 25 cycles per meter is equivalent to a temporal frequency of $560 \mathrm{~Hz}$ for a vehicle speed of $50 \mathrm{mph}(80.5 \mathrm{~km} / \mathrm{hr})$. Then, utilizing Equation 3, the band levels were summed directly (second column of Table 3) or were A-weighted and then summed (third column of Table 3). A comparison of these values with the corresponding values listed in Table 2 shows that the mean square values calculated by these three methods differ only slightly and that the relative rank ordering of the pavement texture is the same regardless of the technique utilized.

A typical A-weighted profile spectrum [scaled up to temporal frequencies for a vehicle speed of $50 \mathrm{mph}(80.5 \mathrm{~km} / \mathrm{hr})]$ and a corresponding A-weighted acoustic spectrum for a vehicle coastby on this suxface at $50 \mathrm{mph}(80.5 \mathrm{~km} / \mathrm{hr})$ are shown in Figure 19. It should be noted that data below $560 \mathrm{~Hz}$ [25 cycles per meter at $50 \mathrm{mph}(80.5 \mathrm{~km} / \mathrm{hr})]$ are not available because of the limitations of the PTI analysis system. Although the lower frequency data would be valuable for investigating correlation between the surface profile and acoustic spectra, the profile data below 25 cycles per meter would have little effect on the over-all A-weighted mean square value unless the profile band levels were to increase rapidly at these low frequencies so as to counterbalance the effect of the A-weighting. Coherence and/or correlation analysis between the surface profile and acoustic spectra was not attempted due to the fact that there was a potential error of +10 percent in the recording speed of the profile data tapes - - and thus also in the estimation of space frequency -- due to power fluctuations of the gasoline driven inverter which was utilized to drive the FM tape recorder in the field. This does not, however, affect the mean square value of the pavement macrotexture since this quantity is simply a summation over all one-third octave bands and as such is not directly related to frequency. 
Table 2. Mean square values of the pavement

macrotexture for the eight test pads, determined from the one-third octave band data ( 25 to 10,000 cycles per meter) of profile displacement as measured with the macrotexture profile tracer, and the relative rank ordering of the surfaces from smooth (a) to coarse ( $h$ ) based on these values.

\begin{tabular}{|c|c|c|}
\hline $\begin{array}{c}\text { Test Pad } \\
\text { Number }\end{array}$ & $\begin{array}{l}\text { Mean Square Value } \\
\text { of the Profile } \\
\text { Displacement, } \mathrm{m}^{2}\end{array}$ & $\begin{array}{l}\text { Relative Rank } \\
\text { Ordering of } \\
\text { Pavement Macrotexture } \\
\text { Smooth } \\
\text { (a) }\end{array}$ \\
\hline 1 & $4.85 \times 10^{-8}$ & $\mathrm{~b}$ \\
2 & $7.95 \times 10^{-9}$ & $\mathrm{a}$ \\
3 & $4.08 \times 10^{-7}$ & $\mathrm{~d}$ \\
4 & $8.89 \times 10^{-7}$ & $\mathrm{~h}$ \\
5 & $4.35 \times 10^{-7}$ & $\mathrm{e}$ \\
6 & $8.07 \times 10^{-7}$ & $\mathrm{~g}$ \\
7 & $6.79 \times 10^{-7}$ & $\mathrm{f}$ \\
8 & $1.90 \times 10^{-7}$ & $\mathrm{c}$ \\
\hline
\end{tabular}

Table 3. Mean square values of the pavement macrotexture for the eight test pads, determined from the one-third octave band data (bands corresponding to the temporal frequencies from 500 to $10000 \mathrm{~Hz}$ ) of profile displacement. Vehicle speed is $50 \mathrm{mph}(80.5 \mathrm{~km} / \mathrm{hr})$.

\begin{tabular}{|c|c|c|}
\hline $\begin{array}{c}\text { Test Pad } \\
\text { Number }\end{array}$ & $\begin{array}{l}\text { Mean Square Value of the } \\
\text { Profile Displacement for } \\
\text { the Temporal Frequencies } \\
\text { from } 500 \text { to } 10,000 \mathrm{~Hz}, \mathrm{~m}^{2}\end{array}$ & $\begin{array}{l}\text { A-weighted Mean Square } \\
\text { Value of the Profile Dis- } \\
\text { placement for the Temporal } \\
\text { Frequencies from 500 to, } \\
10,000 \mathrm{~Hz}, \mathrm{~m}^{2}\end{array}$ \\
\hline 1 & $4.47 \times 10^{-8}$ & $4.50 \times 10^{-8}$ \\
2 & $5.06 \times 10^{-9}$ & $4.45 \times 10^{-9}$ \\
3 & $3.92 \times 10^{-7}$ & $4.39 \times 10^{-7}$ \\
4 & $8.31 \times 10^{-7}$ & $8.71 \times 10^{-7}$ \\
5 & $4.15 \times 10^{-7}$ & $4.50 \times 10^{-7}$ \\
6 & $7.92 \times 10^{-7}$ & $8.60 \times 10^{-7}$ \\
7 & $1.76 \times 10^{-7}$ & $6.77 \times 10^{-7}$ \\
8 & $1.52 \times 10^{-7}$ & $1.85 \times 10^{-7}$ \\
\hline
\end{tabular}




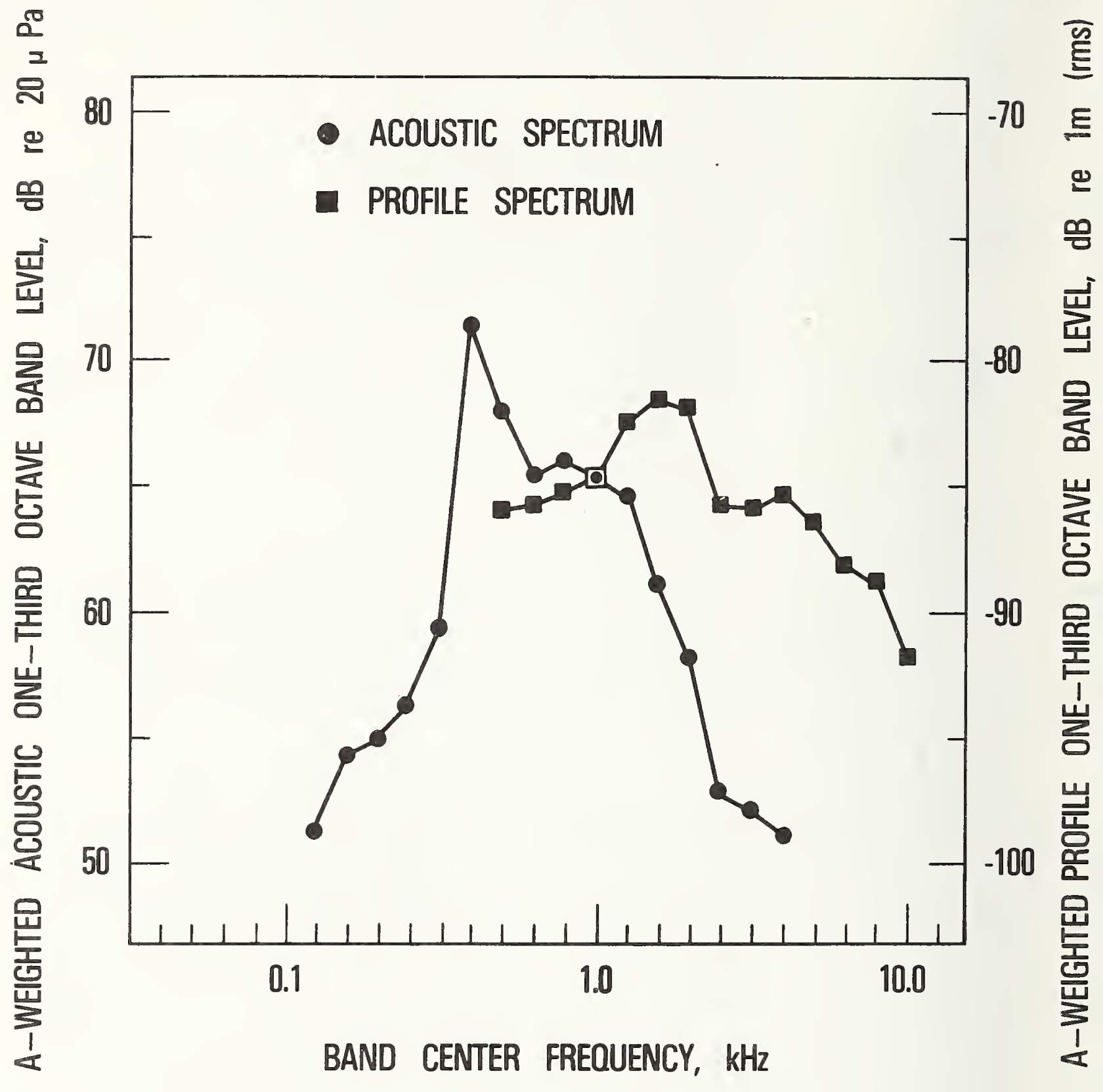

Figure 19. A-weighted profile spectrum for pad 1 scaled-up to temporal frequencies for a vehicle speed of $50 \mathrm{mph}(80.5 \mathrm{~km} / \mathrm{hr})$ and a corresponding A-weighted acoustic spectrum for tire TB at $50 \mathrm{mph}$ $(80.5 \mathrm{~km} / \mathrm{hr})$ on pad 1 . The profile data are plotted at the center frequency of the one-third octave band in which the temporal frequency lies, e.g., $560 \mathrm{~Hz}$ profile data are plotted at $500 \mathrm{~Hz}$. 
Since the results from these three techniques are similar, the mean square values obtained for the space frequencies from 25 to 10,000 cycles per meter (Table 2) are used to investigate the correlation between surface macrotexture and tire noise. The maximum A-weighted sound levels measured at 50 feet ( 15.2 $\mathrm{m}$ ) are plotted versus the corresponding mean square value of the pavement macrotexture of each test pad in Figure 20. These data correspond to vehicle coastbys at $50 \mathrm{mph}(80.5 \mathrm{~km} / \mathrm{hr})$ for each of the three test tires. The variation in sound level due to road surface effects is much greater for the pocket tread tire than for either the rib or cross-bar tire. This result was expected based on previous stúfiss[1,2,4,6]. Up to a certain macrotexture scale -- approximately $4 \times 10^{-1} \mathrm{~m}^{2}$-- the characteristic sound level appears to be tire dependent. Above this value, however, the pavement macrotexture appears to be the controlling factor -- sound levels for all tires, regardless of tread design, are essentially the same (within $5 \mathrm{~dB}$ ) for the five surfaces. It appears that the mean square value of pavement macrotexture as determined from profile tracer space frequency data properly ranks the pavements according to surface texture; however, there is no obvious method of predicting the resultant tire noise on the basis of macrotexture data. This problem is not so much a deficiency in the profile tracer technique as it is a lack of understanding of the tire noise generation mechanisms and how they are affected by pavement surface texture.

Other investigators have attempted to relate tire noise to the texture depth and skid number of the pavement[24,25]. The tire noise data resulting from this study are plotted versus average texture depth (Figure 21) and skid number, $\mathrm{SN}_{40}$ (Figure 22). The texture depth was determined using the putty impression method[26] and the skid numbers were measured according to ASTM E 274-70 procedures[27] using a skid trailer. A review of these two plots reveals no apparent direct relationship between truck tire noise and either texture depth or skid number.

Since the pocket tread tire exhibits such a variance in sound level with changes in surface texture -- due to the fact that the sealing required for efficient entrapment of air within the pockets becomes less effective as the road surface becomes rougher -- an evaluation of the pocket tread tire as a simple calibrator of surface texture was made[28]. The maximum A-weighted sound levels were plotted against pavement surface (Figure 23), with the location of the various surfaces on the abscissa being selected such that the sound level data versus surface for the pocket tread tire formed a straight line. A comparison of Figures 20 and 23 shows that, in general, the curves are quite similar. Rib and cross-bar tires could not be considered as simple calibrators for surface texture since the sound levels characteristic of these tires do not change sufficiently with surface texture changes.

The data for the rib and cross-bar tires using the pocket tread tire as a calibrator are replotted in Figures 24 and 25, respectively. In these plots, the solid lines are the regression lines obtained by simple linear regression analysis and the dashed lines represent the $95 \%$ confidence limits on the mean value. From these figures it is seen that by using the pocket tread tire as a calibrator, the noise level generated by tires TB and TD could be predicted from the regression lines with $95 \%$ confidence that the mean value of the actual noise level would be within $\pm 3 \mathrm{~dB}$. 


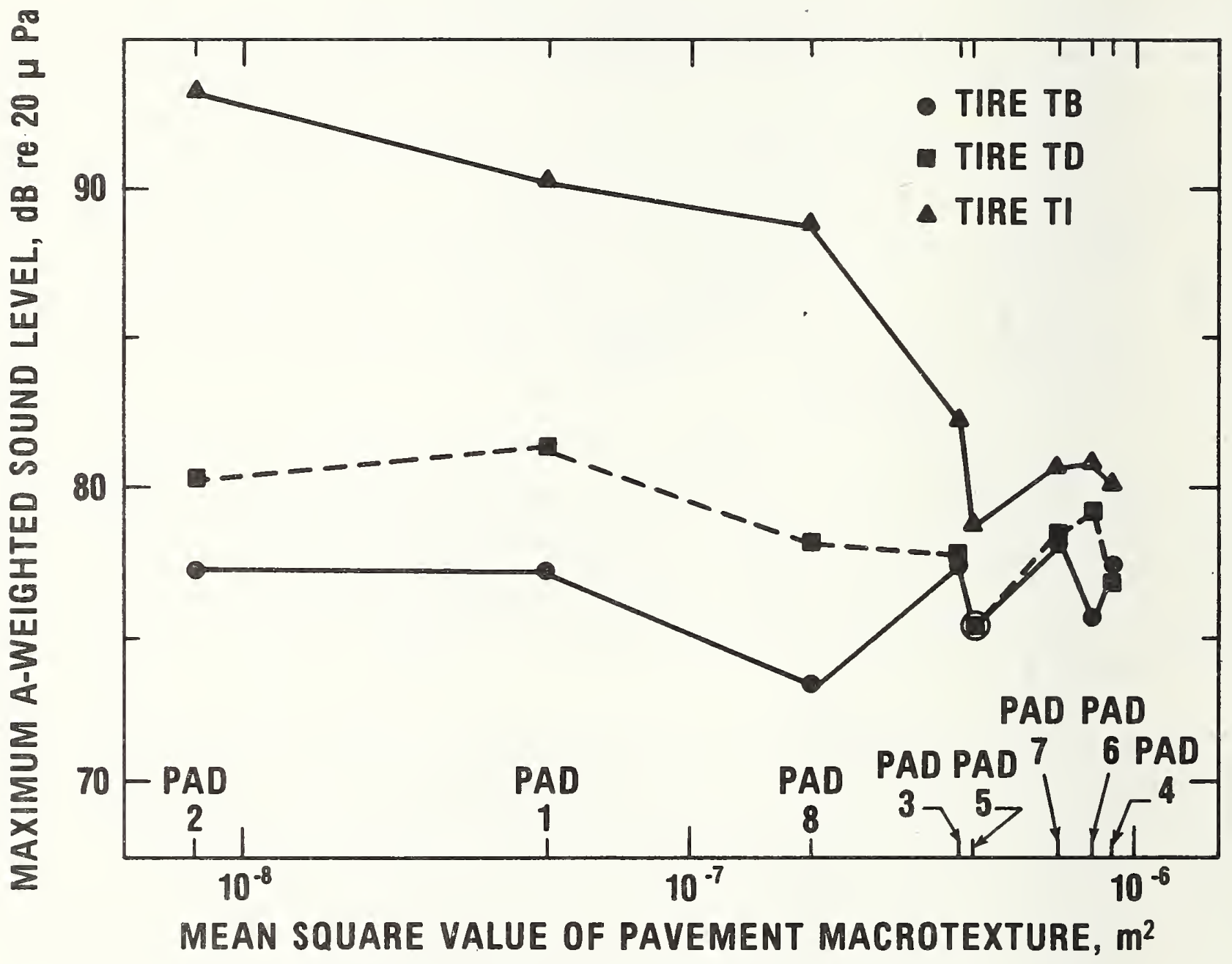

Figure 20. Maximum A-weighted sound levels, as measured at 50 feet (15.2 $\mathrm{m})$, versus the mean square value of the pavement macrotexture with tread design as a variable. These data are for vehicle coastbys at $50 \mathrm{mph}(80.5 \mathrm{~km} / \mathrm{hr})$ over each test pad. 


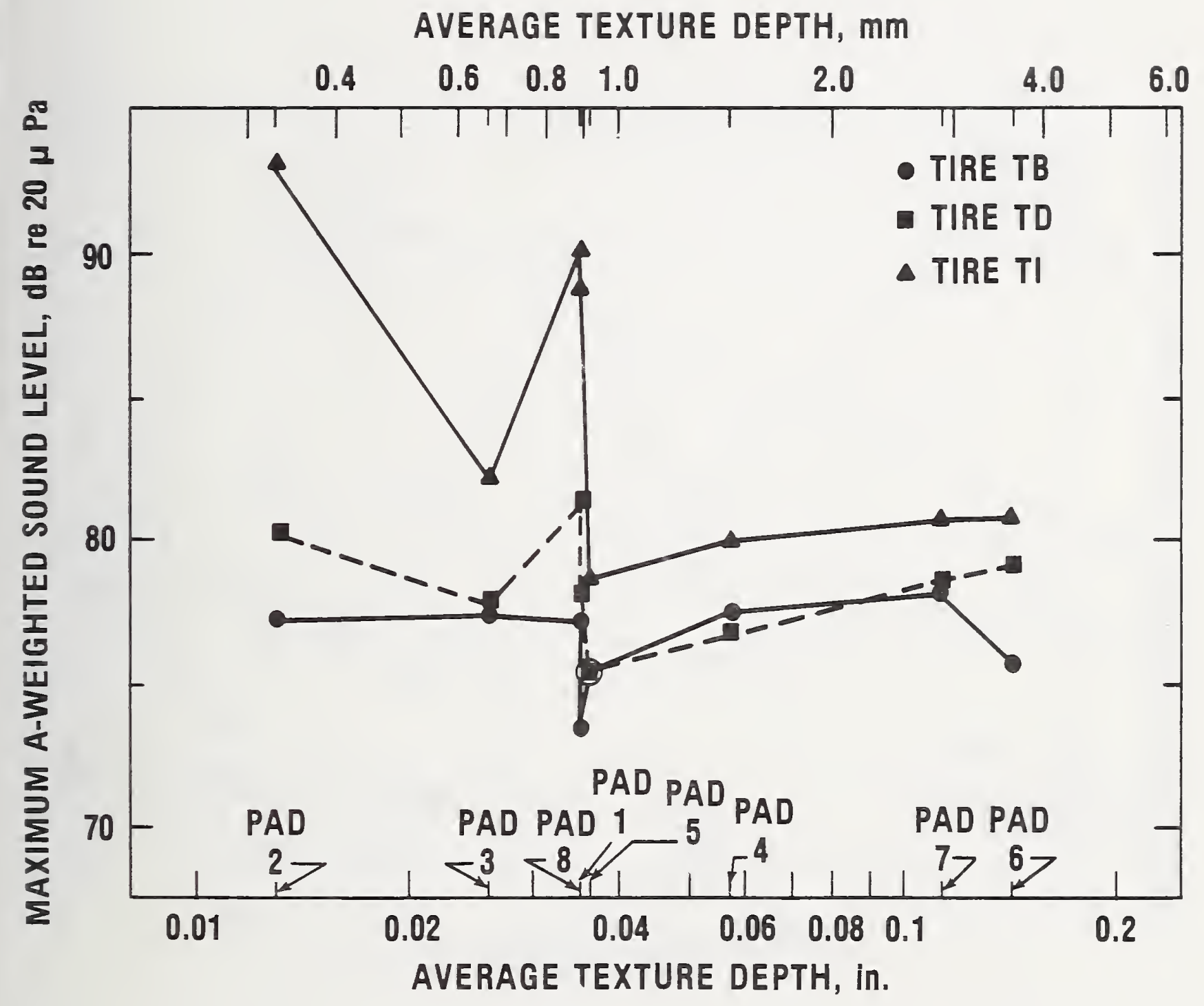

Figure 21. Maximum A-weighted sound levels, as measured at 50 feet (15.2 $\mathrm{m})$, versus the average texture depth with tread design as a variable. The average texture depth was measured by the putty impression method. These data are for vehicle coastbys at 50 mph $(80.5 \mathrm{~km} / \mathrm{hr})$ over each test pad. 

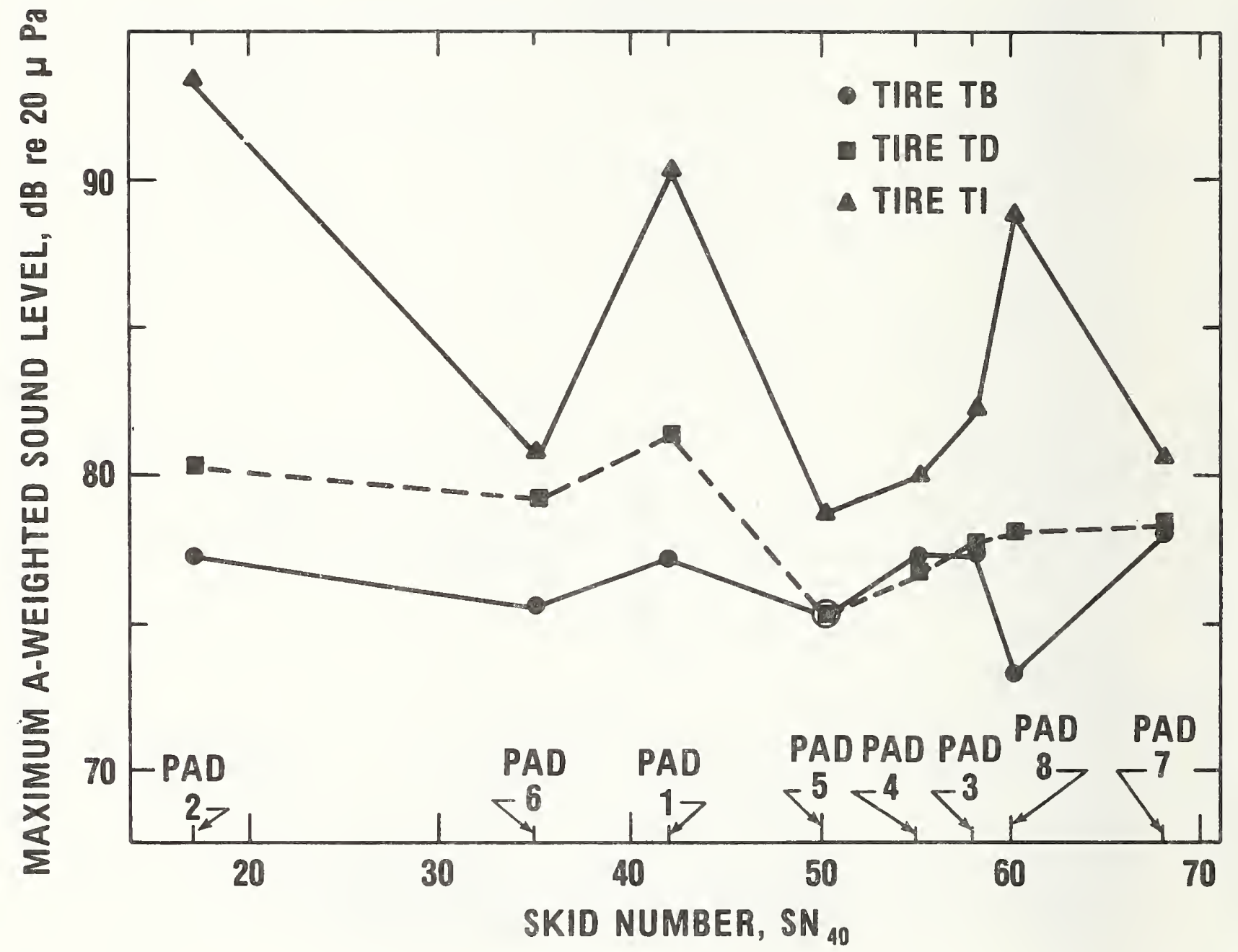

Figure 22. Maximum A-weighted sound levels, as measured at 50 feet (15.2 $\mathrm{m}$ ), versus skid number, $\mathrm{SN}_{40}$, with tread design as a variable. The skid number is measured according to ASTM E 274-70 procedures using a skid trailer. These data are for vehicle coastybs at $50 \mathrm{mph}(80.5 \mathrm{~km} / \mathrm{hr})$ over each test pad. 


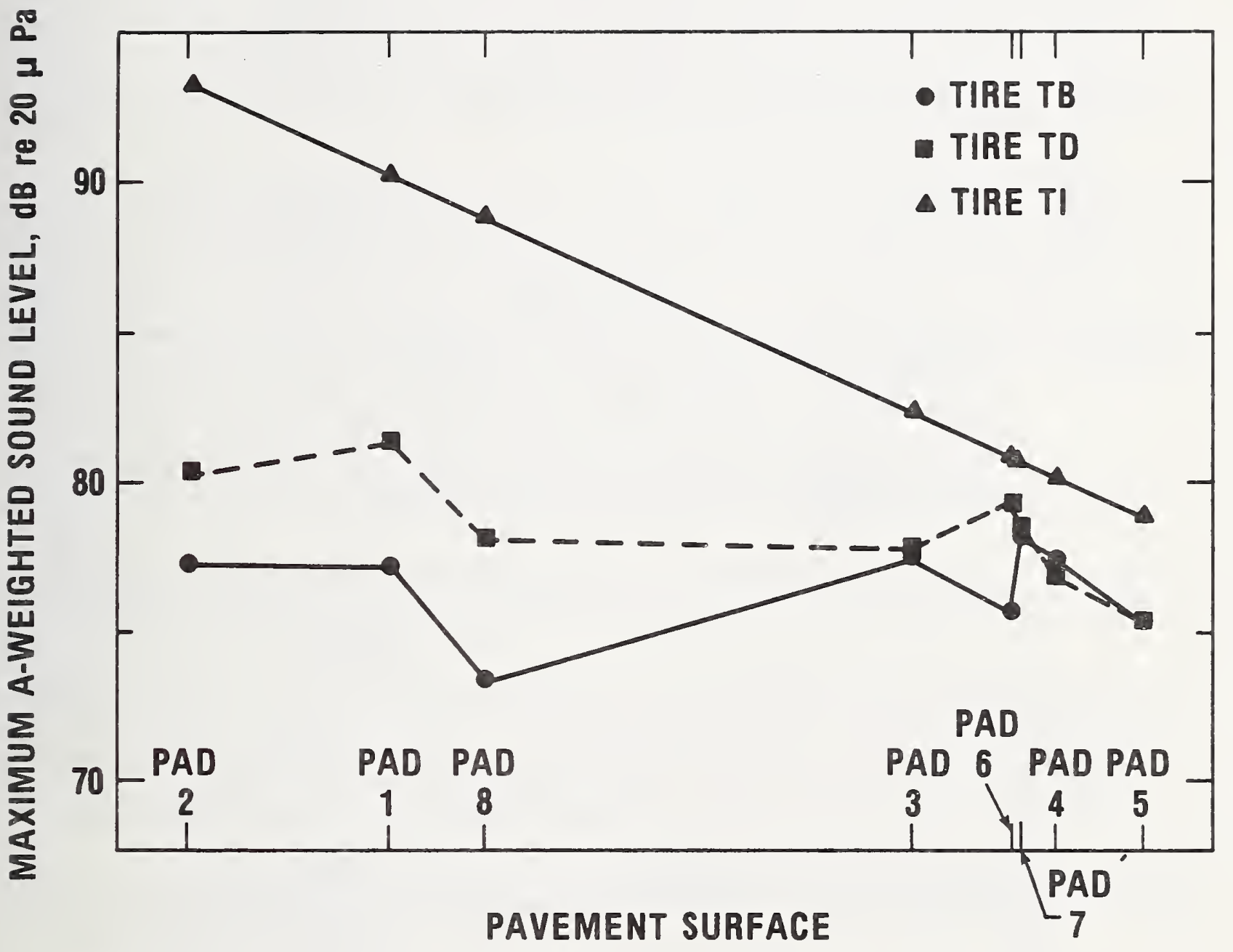

Figure 23. Maximum A-weighted sound levels, as measured at 50 feet (15.2 $\mathrm{m})$, versus pavement surface with tread design as a variable. The abscissa was adjusted such that the sound level data versus surface for the pocket retread formed a straight line. These data are for vehicle coastbys at $50 \mathrm{mph}(80.5 \mathrm{~km} / \mathrm{hr})$ over each test pad. 


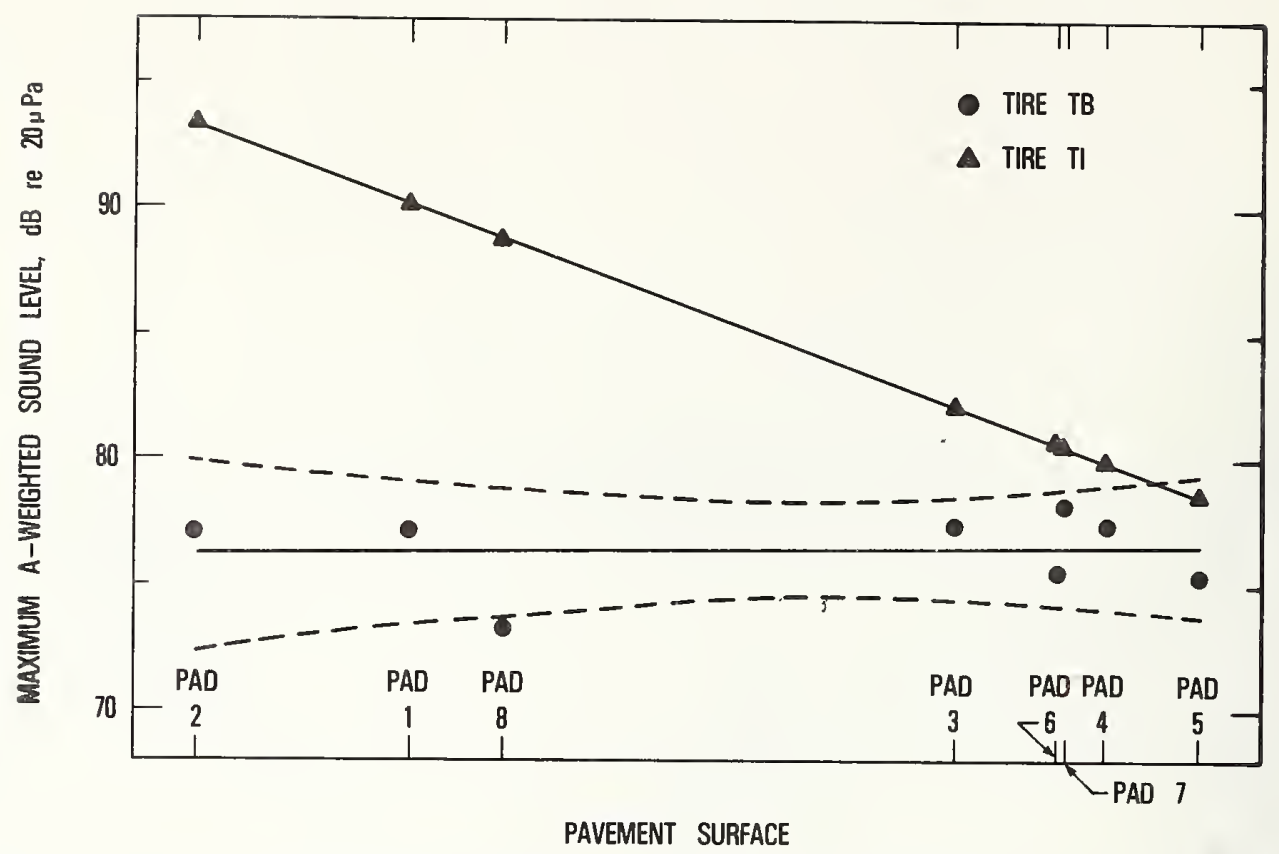

Figure 24. Maximum A-weighted sound levels generated by tire TB versus pavement surface using the pocket tread tire as a calibrator. The solid line corresponds to the linear regression line and the dashed lines to the $95 \%$ confidence limits on the mean value. These data were measured at 50 feet $(15.2 \mathrm{~m})$ for vehicle coastbys at $50 \mathrm{mph}(80.5 \mathrm{~km} / \mathrm{hr})$ over each test pad.

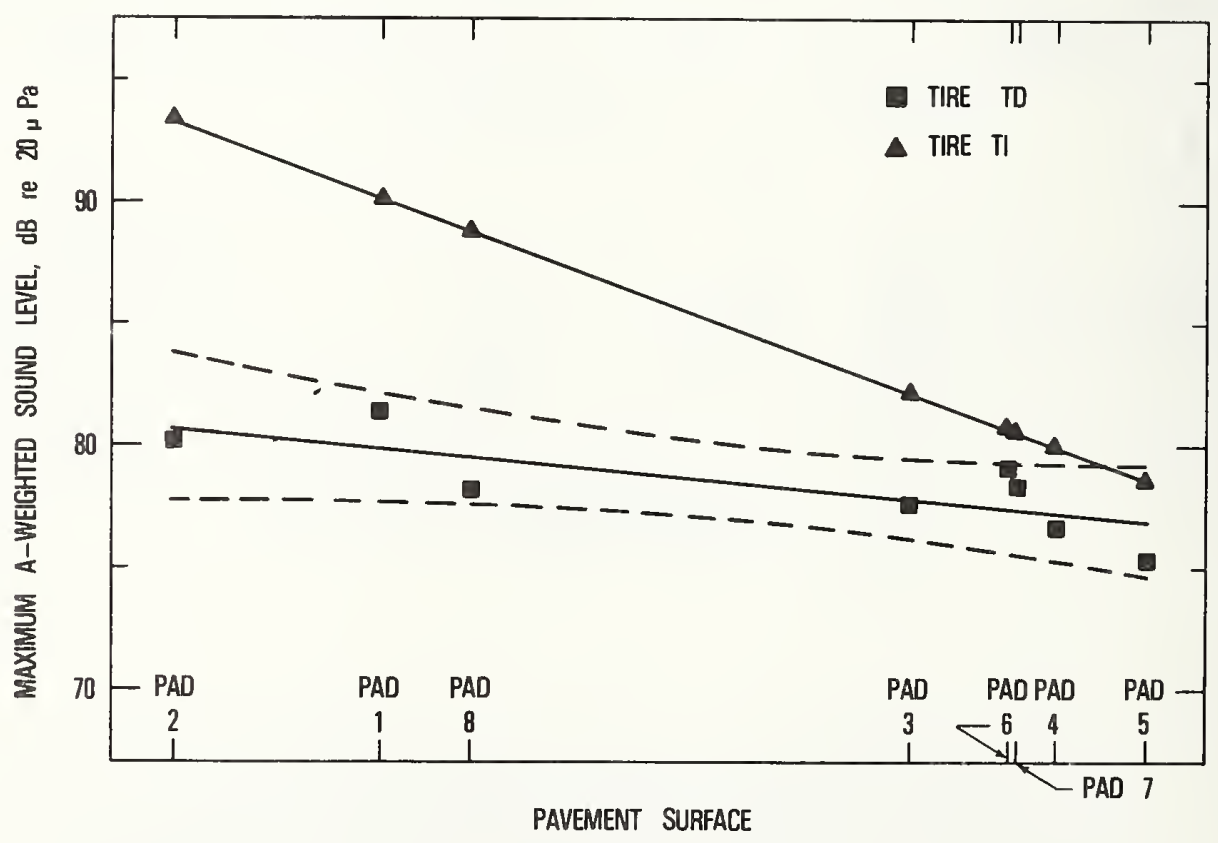

Figure 25. Maximum A-weighted sound levels generated by tire TD versus pavement surface using the pocket tread tire as a calibrator. The solid line corresponds to the linear regression line and the dashed lines to the $95 \%$ confidence limits on the mean value. These data were measured at 50 feet $(15.2 \mathrm{~m})$ for vehicle coastbys at $50 \mathrm{mph}(80.5 \mathrm{~km} / \mathrm{hr})$ over each test pad. 
It should be noted that many of the pavement surfaces characteristic of the eight test pads at the Texas Transportation Institute are not typical of road surfaces utilized for today's highways. Of the eight surfaces investigated, pad 1 (portland cement concrete) and pad 8 (asphaltic concrete) are most representative of typical road surfaces. More information is needed to correlate the noise generated by pocket tread and other tire designs on typical road surfaces in order to thoroughly evaluate the pocket tread tire as a pavement calibrator.

Subsequent studies[29] have shown that road surface has a greater effect on the noise of passenger car tires than on truck tires. This is due to the fact that the pavement texture within the tire-road interaction area is on the same scale as the tread element spacing typical of passenger car tires. Thus, it would be interesting to correlate the noise levels from passenger car tires running on these eight surfaces with the measured surface macrotexture data.

It might be useful to evaluate a blank tire as a simple calibrator of surface texture rather than the pocket tread tire. Tire noise data obtained by Hillquist and Carpenter[10] for continuous and discrete block rib passenger car tires running on six different surfaces are plotted in Figures 26 and 27, respectively, using a blank tire as a calibrator. Based on this limited set of data, it appears that the blank tire potentially could be used as a surface calibrator. More data concerning the use of blank tire calibrators are needed.

\subsection{Conclusions}

Based on the data obtained during the conduct of this test program and subsequent studies, the following conclusions can be drawn:

a Pavement surface had a greater influence on the noise generated by the pocket tread tire -- a range of 10-20 dB for the surfaces tested -- than by the rib or cross-bar tires -- a range of 4-6 dB.

alots of tire noise level versus macrotexture data showed that there were two factors influencing the tire noise generation mechanisms depending on the surface texture. Up to a certain macrotexture scale the generated noise appears to be tire dependent, while above this value the pavement macrotexture appears to be the controlling factor.

anformation is needed to thoroughly understand road surface effects and to determine which tire mechanisms are important and how they are affected by road surface texture.

- Based on subsequent studies, road surface appears to affect passenger car tire noise more than truck tire noise. A detailed investigation similar to this study using passenger car tires may reveal more information on the effects of road surface. Also, further testing using a blank tire may prove useful.

The pocket tread truck tire shows potential as a simple calibrator of surface texture, especially in the region -- in the case of truck tires -where tire characteristics dominate surface effects. 


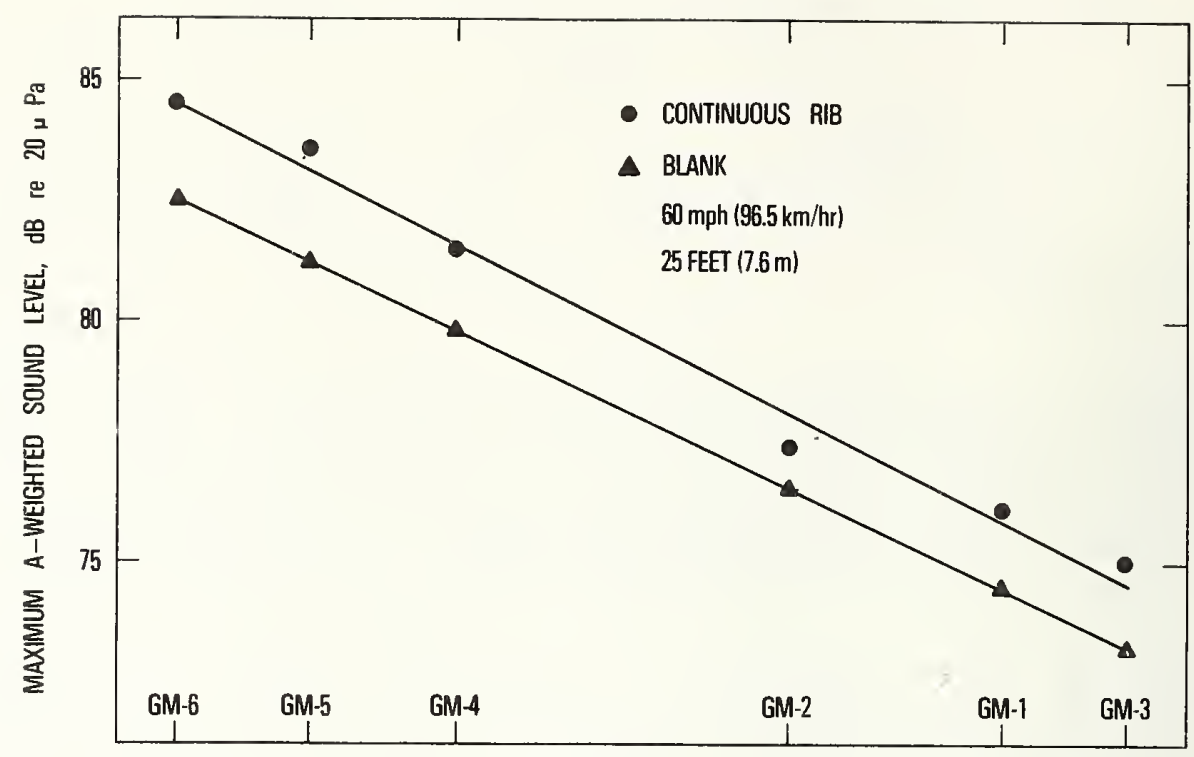

PAVEMENT SURFACE

Figure 26. Maximum A-weighted sound levels generated by a typical automobile continuous rib tire versus pavement surface using a blank tire as a calibrator. The solid line corresponds to the linear regression line. These data were measured by Hillquist[10] at 25 feet $(7.6 \mathrm{~m})$ for passenger car coastbys at $60 \mathrm{mph}(96.5 \mathrm{~km} / \mathrm{hr})$ over six different pavements.

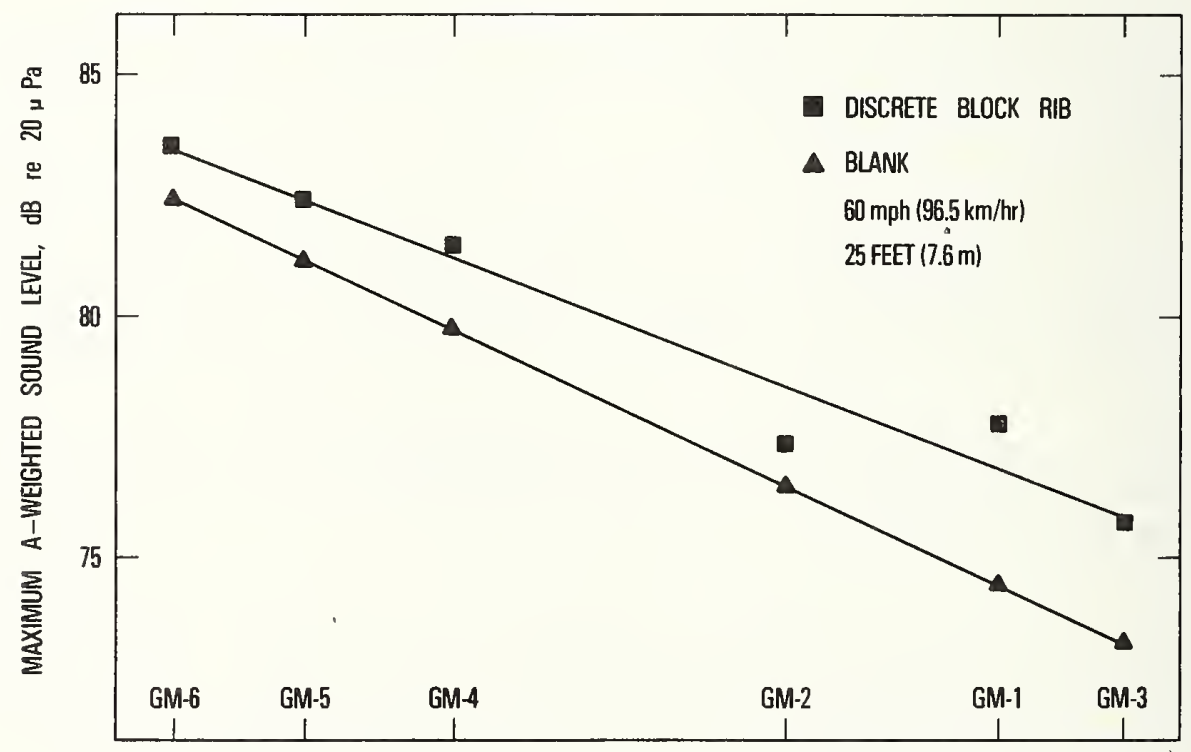

PAVEMENT SURFACE

Figure 27. Maximum A-weighted sound levels generated by a typical automobile discrete block rib tire versus pavement surface using a blank tire as a calibrator. The solid line corresponds to the linear regression 1 ine. These data were measured by Hillquist[10] at 25 feet $(7.6 \mathrm{~m})$ for passenger car coastbys at $60 \mathrm{mph}(96.5 \mathrm{~km} / \mathrm{hr})$ over six different pavements. 


\section{Truck Tire Iroise Data}

This appendix, which presents the truck tire noise data, is comprised of three separate parts. First, the tabulated values of A-weighted sound level (maximum value of the A-weighted sound level during a passby) measured at the two microphone lccations [25 and 50 feet $(7.6$ and $15.2 \mathrm{~m})$ ] are reported. The data are organized according to tire tread design, vehicle speed and pavement surface. A photograph showing the characteristic tread element pattern for each of the test tires is presented along with the average tread depth of the test tires. Second, spectral data are presented for the three test tires and each of the eight pavement surfaces. The one-third octave band spectra shown are those measured at the 50 foot ( $15.2 \mathrm{~m}$ ) microphone location during a $50 \mathrm{mph}$ ( 80.5 $\mathrm{km} / \mathrm{hr}$ ) coastby at the time corresponding to the occurrence of the maximum A-weighted sound level. Finally, the last three tables of this appendix tabulate the decrease in A-weighted sound level observed between the 25 and 50 foot $(7.6$ and $15.2 \mathrm{~m})$ measurement locations for each test tire and test Davement for vehicle coastbys at nominal speeds of 40,50 and $60 \mathrm{mph}$ (64.4, 80.5 and $96.5 \mathrm{~km} / \mathrm{hr}$ ). 


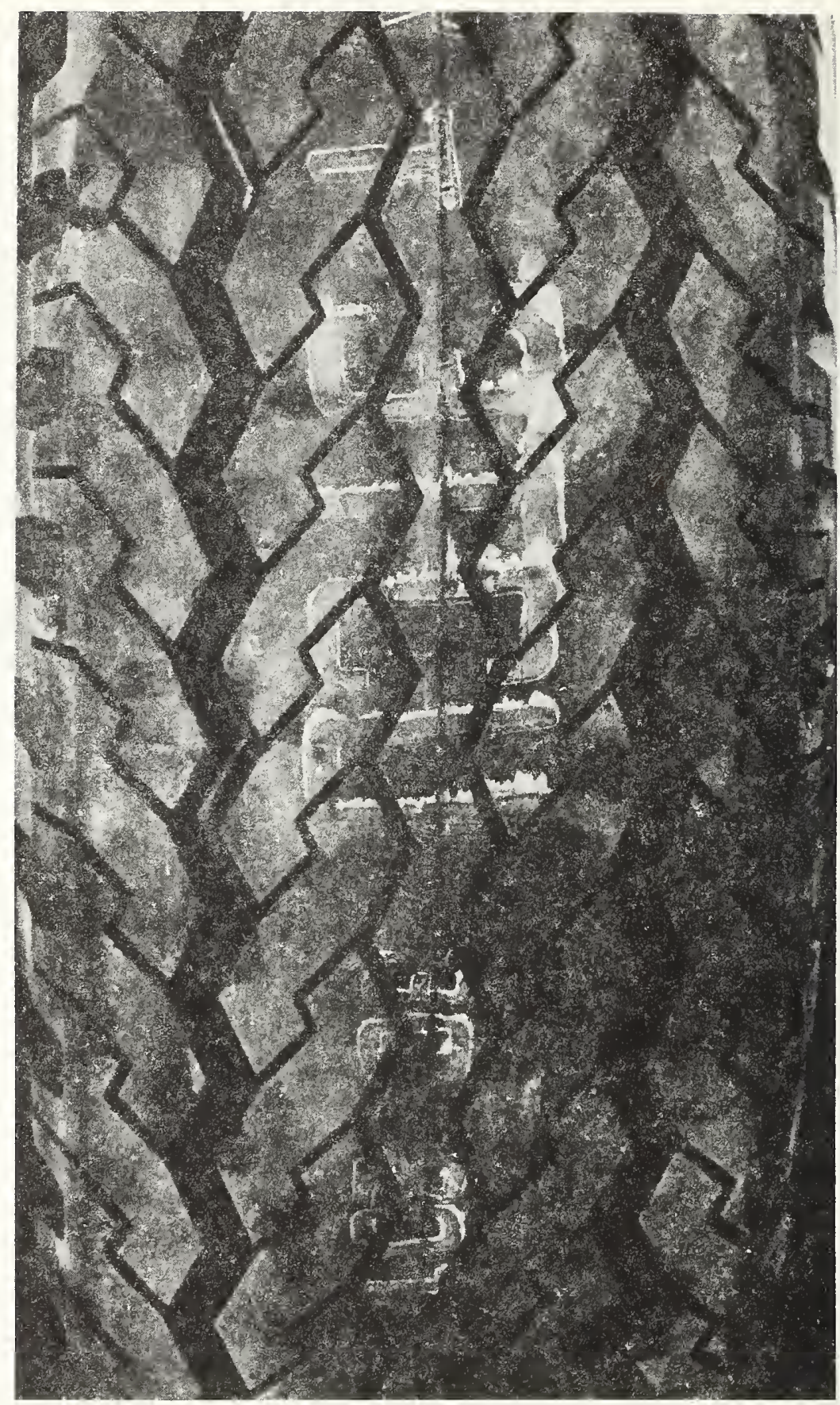

Figure A-I. Characteristic tread element pattern of tire TB (rib tire). The nominal new tread depth for this tire was $17 / 32$ inch ( 1.35 $\mathrm{cm})$. 
Paó I, Portlana Cerent Concrete

A-weightea Sound Ievel, $d B$ re $20 \mu \mathrm{Pa}$

\begin{tabular}{|l|cccccc|}
\hline $\begin{array}{l}\text { Microphone } \\
\text { Iocation, It (m) }\end{array}$ & $40(64.4)$ & $40(64.4)$ & $50(80.5)$ & $50(80.5)$ & $60(96.5)$ & $60(96.5)$ \\
\hline $25(7.6)$ & 78.8 & 79.0 & 81.2 & 83.0 & 83.0 & 83.6 \\
$50(15.2)$ & 75.2 & 73.6 & 76.6 & 77.6 & 78.0 & 78.6 \\
\hline
\end{tabular}

Pac̀ 2, Asphaltic Concrete with Jennite Flush Seal

A-weightec Sound Level, $d B$ re 20 HPa

\begin{tabular}{|l|cccccc|}
\hline Microphone & \multicolumn{5}{|c|}{ Tominal Speed, mph (km/hr) } \\
Iocation, It $(m)$ & 40 (64.4) & $40(64.4)$ & $50(80.5)$ & $50(80.5)$ & $60(96.5)$ & $60(96.5)$ \\
\hline $25(7.6)$ & 76.8 & 77.8 & 81.4 & 82.0 & 80.2 & 81.0 \\
$50(15.2)$ & 71.8 & 72.2 & 77.0 & 77.2 & 76.6 & 76.6 \\
\hline
\end{tabular}

Paa 3, Iimestone Hot-Yix Asphaltic Concrete (Terrazo Finish)

A-weightea Sound Ievel, dS re $20 \mu \mathrm{Pa}$

\begin{tabular}{|l|cccccc|}
\hline Wicrophone & \multicolumn{5}{|c|}{ Tominal Speed, mph (km/hr) } \\
Location, ft $(m)$ & $40(64.4)$ & $40(64.4)$ & $50(80.5)$ & $50(80.5)$ & $60(96.5)$ & $60(96.5)$ \\
\hline $25(7.6)$ & 76.0 & 77.4 & 81.0 & 82.0 & 81.2 & 81.0 \\
$50(15.2)$ & 71.2 & 71.2 & 76.8 & 78.0 & 75.6 & 77.4 \\
\hline
\end{tabular}

Pad 4, Crushed Gravel Hot-Mix Asphaltic Concrete $A$-weighted Sound Level, dB re $20 \mu \mathrm{Pa}$

\begin{tabular}{|l|cccccc|}
\hline Wicropione & \multicolumn{7}{|c|}{ Iiominal Speea, mph (km/hr) } \\
Location, fi (m) & $40(64.4)$ & $40(64.4)$ & $50(80.5)$ & $50(80.5)$ & $60(96.5)$ & $60(96.5)$ \\
\hline $25(7.6)$ & 77.4 & 78.2 & 82.4 & 82.2 & 81.2 & 82.4 \\
$50(15.2)$ & 72.2 & 72.2 & 77.8 & 77.0 & 76.6 & 77.4 \\
\hline
\end{tabular}

Pad 5, Rounded Gravel Hot-Mix Asphaltic Concrete

A-weighted Souna Ievel, $d B$ re $20 \mu \mathrm{Pa}$

\begin{tabular}{|l|cccccc|}
\hline Wicrophone & \multicolumn{7}{|c|}{ Nominal Speed, mph $(\mathrm{km} / \mathrm{hr})$} \\
Location, ft $(m)$ & $40(64.4)$ & $40(64.4)$ & $50(80.5)$ & $50(80.5)$ & $60(96.5)$ & $60(96.5)$ \\
\hline $25(7.6)$ & 76.6 & 75.6 & 79.2 & 79.6 & 80.8 & 80.6 \\
$50(15.2)$ & 70.8 & 70.6 & 76.2 & 74.4 & 76.4 & 76.4 \\
\hline
\end{tabular}


Pad 6, Rounded Gravel Asphalt Chip Seal A-weighted Sound Level, dB re $20 \mu \mathrm{Pa}$

\begin{tabular}{|l|cccccc|}
\hline Microphone & \multicolumn{7}{|c|}{ Nominal Speed, mph $(\mathrm{km} / \mathrm{hr})$} \\
Location, ft (m) & $40(64.4)$ & $40(64.4)$ & $50(80.5)$ & $50(80.5)$ & $60(96.5)$ & $60(96.5)$ \\
\hline $25(7.6)$ & 75.4 & 75.0 & 78.8 & 79.0 & 82.0 & 81.6 \\
$50(15.2)$ & 72.2 & 72.8 & 75.6 & 75.6 & 78.2 & 79.0 \\
\hline
\end{tabular}

Pad 7, Lightweight Aggregate Asphalt Chip Seal

A-weighted Sound Level, dB re $20 \mu \mathrm{Pa}$

\begin{tabular}{|l|cccccc|}
\hline $\begin{array}{l}\text { Microphone } \\
\text { Location, ft }(\mathrm{m})\end{array}$ & $40(64.4)$ & $40(64.4)$ & $50(80.5)$ & $50(80.5)$ & $60(96.5)$ & $60(96.5)$ \\
\hline $25(7.6)$ & 78.2 & 78.4 & 82.6 & 82.6 & 85.0 & 85.2 \\
$50(15.2)$ & 73.8 & 74.4 & 78.2 & 78.0 & 81.0 & 81.4 \\
\hline
\end{tabular}

Pad 8, Lightweight Aggregate Hot-Mix Asphaltic Concrete A-weighted Sound Level, dB re $20 \mu \mathrm{Pa}$

\begin{tabular}{|l|cccccc|}
\hline $\begin{array}{l}\text { Microphone } \\
\text { Location, ft }(\mathrm{m})\end{array}$ & 40 (64.4) & $40(64.4)$ & $50(80.5)$ & $50(80.5)$ & $60(96.5)$ & $60(96.5)$ \\
\hline $25(7.6)$ & 72.6 & 73.8 & 77.0 & 78.0 & 80.8 & 80.0 \\
$50(15.2)$ & 68.2 & 68.8 & 73.2 & 73.4 & 76.2 & 75.4 \\
\hline
\end{tabular}




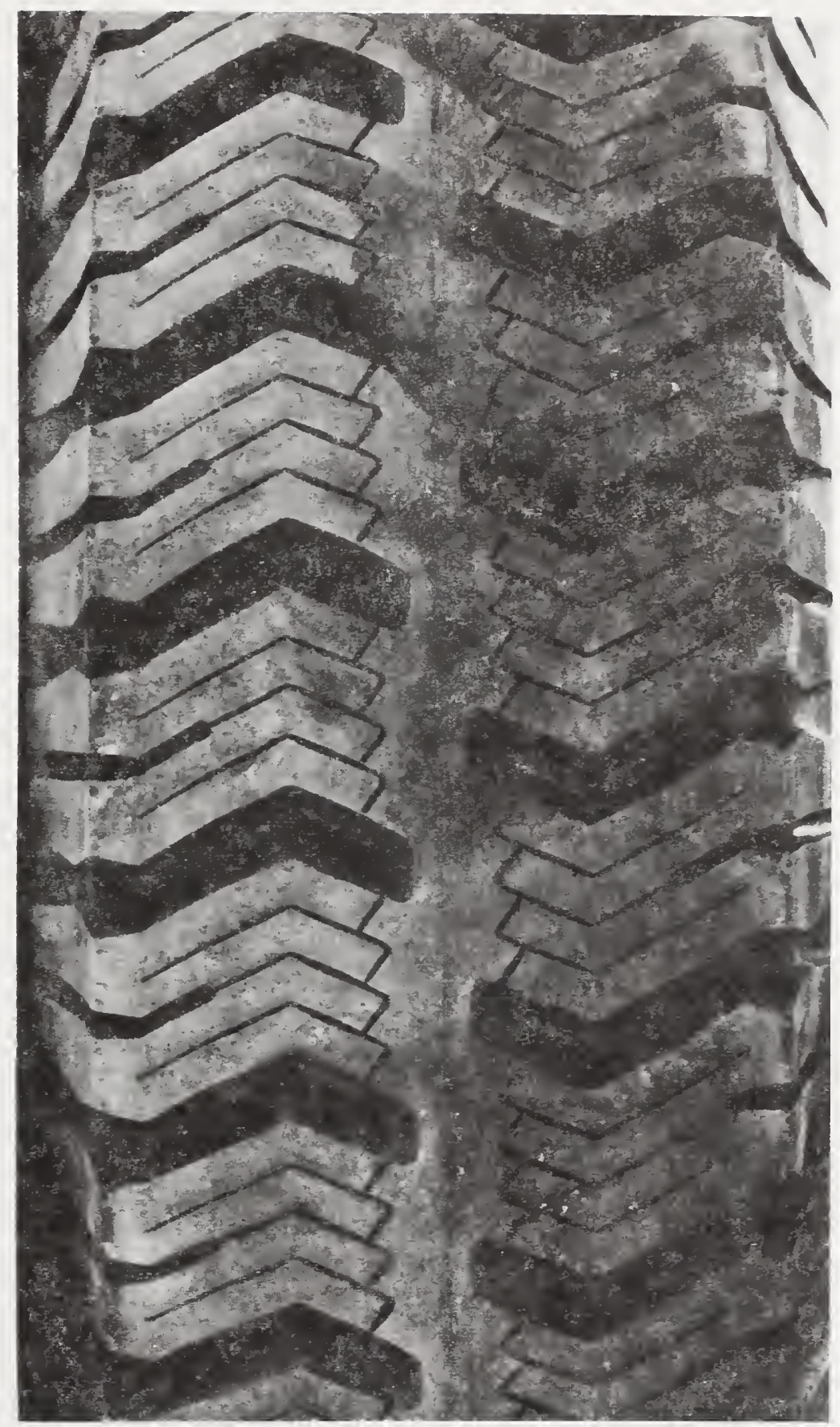

Figure A-2. Characteristic tread element pattern of tire TD (cross-bar tire). The nominal new tread depth for this tire was $28 / 32$ inch $(2.22 \mathrm{~cm})$. 
Pad 1, Portland Cement Concrete

A-weighted Sound Level, dB re $20 \mu \mathrm{Pa}$

\begin{tabular}{|l|cccccc|}
\hline $\begin{array}{l}\text { Microphone } \\
\text { Location, ft (m) }\end{array}$ & $40(64.4)$ & $40(64.4)$ & $50(80.5)$ & $50(80.5)$ & $60(96.5)$ & $60(96.5)$ \\
\hline $25(7.6)$ & 81.4 & 81.2 & 85.2 & 84.2 & 85.4 & 86.0 \\
$50(15.2)$ & 77.2 & 77.4 & 81.2 & 81.4 & 83.0 & 82.0 \\
\hline
\end{tabular}

Pad 2, Asphaltic Concrete with Jennite Flush Seal

A-weighted Sound Level, dB re $20 \mu \mathrm{Pa}$

\begin{tabular}{|l|cccccc|}
\hline $\begin{array}{l}\text { Microphone } \\
\text { Location, ft (m) }\end{array}$ & \multicolumn{6}{|c|}{ Nominal Speed, mph (km/hr) } \\
\hline $25(7.6)$ & 83.0 & 81.4 & 83.8 & 82.2 & 85.4 & 85.4 \\
$50(15.2)$ & 78.0 & 79.0 & 80.8 & 79.6 & 81.8 & 82.0 \\
\hline
\end{tabular}

Pad 3, Limestone Hot-Mix Asphaltic Concrete (Terrazo Finish)

A-weighted Sound Level, dB re $20 \mu \mathrm{Pa}$

\begin{tabular}{|l|cccccc|}
\hline $\begin{array}{l}\text { Microphone } \\
\text { Location, ft (m) }\end{array}$ & 40 (64.4) & $40(64.4)$ & $50(80.5)$ & $50(80.5)$ & $60(96.5)$ & $60(96.5)$ \\
\hline $25(7.6)$ & 79.8 & 81.0 & 82.4 & 82.2 & 83.6 & 85.8 \\
$50(15.2)$ & 75.8 & 76.0 & 78.0 & 77.4 & 79.2 & 79.8 \\
\hline
\end{tabular}

Pad 4, Crushed Gravel Hot-Mix Asphaltic Concrete

A-weighted Sound Level, dB re $20 \mu \mathrm{Pa}$

\begin{tabular}{|l|cccccc|}
\hline Microphone & \multicolumn{5}{|c|}{ Nominal Speed, mph (km/hr) } \\
Location, ft (m) & 40(64.4) & $40(64.4)$ & $50(80.5)$ & $50(80.5)$ & $60(96.5)$ & $60(96.5)$ \\
\hline $25(7.6)$ & 80.0 & 79.8 & 82.2 & 82.6 & 84.2 & 83.6 \\
$50(15.2)$ & 73.4 & 74.4 & 76.6 & 76.8 & 78.6 & 80.0 \\
\hline
\end{tabular}

Pad 5, Rounded Gravel Hot-Mix Asphaltic Concrete

A-weighted Sound Level, dB re $20 \mu \mathrm{Pa}$

\begin{tabular}{|c|c|c|c|c|c|c|}
\hline $\begin{array}{l}\text { Microphone } \\
\text { Location, ft (m) }\end{array}$ & $40(64.4)$ & $40\left(64.4^{N}\right.$ & $\begin{array}{l}\text { hinal Spee } \\
50(80.5)\end{array}$ & $\begin{array}{l}, \operatorname{mph}(\mathrm{km} / \mathrm{h} \\
50(80.5)\end{array}$ & $60 \quad(96.5$ & $60(96.5)$ \\
\hline $\begin{array}{ll}25 & (7.6) \\
50 & (15.2)\end{array}$ & $\begin{array}{l}77.4 \\
73.0\end{array}$ & $\begin{array}{l}77.2 \\
73.4\end{array}$ & $\begin{array}{l}81.0 \\
75.2\end{array}$ & $\begin{array}{l}80.8 \\
75.4\end{array}$ & $\begin{array}{l}83.8 \\
78.6\end{array}$ & $\begin{array}{l}83.4 \\
79.0\end{array}$ \\
\hline
\end{tabular}


Pad 6, Rounded Gravel Asphalt Chip Seal A-weighted Sound Level, $\mathrm{dB}$ re $20 \mu \mathrm{Pa}$

\begin{tabular}{|l|cccccc|}
\hline $\begin{array}{l}\text { Microphone } \\
\text { Location, ft }(\mathrm{m})\end{array}$ & $40(64.4)$ & $40(64.4)$ & $50(80.5)$ & $50(80.5)$ & $60(96.5)$ & $60(96.5)$ \\
\hline $25(7.6)$ & 81.2 & 81.0 & 84.4 & 84.6 & 87.0 & 87.8 \\
$50(15.2)$ & 76.0 & 75.6 & 79.0 & 79.2 & 81.4 & 82.0 \\
\hline
\end{tabular}

Pad 7, Lightweight Aggregate Asphalt Chip Seal A-weighted Sound Level, $d B$ re $20 \mu \mathrm{Pa}$

\begin{tabular}{|l|cccccc|}
\hline $\begin{array}{l}\text { Microphone } \\
\text { Location, ft (m) }\end{array}$ & 40 (64.4) & $40(64.4)$ & $50(80.5)$ & $50(80.5)$ & $60(96.5)$ & $60(96.5)$ \\
\hline $25(7.6)$ & 79.6 & 79.8 & 84.2 & 83.2 & 87.0 & 86.4 \\
$50(15.2)$ & 74.4 & 74.4 & 78.8 & 78.0 & 81.6 & 81.6 \\
\hline
\end{tabular}

Pad 8, Lightweight Aggregate Hot-Mix Asphaltic Concrete A-weighted Sound Level, $\mathrm{dB}$ re $20 \mu \mathrm{Pa}$

\begin{tabular}{|l|cccccc|}
\hline Microphone & \multicolumn{7}{|c|}{ Nominal Speed, mph (km/hr) } \\
Location, ft $(\mathrm{m})$ & $40(64.4)$ & $40(64.4)$ & $50(80.5)$ & $50(80.5)$ & $60(96.5)$ & $60(96.5)$ \\
\hline $25(7.6)$ & 81.4 & 81.2 & 83.4 & 83.8 & 85.4 & 85.8 \\
$50(15.2)$ & 75.8 & 76.2 & 78.0 & 78.2 & 80.8 & 81.0 \\
\hline
\end{tabular}




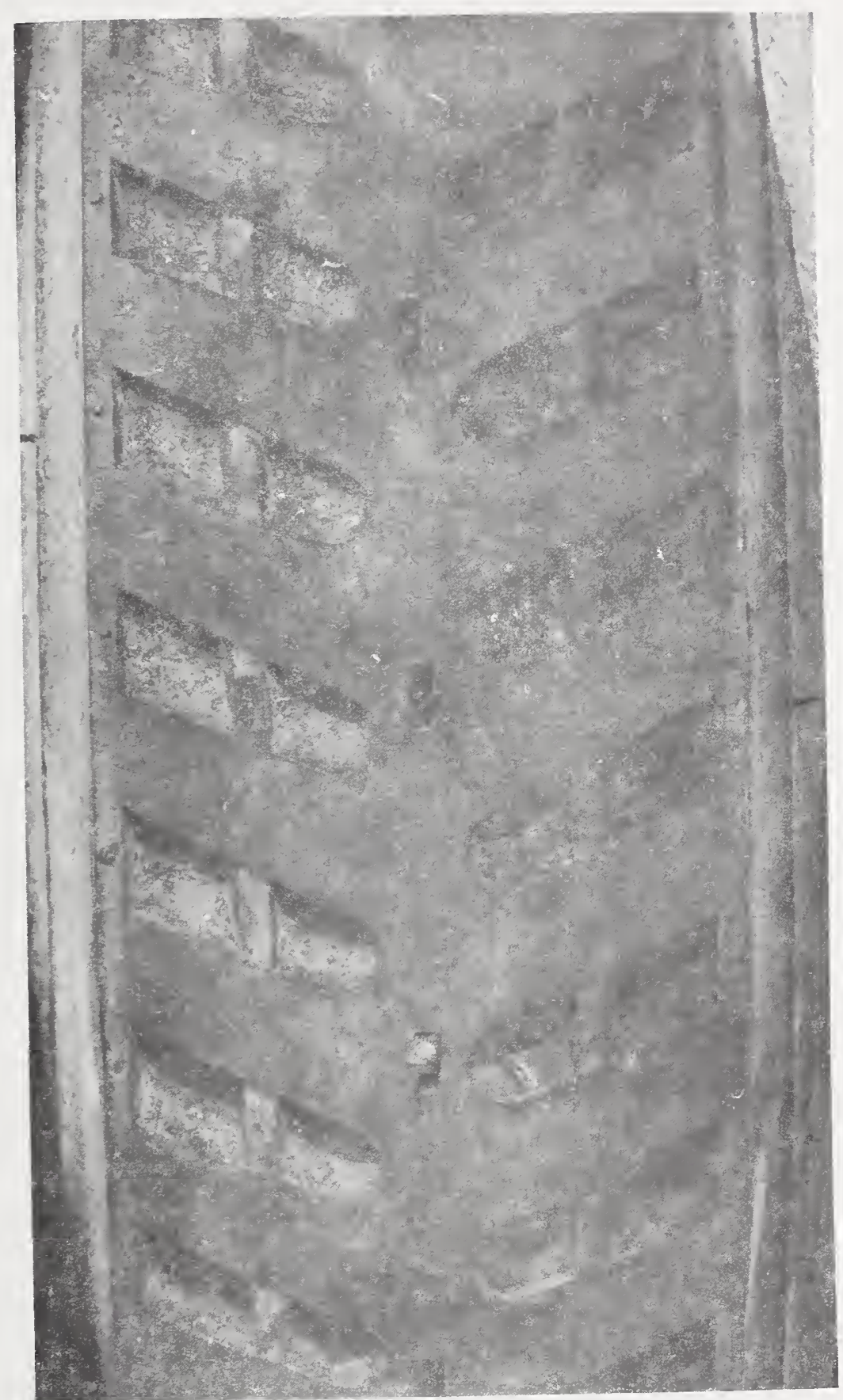

Figure A-3. Characteristic tread element pattern of tire TI (pocket retread). The nominal new tread depth for this tire was 12/32 inch $(0.95 \mathrm{~cm})$. 
Pad 1, Portland Cement Concrete

A-weighted Sound Ievel, $\mathrm{dB}$ re $20 \mathrm{\mu Pa}$

\begin{tabular}{|l|cccccc|}
\hline $\begin{array}{l}\text { Microphone } \\
\text { Location, ft }(m)\end{array}$ & $40(64.4)$ & $40(64.4)$ & $50(80.5)$ & $50(80.5)$ & $60(96.5)$ & $60(96.5)$ \\
\hline $25(7.6)$ & 91.8 & 91.6 & 95.6 & 95.4 & 97.2 & 98.0 \\
$50(15.2)$ & 85.6 & 85.4 & 89.6 & 90.8 & 92.8 & 92.8 \\
\hline
\end{tabular}

Pad 2, Asphaltic Concrete with Jennite Flush Seal

A-weighted Sound Ievel, $d B$ re $20 \mathrm{\mu Pa}$

\begin{tabular}{|l|cccccc|}
\hline Microphone & \multicolumn{5}{|c|}{ Nominal Speed, mph (km/hr) } \\
Iocation, It (m) & $40(64.4)$ & $40(64.4)$ & $50(80.5)$ & $50(80.5)$ & $60(96.5)$ & $60(96.5)$ \\
\hline $25(7.6)$ & 93.8 & 93.4 & 97.8 & 98.2 & 100.2 & 99.0 \\
$50(15.2)$ & 89.6 & 89.8 & 92.8 & 93.8 & 94.2 & 94.6 \\
\hline
\end{tabular}

Pad '3, Iimestone Hot-Mix Asphaltic Concrete (Terrazo Finish) A-weighted Sound Level, dB re $20 \mu \mathrm{Pa}$

\begin{tabular}{|l|cccccc|}
\hline Microphone & \multicolumn{5}{|c|}{ Nominal Speed, mph (km/hr) } \\
Location, ft (m) & $40(64.4)$ & $40(64.4)$ & $50(80.5)$ & $50(80.5)$ & $60(96.5)$ & $60(96.5)$ \\
\hline $25(7.6)$ & 84.0 & 83.6 & 87.8 & 88.0 & 92.8 & 94.0 \\
$50(15.2)$ & 77.8 & 77.4 & 82.8 & 81.6 & 87.4 & 87.0 \\
\hline
\end{tabular}

Pad 4, Crushed Gravel Hot-Mix Asphaltic Concrete A-weighted Sound Ievel, $\mathrm{dB}$ re $20 \mathrm{\mu Pa}$

\begin{tabular}{|c|c|c|c|c|c|}
\hline $\begin{array}{l}\text { Microphone } \\
\text { Iocation, it }(m)\end{array}$ & $40(64.4)$ & $\begin{array}{l}\text { Nominal Speed } \\
40(64.4) 50(80.5)\end{array}$ & $\begin{array}{l}\mathrm{mph}(\mathrm{km} / \\
50(80.5)\end{array}$ & r) $60(96.5)$ & $60(96.5)$ \\
\hline $\begin{array}{ll}25 & (7.6) \\
50 & (15.2)\end{array}$ & $\begin{array}{l}79.6 \\
73.8\end{array}$ & $\begin{array}{l}80.2 \\
74.8\end{array}$ & $\begin{array}{l}87.4 \\
79.4\end{array}$ & $\begin{array}{l}88.2 \\
83.8\end{array}$ & $\begin{array}{l}88.2 \\
83.8\end{array}$ \\
\hline
\end{tabular}

Pad 5, Rounded Gravel Hot-Mix Asphaltic Concrete

A-weighted Sound Ievel, $\mathrm{a}$ re $20 \mu \mathrm{Pa}$

\begin{tabular}{|l|cccccc|}
\hline $\begin{array}{l}\text { Microphone } \\
\text { Iocation, It (m) }\end{array}$ & $40(64.4)$ & $40(64.4)$ & $50(80.5)$ & $50(80.5)$ & $60(96.5)$ & $60(96.5)$ \\
\hline $25(7.6)$ & 81.0 & 81.2 & 84.6 & 86.6 & 91.6 & 90.8 \\
$50(15.2)$ & 74.6 & 75.0 & 78.6 & 78.6 & 84.8 & 84.8 \\
\hline
\end{tabular}


Pad 6, Rounded Gravel Asphalt Chip Seal A-weighted Sound Level, $\mathrm{dB}$ re $20 \mu \mathrm{Pa}$

\begin{tabular}{|l|cccccc|}
\hline $\begin{array}{l}\text { Microphone } \\
\text { Location, ft }(\mathrm{m})\end{array}$ & \multicolumn{6}{|c|}{ Nominal Speed, mph (km/hr) } \\
\hline $20(64.4)$ & $40(64.4)$ & $50(80.5)$ & $50(80.5)$ & $60(96.5)$ & $60(96.5)$ \\
\hline $50(15.6)$ & 81.8 & 81.4 & 86.4 & 86.4 & 89.0 & 88.2 \\
\hline
\end{tabular}

Pad 7, Lightweight Aggregate Asphalt Chip Seal A-weighted Sound Level, dB re $20 \mu \mathrm{Pa}$

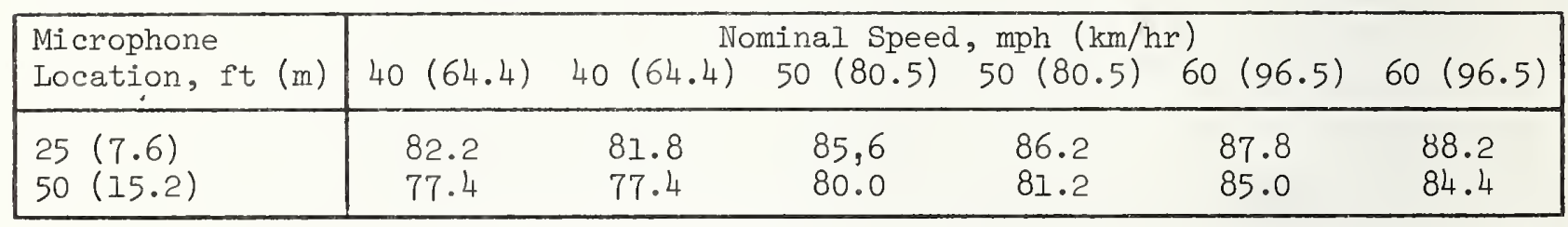

Pad 8, Lightweight Aggregate Hot-Mix Asphaltic Concrete A-weighted Sound Level, dB re $20 \mu \mathrm{Pa}$

\begin{tabular}{|l|cccccc|}
\hline Microphone & \multicolumn{6}{|c|}{ Nominal Speed, mph $(\mathrm{km} / \mathrm{hr})$} \\
Location, ft $(\mathrm{m})$ & $40(64.4)$ & $40(64.4)$ & $50(80.5)$ & $50(80.5)$ & $60(96.5)$ & $60(96.5)$ \\
\hline $25(7.6)$ & 88.0 & 87.8 & 94.6 & 92.6 & 96.6 & 95.4 \\
$50(15.2)$ & 81.6 & 82.8 & 89.0 & 88.6 & 90.6 & 91.0 \\
\hline
\end{tabular}




\section{TEST PAD 1}

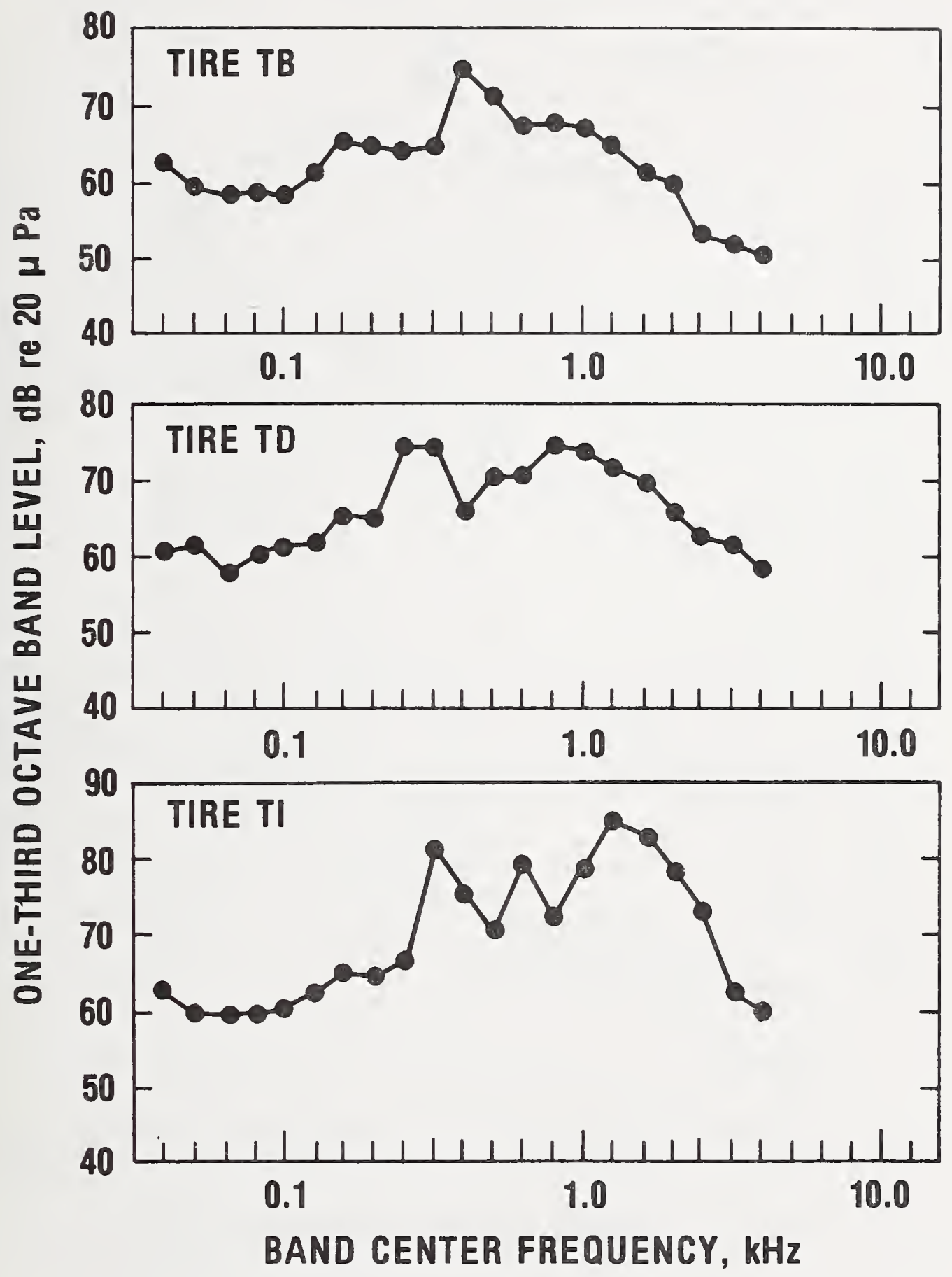

Figure A-4. One-third octave band sound pressure levels versus frequency as measured at the 50 foot $(15.2 \mathrm{~m})$ microphone at the time corresponding to the occurrence of the maximum A-weighted sound level. These plots correspond to a vehicle coastby of $50 \mathrm{mph}(80.5 \mathrm{~km} / \mathrm{hr})$ on test pad 1 . New rib tires were mounted on the steering axle and the test tires on the drive axle. 


\section{TEST PAD 2}

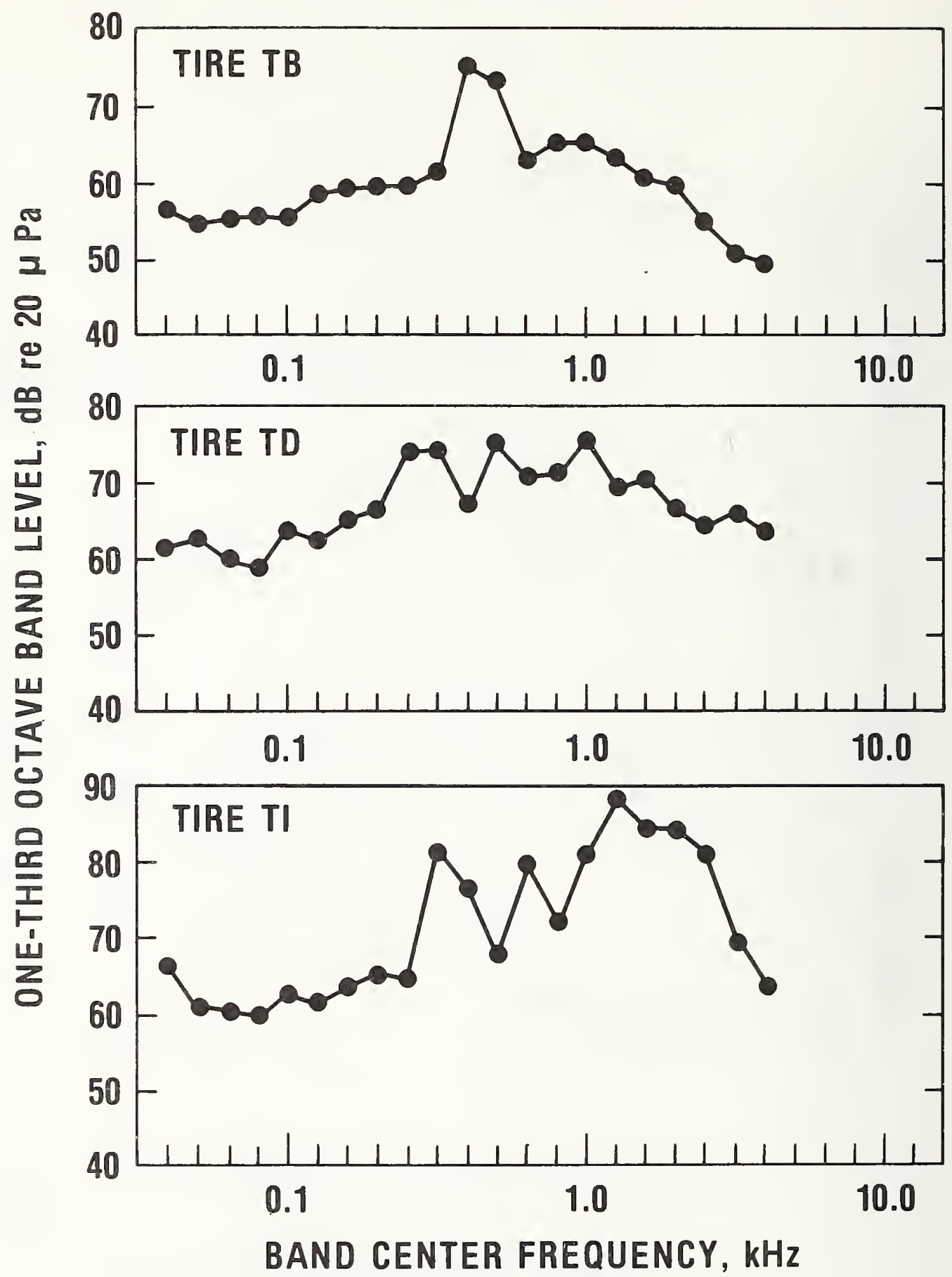

Figure A-5. One-third octave band sound pressure levels versus frequency as measured at the 50 foot $(15.2 \mathrm{~m})$ microphone at the time corresponding to the occurrence of the maximum A-weighted sound level. These plots correspond to a vehicle-coastby of $50 \mathrm{mph}(80.5 \mathrm{~km} / \mathrm{hr})$ on test pad 2. New rib tires were mounted on the steering axle and the test tires on the drive axle. 


\section{TEST PAD 3}

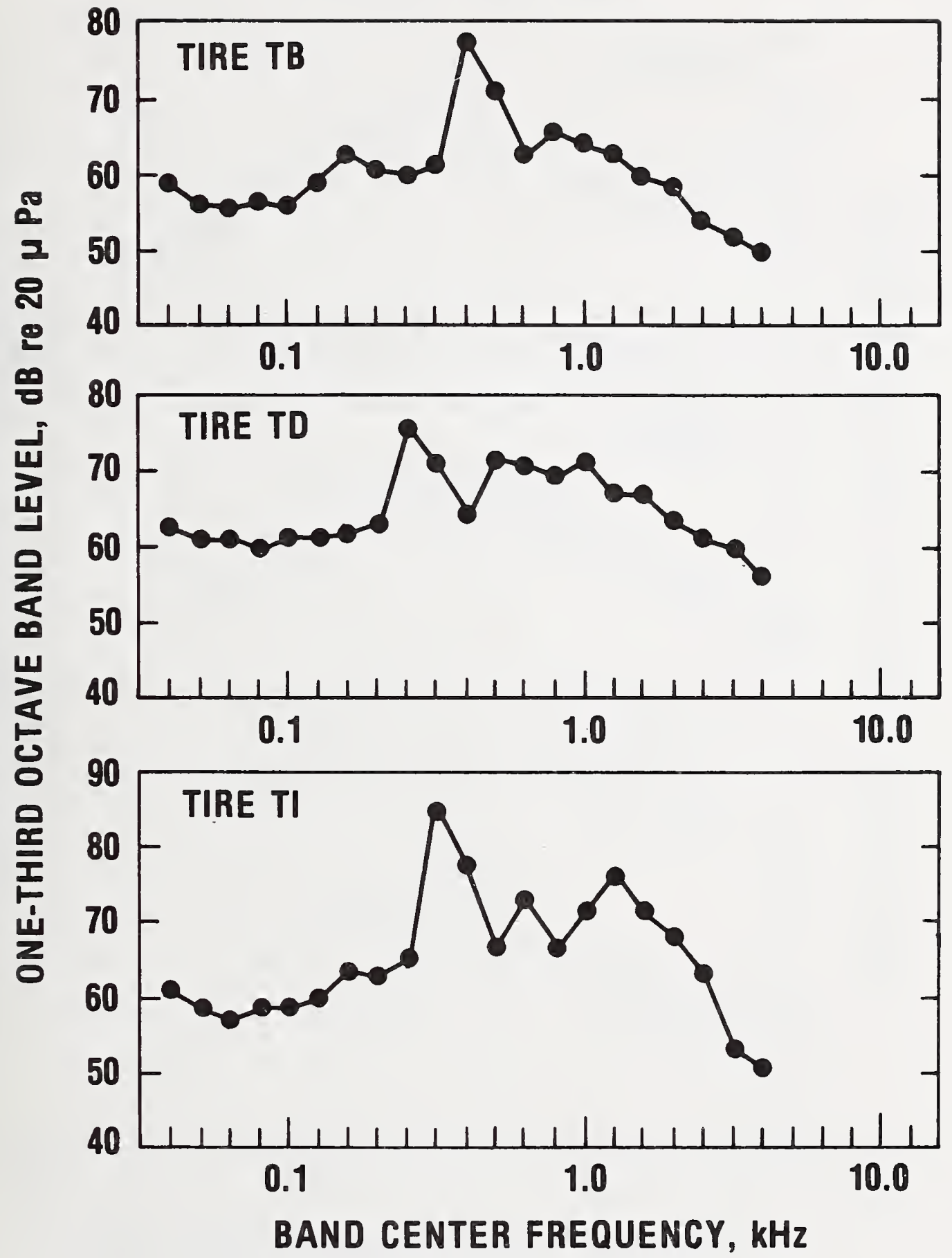

Figure A-6. One-third octave band sound pressure levels versus frequency as measured at the 50 foot $(15.2 \mathrm{~m})$ microphone at the time corresponding to the occurrence of the maximum A-weighted sound level. These plots correspond to a-vehicle coastby of $50 \mathrm{mph}(80.5 \mathrm{~km} / \mathrm{hr})$ on test pad 3. New rib tires were mounted on the steering axle and the test tires on the drive axle. 


\section{TEST PAD 4}

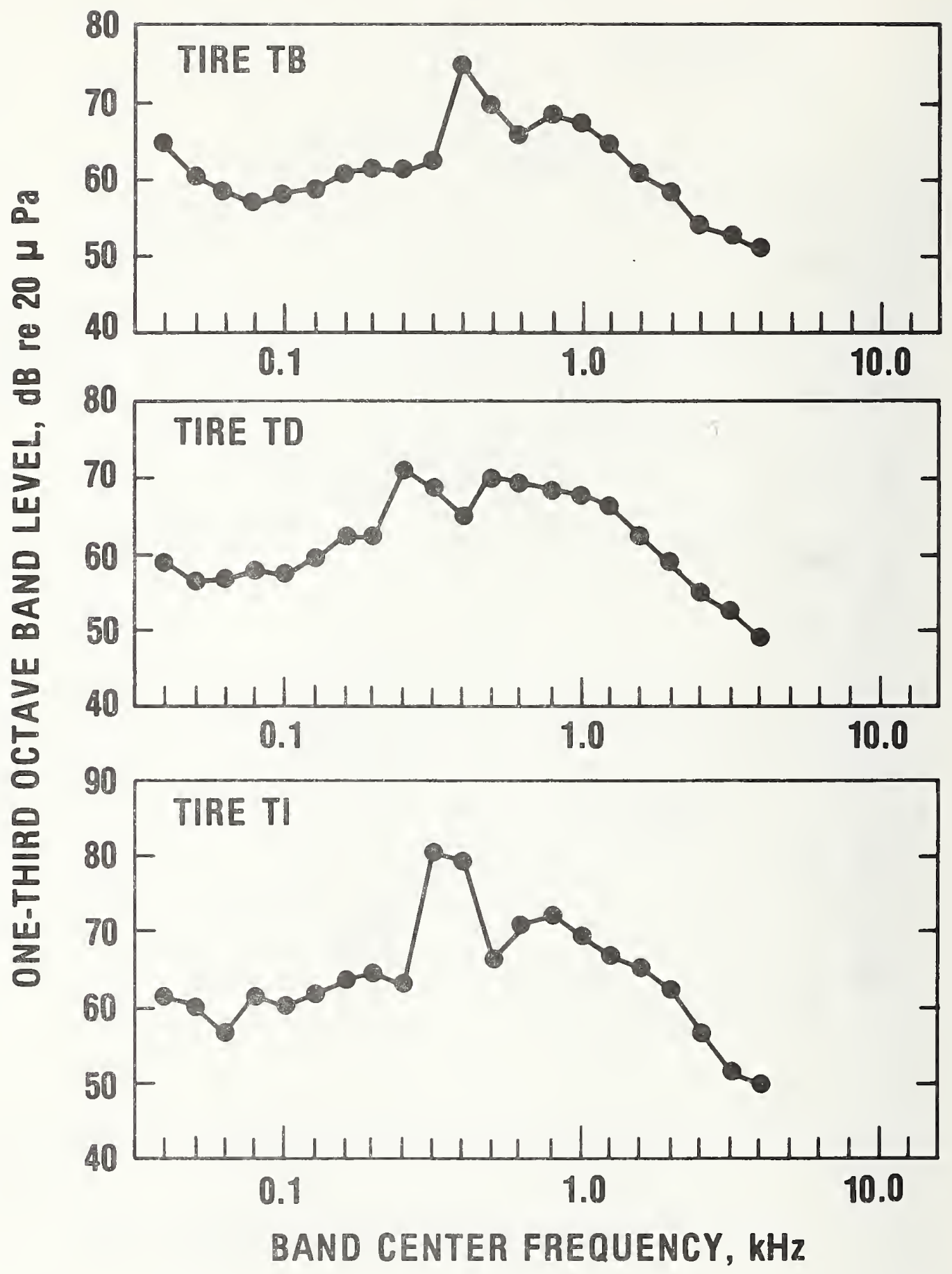

Figure A-7. One-third octave band sound pressure levels versus frequency as measured at the 50 foot $(15.2 \mathrm{~m})$ microphone at the time corresponding to the occurrence of the maximum A-weighted sound level. These plots correspond to a vehicle coastby of $50 \mathrm{mph}(80.5 \mathrm{~km} / \mathrm{hr})$ on test pad 4. New rib tires were mounted on the steering axle and the test tires on the drive axle. 


\section{TEST PAD 5}

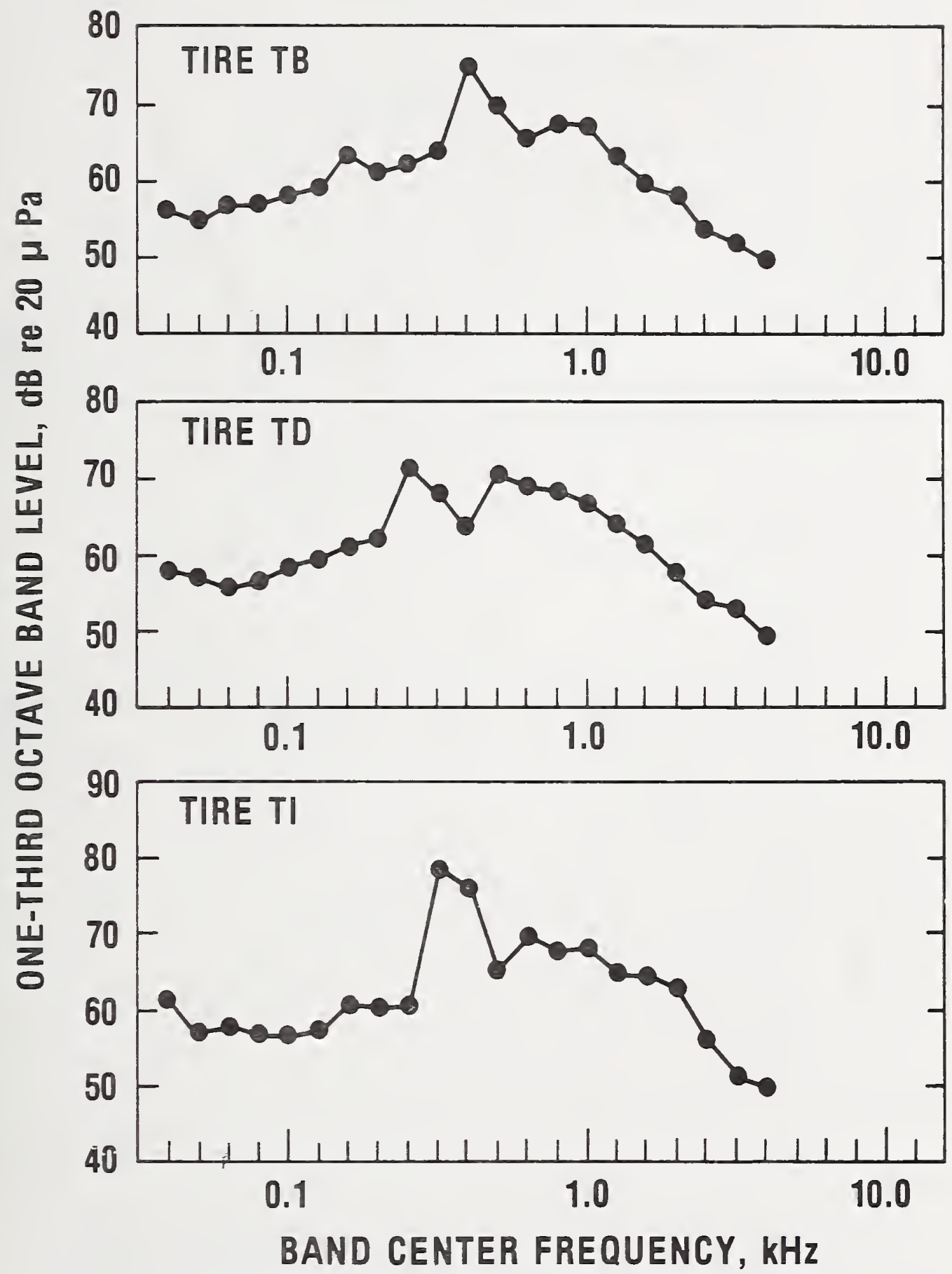

Figure A-8. One-third octave band sound pressure levels versus frequency as measured at the 50 foot $(15.2 \mathrm{~m})$ microphone at the time corresponding to the occurrence of the maximum A-weighted sound level. These plots correspond to a vehicle coastby of $50 \mathrm{mph}(80.5 \mathrm{~km} / \mathrm{hr})$ on test pad 5. New rib tires were mounted on the steering axle and the test tires on the drive axle. 


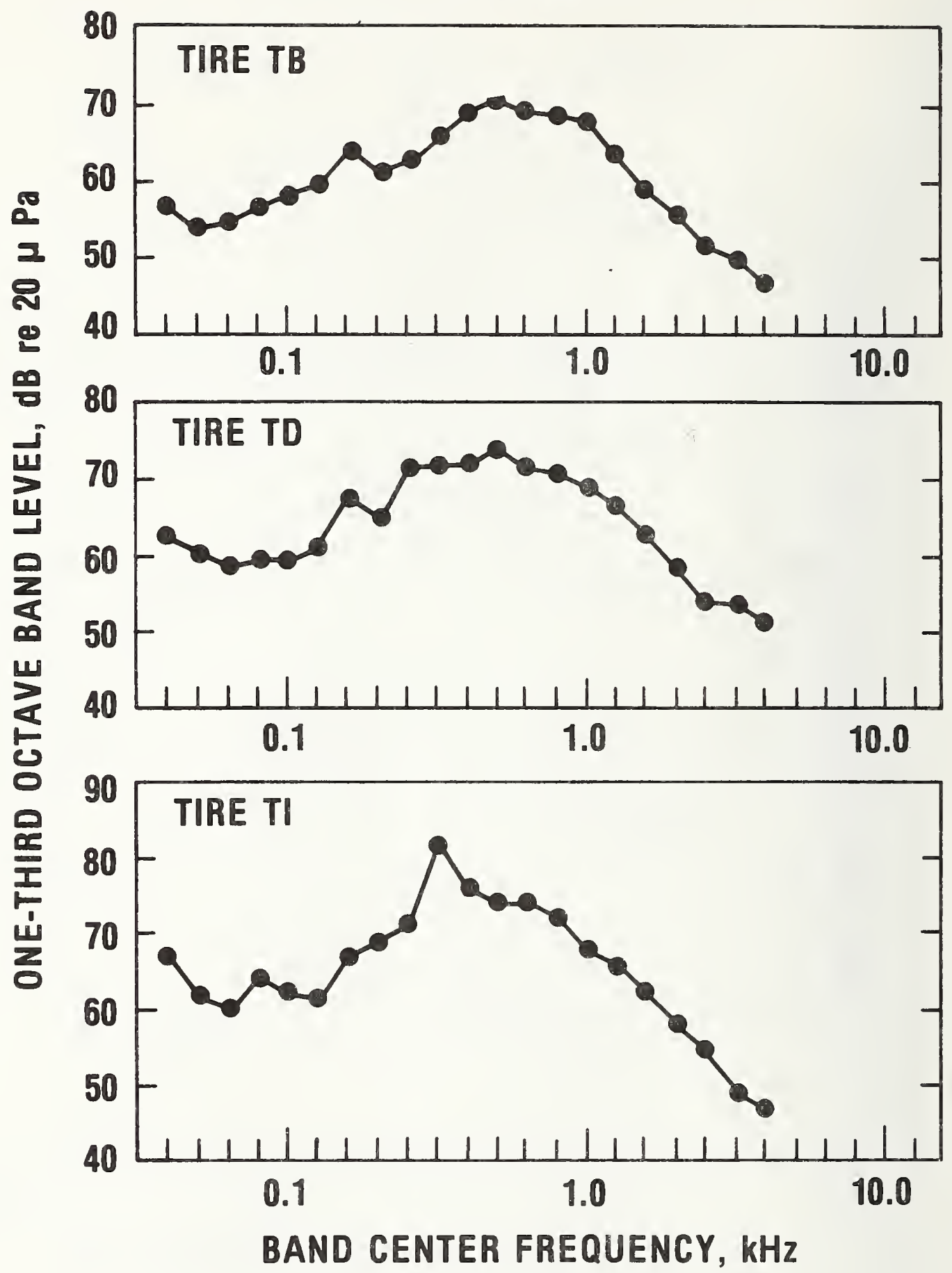

Figure A-9. One-third octave band sound pressure levels versus frequency as measured at the 50 foot $(15.2 \mathrm{~m})$ microphone at the time corresponding to the occurrence of the maximum A-weighted sound level. These plots correspond to a vehicle coastby of $50 \mathrm{mph}(80.5 \mathrm{~km} / \mathrm{hr})$ on test pad 6 . New rib tires were mounted on the steering axle and the test tires on the drive axle. 


\section{TEST PAD 7}

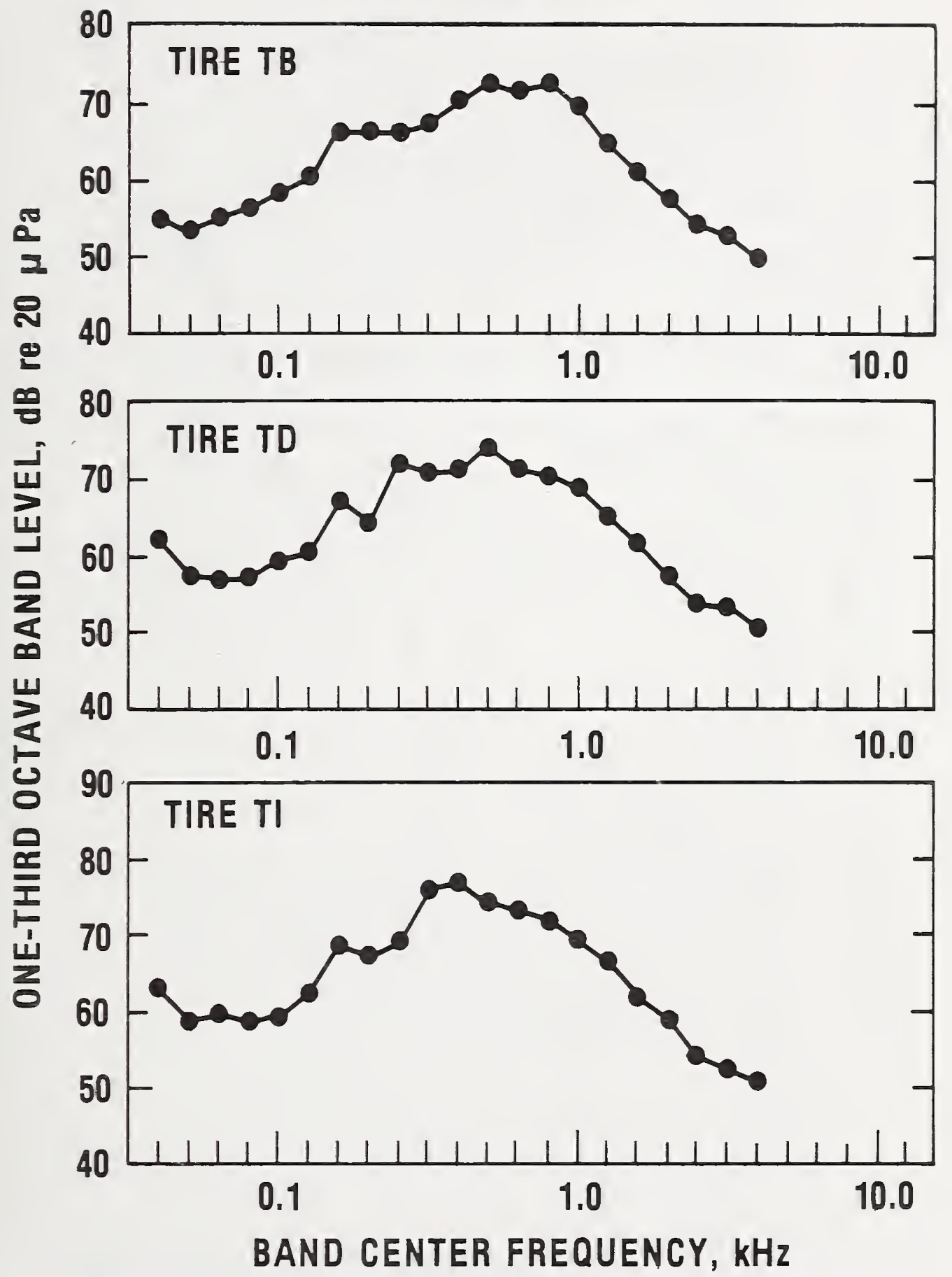

Figure A-10. One-third octave band sound pressure levels versus frequency as measured at the 50 foot ( $15.2 \mathrm{~m}$ ) microphone at the time corresponding to the occurrence of the maximum A-weighted sound level. These plots correspond to a vehicle coastby of $50 \mathrm{mph}(80.5 \mathrm{~km} / \mathrm{hr})$ on test pad 7 . New rib tires were mounted on the steering axle and the test tires on the drive axle. 
TEST PAD 8

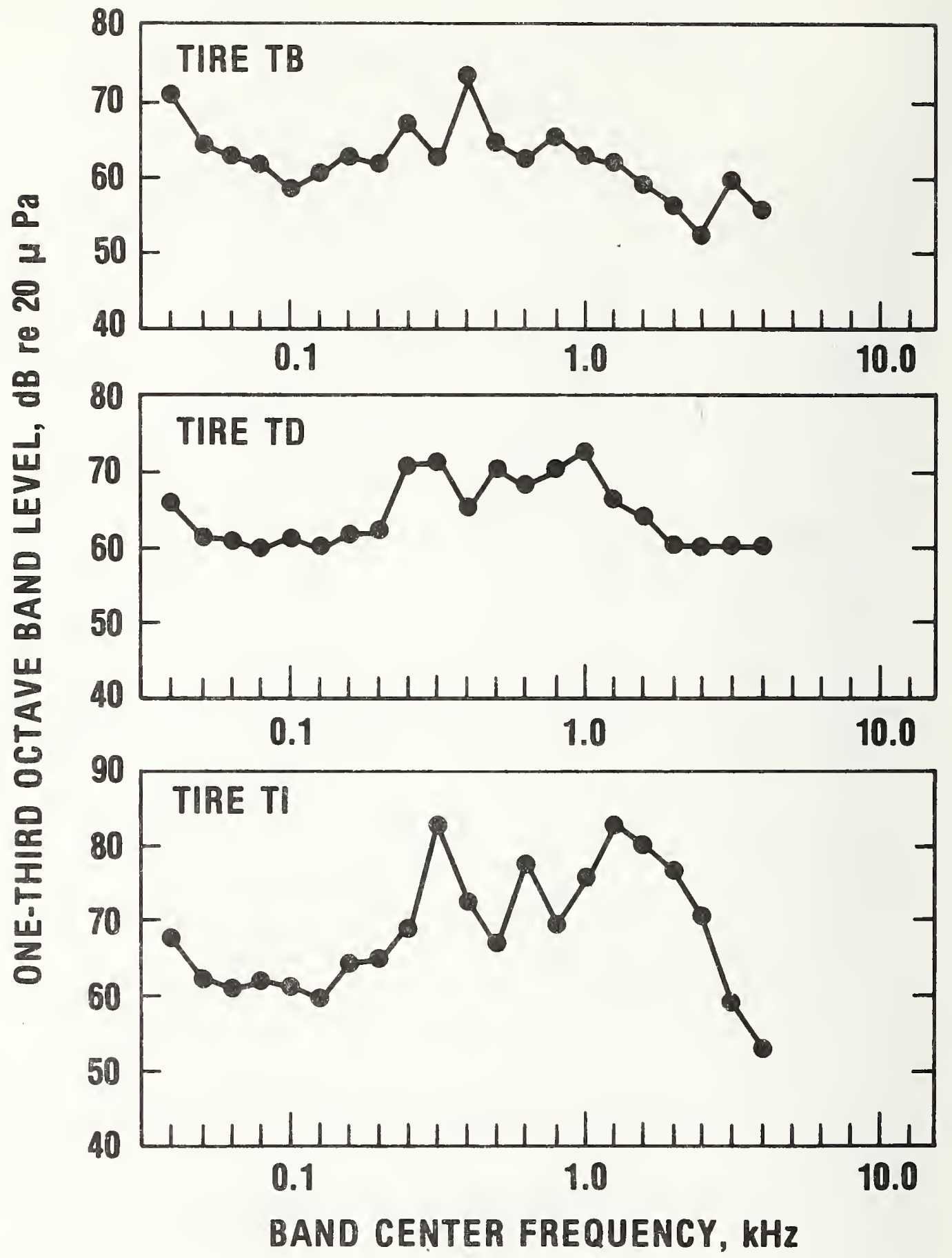

Figure A-11. One-third octave band sound pressure levels versus frequency as measured at the 50 foot $(15.2 \mathrm{~m})$ microphone at the time corresponding to the occurrence of the maximum A-weighted sound level. These plots correspond to a vehicle coastby of $50_{-} \mathrm{mph}(80.5 \mathrm{~km} / \mathrm{hr})$ on test pad 8 . New rib tires were mounted on the steering axle and the test tires on the drive axle. 
Table A-1. Decrease in maximum A-weighted sound level (in decibels re $20 \mu \mathrm{Pa}$ ) from 25 to 50 feet $(7.6$ to $15.2 \mathrm{~m}$ ) observed for test tire TB running on the various test pads. The speeds 40,50 and $60 \mathrm{mph}$ correspond to 64.4 , 80.5 , and $96.5 \mathrm{~km} / \mathrm{hr}$, respectively.

\begin{tabular}{|c|c|c|c|c|}
\hline \multirow{2}{*}{ Pad } & \multicolumn{3}{|c|}{$\mathrm{I}_{\mathrm{A}}(25)-\mathrm{I}_{\mathrm{A}}(50)$} & \multirow{2}{*}{ Average } \\
\cline { 2 - 4 } Number & $40 \mathrm{mph}$ & $50 \mathrm{mph}$ & $60 \mathrm{mph}$ & \\
\hline I & 4.5 & 5.0 & 5.0 & 4.8 \\
2 & 5.8 & 4.6 & 4.0 & 4.8 \\
3 & 5.5 & 4.1 & 4.6 & 4.7 \\
4 & 5.6 & 4.9 & 4.8 & 5.1 \\
5 & 5.4 & 4.1 & 4.3 & 4.6 \\
6 & 2.7 & 3.3 & 3.2 & 3.1 \\
7 & 4.2 & 4.5 & 3.9 & 4.2 \\
8 & 6.7 & 4.2 & 4.6 & 5.2 \\
\hline Average & 5.1 & 4.3 & 4.3 & 4.6 \\
\hline
\end{tabular}

Table A-2. Decrease in maximum A-weighted sound level (in decibels re $20 \mu \mathrm{Pa}$ ) from 25 to 50 feet $(7.6$ to $15.2 \mathrm{~m}$ ) observed for test tire TD running on the various test pads. The speeds 40,50 and $60 \mathrm{mph}$ correspond to 64.4, 80.5 , and $96.5 \mathrm{~km} / \mathrm{hr}$, respectively.

\begin{tabular}{|c|c|c|c|c|}
\hline \multirow{2}{*}{$\begin{array}{c}\text { Pad } \\
\text { Number }\end{array}$} & \multicolumn{3}{|c|}{$\mathrm{I}_{\mathrm{A}}(25)-\mathrm{I}_{\mathrm{A}}(50)$} & \multirow{2}{*}{ Average } \\
\cline { 2 - 4 } & $40 \mathrm{mph}$ & $50 \mathrm{mph}$ & $60 \mathrm{mph}$ & \\
\hline 1 & 4.0 & 3.4 & 3.2 & 3.5 \\
2 & 3.7 & 2.8 & 3.5 & 3.3 \\
3 & 4.5 & 4.6 & 5.2 & 4.8 \\
4 & 6.0 & 5.7 & 4.6 & 5.4 \\
5 & 4.1 & 5.6 & 5.3 & 5.0 \\
6 & 5.3 & 5.4 & 5.7 & 5.5 \\
7 & 5.3 & 5.3 & 5.1 & 5.2 \\
8 & 5.3 & 5.5 & 4.7 & 5.2 \\
\hline \multirow{2}{*}{ Average } & 4.8 & 4.8 & 4.7 & 4.7 \\
\hline
\end{tabular}


Table A-3. Decrease in maximum A-weighted sound level (in decibels re $20 \mu \mathrm{Pa}$ ) from 25 to 50 feet $(7.6$ to $15.2 \mathrm{~m})$ observed for test tire TI running on the various test pads. The speeds 40,50 and $60 \mathrm{mph}$ correspond to 64.4, 80.5 , and $96.5 \mathrm{~km} / \mathrm{hr}$, respectively.

\begin{tabular}{|c|c|c|c|c|}
\hline \multirow{2}{*}{ Pad } & \multicolumn{3}{|c|}{$\mathrm{L}_{\mathrm{A}}(25)-\mathrm{L}_{\mathrm{A}}(50)$} & \multirow{2}{*}{ Average } \\
\cline { 2 - 4 } Number & $40 \mathrm{mph}$ & $50 \mathrm{mph}$ & $60 \mathrm{mph}$ & \\
\hline 1 & 6.2 & 5.3 & 4.8 & 5.4 \\
2 & 3.9 & 4.7 & 5.2 & 4.6 \\
3 & 6.2 & 5.7 & 6.2 & 6.0 \\
4 & 6.1 & 6.1 & 4.4 & 5.5 \\
5 & 6.3 & 7.0 & 6.4 & 6.6 \\
6 & 4.8 & 5.7 & 4.6 & 5.0 \\
7 & 4.1 & 5.3 & 3.3 & 4.2 \\
8 & 5.7 & 4.8 & 5.2 & 5.2 \\
\hline \multirow{2}{*}{ Average } & 5.4 & 5.6 & 5.0 & 5.3 \\
\hline
\end{tabular}




\section{Macrotexture Profile Measurement Results}

The macrotexture profiles measured with the macrotexture profile tracer are reported for the eight test pads located at the Texas Transportation Institute, College Station, Texas. These measurements were made by the personnel of the Pennsylvania Transportation Institute, University Park, Pa., under contract to the National Bureau of Standards (program sponsored by the U. S. Department of Transportation). The data are presented in tabular form as an arithmetic mean and standard deviation of the profile (displacement) band level in $\mathrm{dB}$ re $1 \mathrm{~m}$ ( $\mathrm{rms}$ ) for the one-third octave bands corresponding to the space frequency from 25 to 10,000 cycles per meter. These data are based on five profile traverses in a direction parallel to the traffic flow. The data are also presented in graphical form as plots of one-third octave band macrotexture profile levels in $\mathrm{dB}$ re $1 \mathrm{~m}$ ( $r \mathrm{~ms}$ ). versus space frequency for the eight test pads. 
Table B-1. Mean and standard deviation of the profile band levels for test pad 1, as measured with the macrotexture profile tracer. Data are based on five profile traverses in a direction parallel to the traffic flow.

Mean and standard deviation of the profile band levels in $\mathrm{dB}$ re $1 \mathrm{~m}$ ( $\mathrm{rms}$ )* for the one-third octave bands corresponding to the space frequency

in cycles/meter.

\begin{tabular}{|l|ccccccccc|}
\hline $\begin{array}{l}\text { Band Center } \\
\text { Frequency }\end{array}$ & 25 & 31.5 & 40 & 50 & 63 & 80 & 100 & 125 & 160 \\
\hline $\begin{array}{l}\text { Mean } \\
\begin{array}{l}\text { Standard } \\
\text { Deviation }\end{array}\end{array}$ & 22.8 & 83.9 & 84.4 & 84.7 & 83.1 & 82.3 & 83.1 & 87.1 & 87.0 \\
\hline \hline $\begin{array}{l}\text { Band Center } \\
\text { Frequency }\end{array}$ & 200 & 250 & 315 & 400 & 500 & 630 & 800 & 1000 & 1250 \\
\hline $\begin{array}{l}\text { Mean } \\
\text { Standaird } \\
\text { Deviation }\end{array}$ & 1.7 & 1.3 & 1.0 & 0.7 & 0.7 & 1.1 & 1.0 & 1.0 & 0.7 \\
\hline \hline $\begin{array}{l}\text { Band Center } \\
\text { Frequency }\end{array}$ & 1600 & 2000 & 2500 & 3150 & 4000 & 5000 & 6300 & 8000 & 10000 \\
\hline $\begin{array}{l}\text { Mean } \\
\text { Standard } \\
\text { Deviation }\end{array}$ & 94.2 & 97.6 & 97.7 & 99.1 & 98.9 & 102.1 & 100.7 & 102.2 & 100.9 \\
\hline
\end{tabular}

*All $d B$ values are negative. 


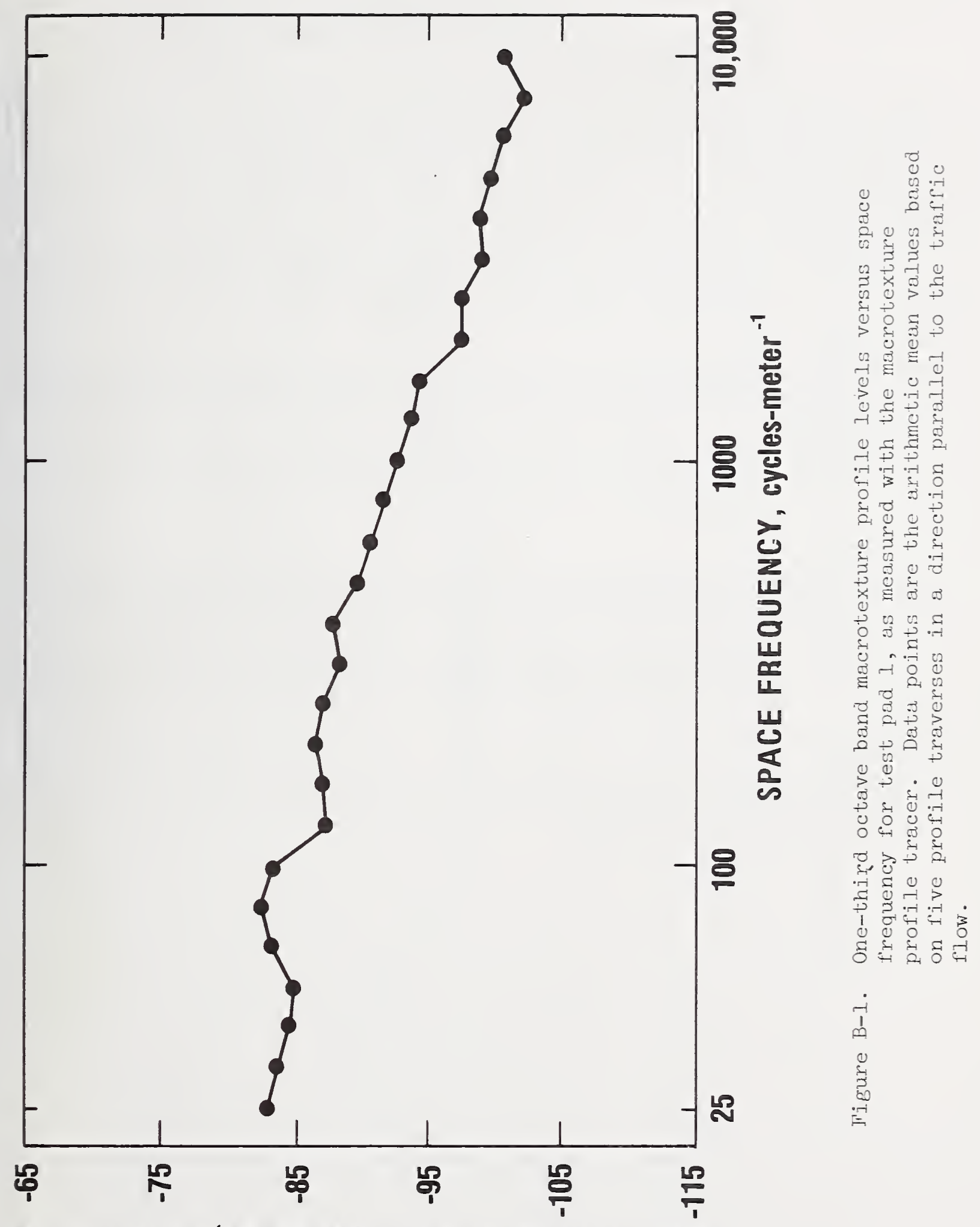

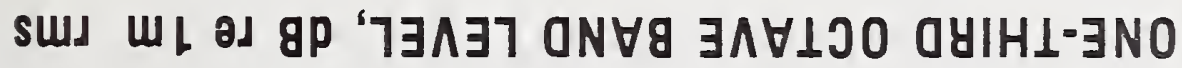


Table B-2. Mean and standard deviation of the profile band levels for test pad 2, as measured with the macrotexture profile tracer. Data are based on five profile traverses in a direction parallel to the traffic flow.

Mean and standard deviation of the profile band levels in dB re $1 \mathrm{~m}$ ( $\mathrm{rms}$ )* for the one-third octave bands corresponding to the space frequency in cycles/meter.

\begin{tabular}{|l|ccccccccc|}
\hline $\begin{array}{l}\text { Band Center } \\
\text { Frequency }\end{array}$ & 25 & 31.5 & 40 & 50 & 63 & 80 & 100 & 125 & 160 \\
\hline Mean & 92.5 & 90.1 & 89.7 & 91.5 & 94.0 & 96.3 & 98.1 & 98.6 & 98.6 \\
$\begin{array}{l}\text { Standard } \\
\text { Deviation }\end{array}$ & 1.7 & 3.9 & 2.4 & 2.1 & 4.0 & 4.4 & 6.0 & 6.5 & 5.8 \\
\hline $\begin{array}{l}\text { Band Center } \\
\text { Frequency }\end{array}$ & 200 & 250 & 315 & 400 & 500 & 630 & 800 & 1000 & 1250 \\
\hline $\begin{array}{l}\text { Mean } \\
\text { Standard } \\
\text { Deviation }\end{array}$ & 98.6 & 99.1 & 99.2 & 98.4 & 98.2 & 98.3 & 97.6 & 97.6 & 95.7 \\
\hline \hline $\begin{array}{l}\text { Band Center } \\
\text { Frequency }\end{array}$ & 1600 & 2000 & 2500 & 3150 & 4000 & 5000 & 6300 & 8000 & 10000 \\
\hline $\begin{array}{l}\text { Mean } \\
\text { Standard } \\
\text { Deviation }\end{array}$ & 95.2 & 96.9 & 95.6 & 95.6 & 95.3 & 94.8 & 97.6 & 96.6 & 102.5 \\
\hline
\end{tabular}

*All $d B$ values are negative. 


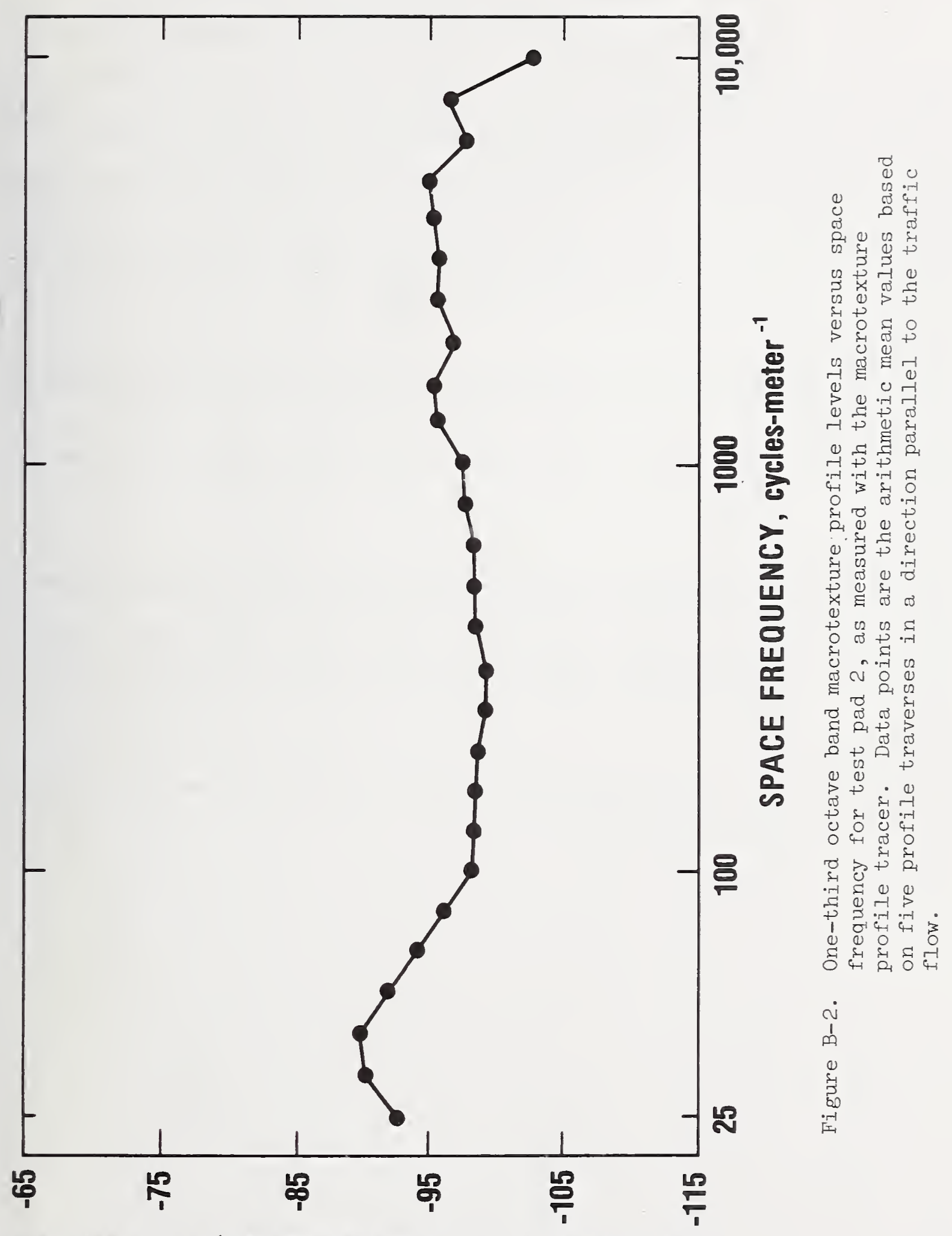

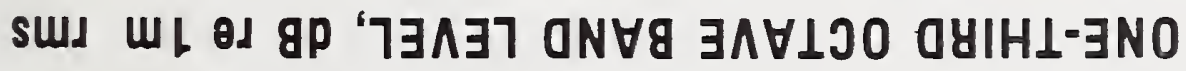


Table B-3. Mean and standard deviation of the profile band levels for test pad 3, as measured with the macrotexture profile tracer. Data are based on five profile traverses in a direction parallel to the traffic flow.

Mean and standard deviation of the profile band levels in dB re $1 \mathrm{~m}$ ( $\mathrm{rms}$ )* for the one-third octave bands corresponding to the space frequency in cycles/meter.

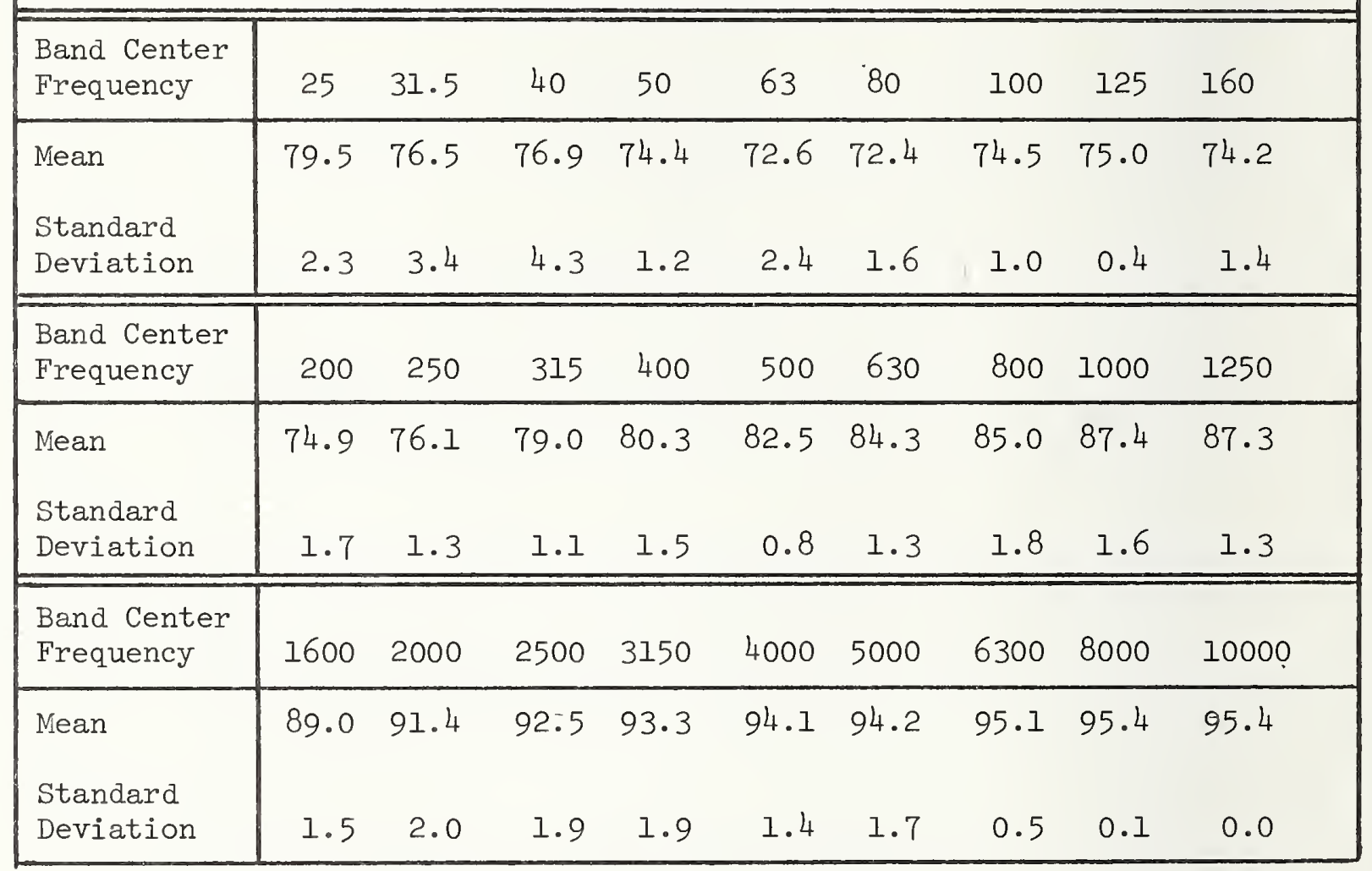

*All dB values are negative. 


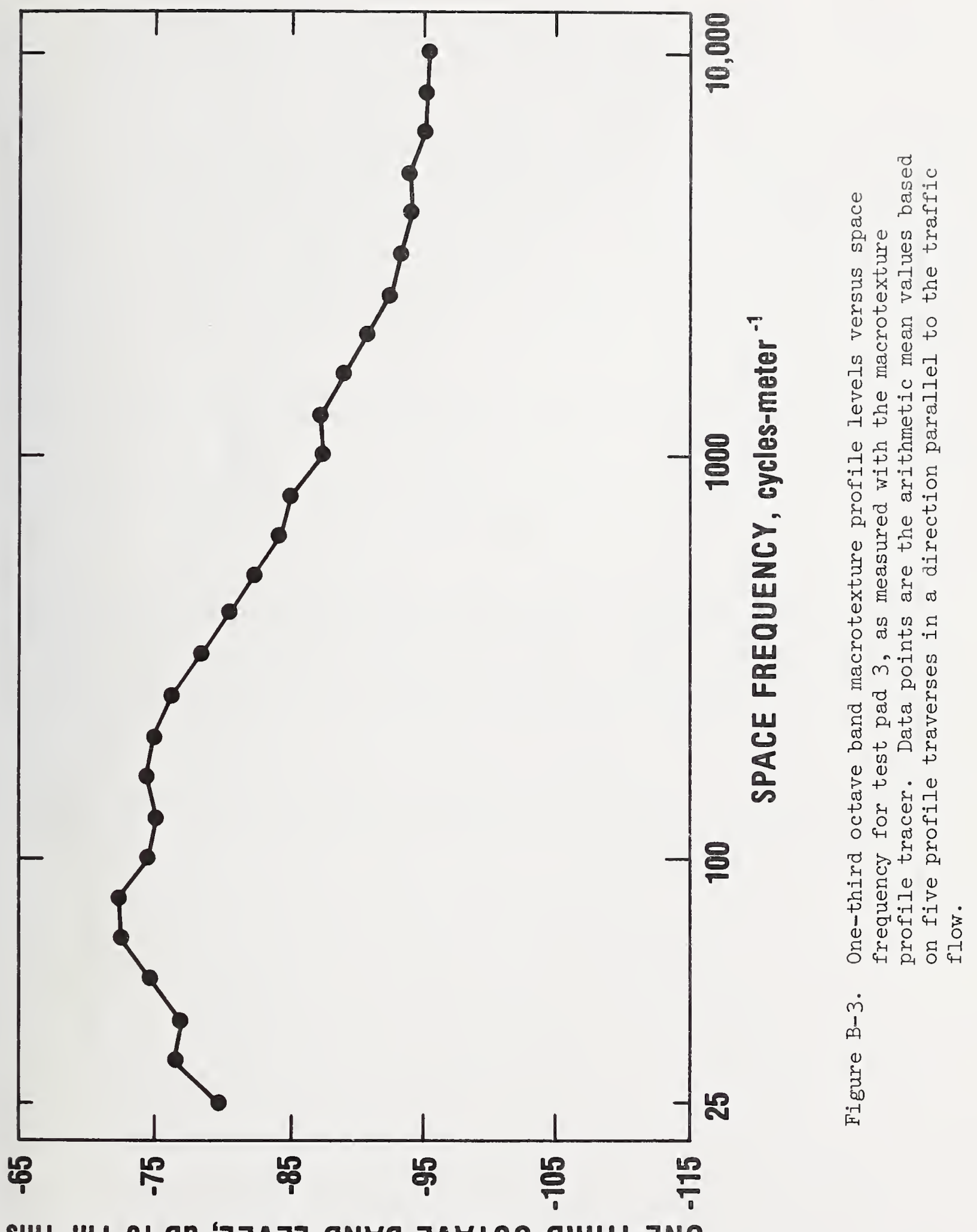

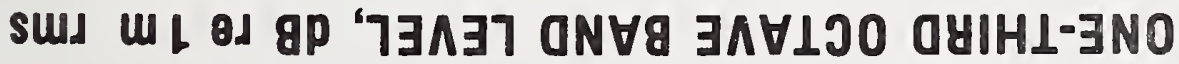


Table B-4. Mean and standard deviation of the profile band levels for test pad 4, as measured with the macrotexture profile tracer. Data are based on five profile traverses in a direction parallel to the traffic flow.

Mean and standard deviation of the profile band levels in dB re $1 \mathrm{~m}$ ( $\mathrm{rms}$ )* for the one-third octave bands corresponding to the space frequency in cycles/meter.

\begin{tabular}{|l|ccccccccc|}
\hline $\begin{array}{l}\text { Band Center } \\
\text { Frequency }\end{array}$ & 25 & 31.5 & 40 & 50 & 63 & 80 & 100 & 125 & 160 \\
\hline Mean & 72.5 & 71.1 & 70.4 & 73.0 & 70.7 & 70.3 & 71.3 & 70.8 & 72.3 \\
$\begin{array}{l}\text { Standard } \\
\text { Deviation }\end{array}$ & 1.5 & 2.2 & 1.0 & 2.2 & 2.1 & 1.0 & 2.1 & 1.3 & 2.1 \\
\hline $\begin{array}{l}\text { Band Center } \\
\text { Frequency }\end{array}$ & 200 & 250 & 315 & 400 & 500 & 630 & 800 & 1000 & 1250 \\
\hline $\begin{array}{l}\text { Mean } \\
\text { Standard } \\
\text { Deviation }\end{array}$ & 72.7 & 74.5 & 75.3 & 76.1 & 77.5 & 78.4 & 79.2 & 81.7 & 82.5 \\
\hline $\begin{array}{l}\text { Band Center } \\
\text { Frequency }\end{array}$ & 1600 & 2000 & 2500 & 3150 & 4000 & 5000 & 6300 & 8000 & 10000 \\
\hline Mean & 83.2 & 85.3 & 86.9 & 88.3 & 89.5 & 89.4 & 91.6 & 90.5 & 91.9 \\
\hline $\begin{array}{l}\text { Standard } \\
\text { Deviation }\end{array}$ & 2.3 & 2.2 & 2.1 & 2.9 & 2.4 & 3.6 & 4.3 & 3.9 & 1.2 \\
\hline
\end{tabular}

*All aB values are negative. 


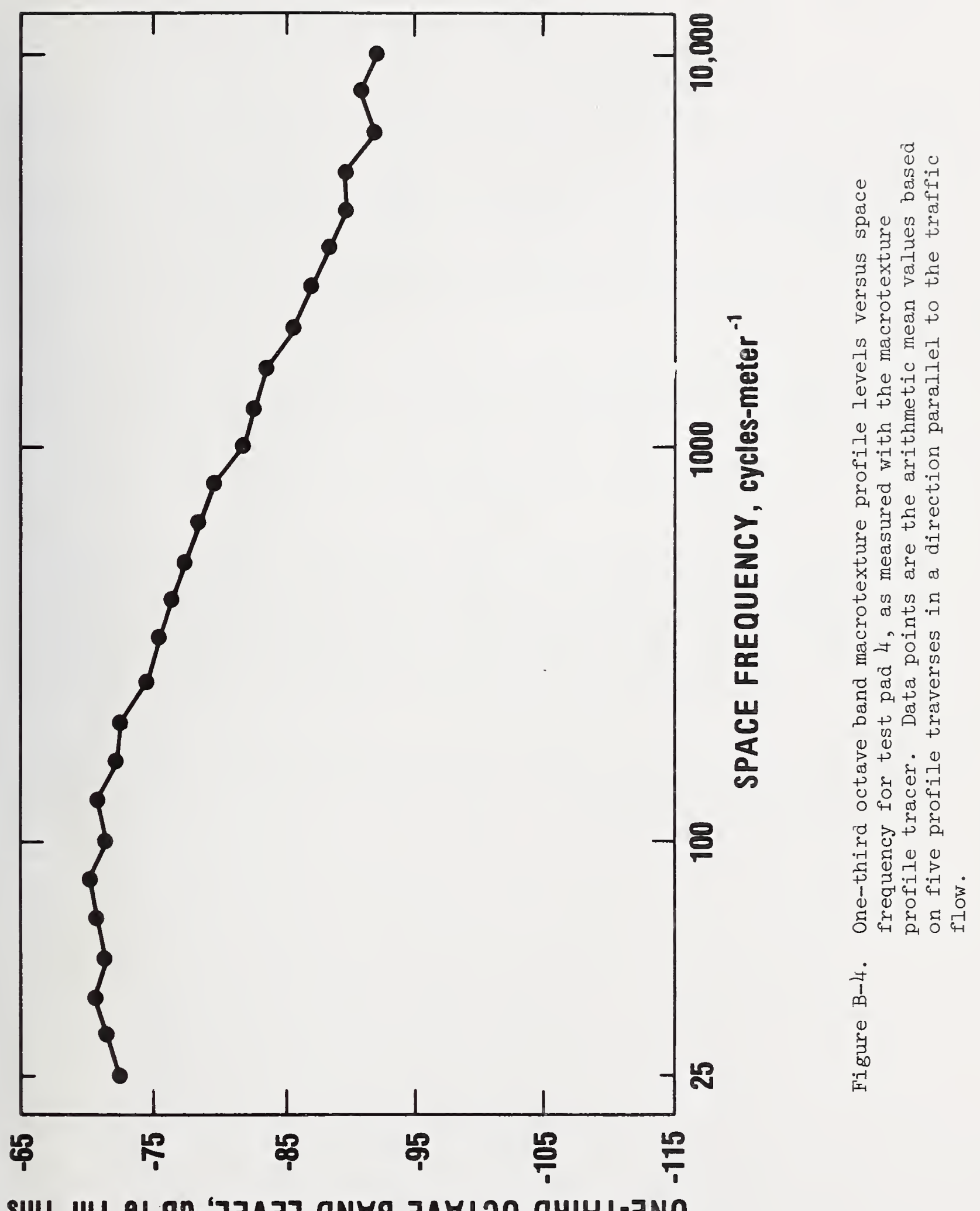

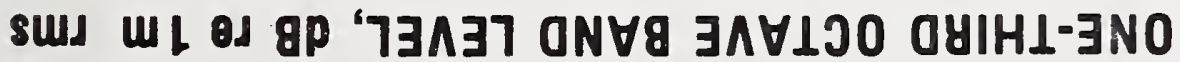


Table B-5. Mean and standard deviation of the profile band levels for test pad 5, as measured with the macrotexture profile tracer. Data are based on five profile traverses in a direction parallel to the traffic flow.

Mean and standard deviation of the profile band levels in $\mathrm{dB}$ re $1 \mathrm{~m}$ ( $\mathrm{rms}$ )* for the one-third octave bands corresponding to the space frequency in cycles/meter.

\begin{tabular}{|l|ccccccccc|}
\hline $\begin{array}{l}\text { Band Center } \\
\text { Frequency }\end{array}$ & 25 & 31.5 & 40 & 50 & 63 & 80 & 100 & 125 & 160 \\
\hline Mean & 75.7 & 77.2 & 75.6 & 72.6 & 73.4 & 72.6 & 73.1 & 74.4 & 75.1 \\
$\begin{array}{l}\text { Standard } \\
\text { Deviation }\end{array}$ & 2.9 & 6.4 & 2.0 & 1.7 & 2.8 & 0.9 & 1.8 & 1.5 & 1.6 \\
\hline \hline $\begin{array}{l}\text { Band Center } \\
\text { Frequency }\end{array}$ & 200 & 250 & 315 & 400 & 500 & 630 & 800 & 1000 & 1250 \\
\hline $\begin{array}{l}\text { Mean } \\
\text { Standard } \\
\text { Deviation }\end{array}$ & 76.6 & 77.6 & 79.3 & 79.7 & 81.2 & 82.3 & 83.2 & 85.9 & 86.0 \\
\hline $\begin{array}{l}\text { Band Center } \\
\text { Frequency }\end{array}$ & 1600 & 2000 & 2500 & 3150 & 4000 & 5000 & 6300 & 8000 & 10000 \\
\hline $\begin{array}{l}\text { Mean } \\
\text { Standard } \\
\text { Deviation }\end{array}$ & 87.3 & 89.8 & 91.6 & 93.5 & 94.0 & 94.9 & 95.3 & 95.4 & 94.5 \\
\hline
\end{tabular}

*All aB values are negative. 


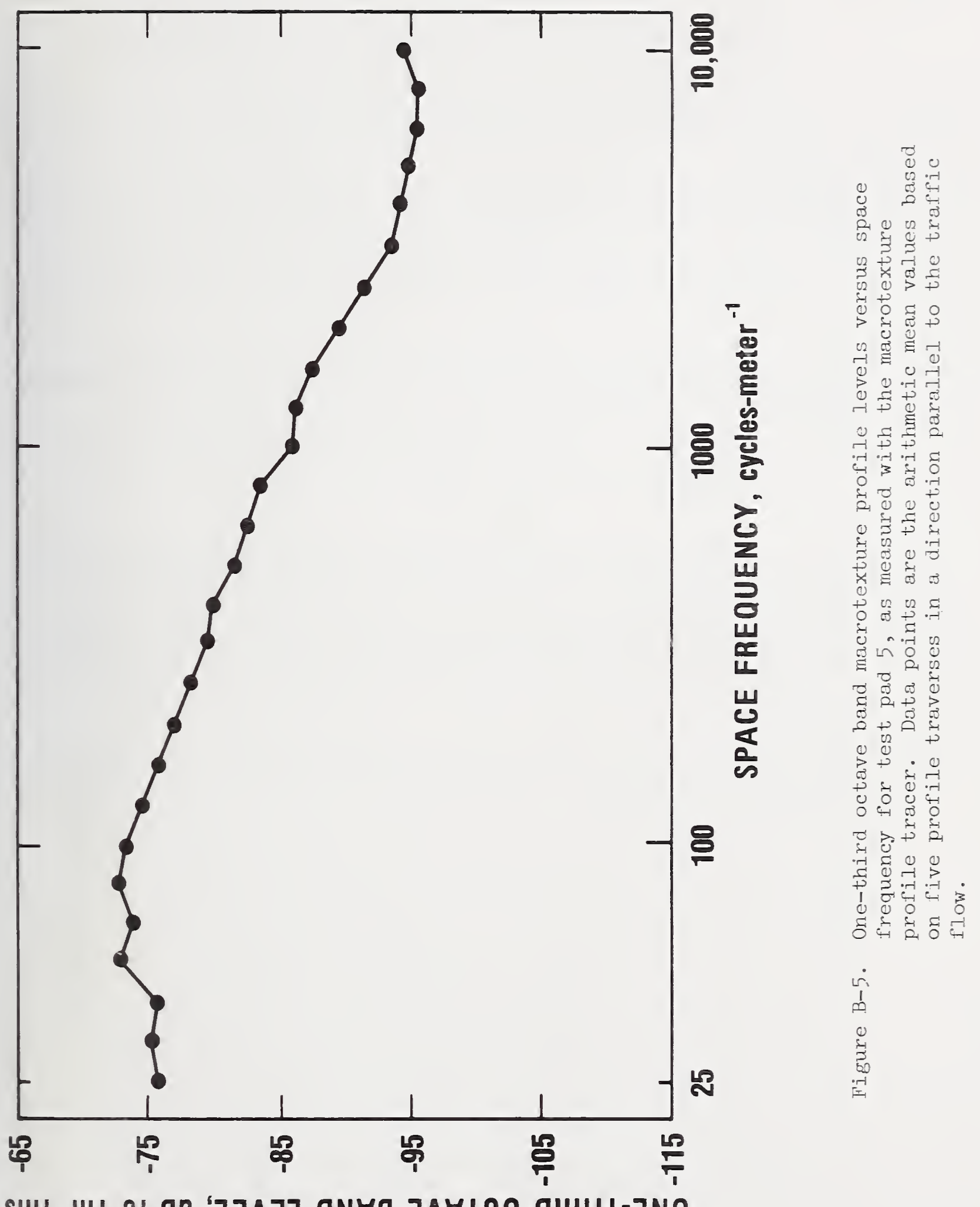

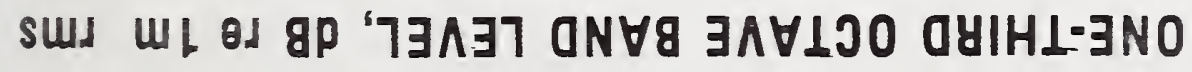


Table B-6. Mean and standard deviation of the profile band levels for test pad 6, as measured with the macrotexture profile tracer. Data are based on five profile traverses in a direction parallel to the traffic flow.

Mean and standard deviation of the profile band levels in $\mathrm{dB}$ re $1 \mathrm{~m}$ ( $\mathrm{rms}$ )* for the one-third octave bands corresponding to the space frequency in cycles/meter.

\begin{tabular}{|l|ccccccccc|}
\hline $\begin{array}{l}\text { Band Center } \\
\text { Frequency }\end{array}$ & 25 & 31.5 & 40 & 50 & 63 & 80 & 100 & 125 & 160 \\
\hline Mean & 72.6 & 74.6 & 70.3 & 71.6 & 69.6 & 70.3 & 70.5 & 70.2 & 73.0 \\
$\begin{array}{l}\text { Standard } \\
\text { Deviation }\end{array}$ & 2.2 & 3.2 & 1.6 & 2.2 & 2.4 & 2.8 & 2.7 & 1.2 & 1.3 \\
\hline $\begin{array}{l}\text { Band Center } \\
\text { Frequency }\end{array}$ & 200 & 250 & 315 & 400 & 500 & 630 & 800 & 1000 & 1250 \\
\hline $\begin{array}{l}\text { Mean } \\
\text { Standard } \\
\text { Deviation }\end{array}$ & 74.3 & 75.5 & 77.6 & 79.4 & 81.4 & 82.7 & 85.2 & 87.5 & 87.3 \\
\hline $\begin{array}{l}\text { Band Center } \\
\text { Frequency }\end{array}$ & 1600 & 2000 & 2500 & 3150 & 4000 & 5000 & 6300 & 8000 & 10000 \\
\hline Mean & 88.9 & 92.1 & 91.8 & 93.6 & 94.6 & 95.1 & 95.1 & 95.4 & 95.5 \\
\hline $\begin{array}{l}\text { Standard } \\
\text { Deviation }\end{array}$ & 0.7 & 0.9 & 1.5 & 1.2 & 1.2 & 0.7 & 0.7 & 0.1 & 0.1 \\
\hline
\end{tabular}

*All dB values are negative. 


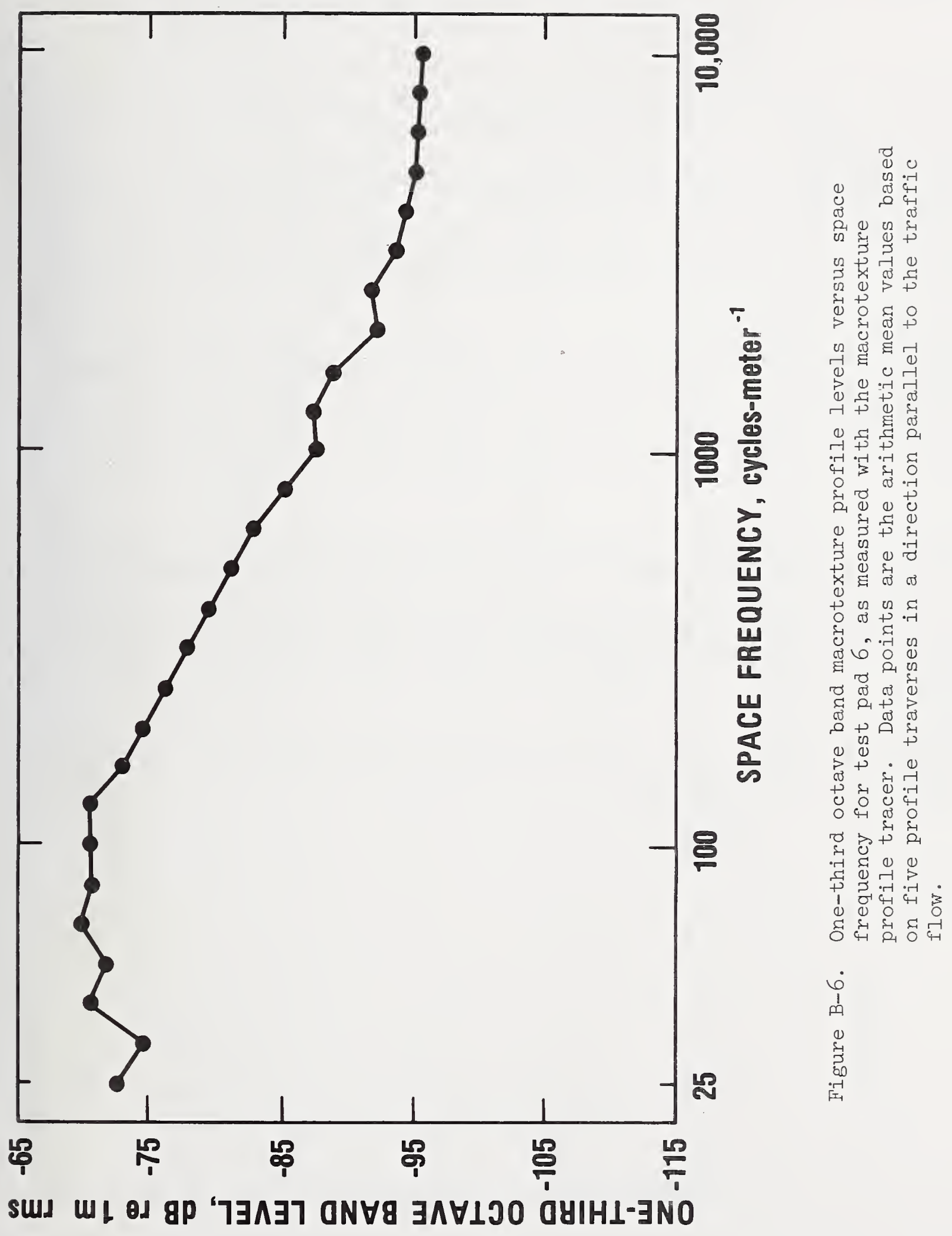


Table B-7. Mean and standard deviation of the profile band levels for test pad 7 , as measured with the macrotexture profile tracer. Data are based on five profile traverses in a direction parallel to the traffic flow.

Mean and standard deviation of the profile band levels in dB re $1 \mathrm{~m}$ ( $\mathrm{rms}$ )* for the one-third octave bands corresponding to the space frequency in cycles/meter.

\begin{tabular}{|l|ccccccccc|}
\hline $\begin{array}{l}\text { Band Center } \\
\text { Frequency }\end{array}$ & 25 & 31.5 & 40 & 50 & 63 & 80 & 100 & 125 & 160 \\
\hline Mean & 71.0 & 74.9 & 71.6 & 72.2 & 71.4 & 72.1 & 71.6 & 72.1 & 73.1 \\
$\begin{array}{l}\text { Standard } \\
\text { Deviation }\end{array}$ & 1.7 & 5.0 & 1.2 & 2.9 & 1.8 & 2.0 & 2.0 & 2.2 & 2.4 \\
\hline $\begin{array}{l}\text { Band Center } \\
\text { Frequency }\end{array}$ & 200 & 250 & 315 & 400 & 500 & 630 & 800 & 1000 & 1250 \\
\hline $\begin{array}{l}\text { Mean } \\
\text { Standard } \\
\text { Deviation }\end{array}$ & 15.1 & 76.0 & 77.4 & 78.7 & 80.5 & 81.4 & 82.5 & 84.4 & 84.9 \\
\hline $\begin{array}{l}\text { Band Center } \\
\text { Frequency }\end{array}$ & 1600 & 2000 & 2500 & 3150 & 4000 & 5000 & 6300 & 8000 & 10000 \\
\hline Mean & 86.0 & 87.9 & 89.9 & 90.7 & 91.4 & 91.6 & 94.2 & 95.0 & 95.0 \\
\hline $\begin{array}{l}\text { Standard } \\
\text { Deviation }\end{array}$ & 2.2 & 2.4 & 1.7 & 1.9 & 1.8 & 4.0 & 2.4 & 1.2 & 1.1 \\
\hline
\end{tabular}

*All dB values are negative. 


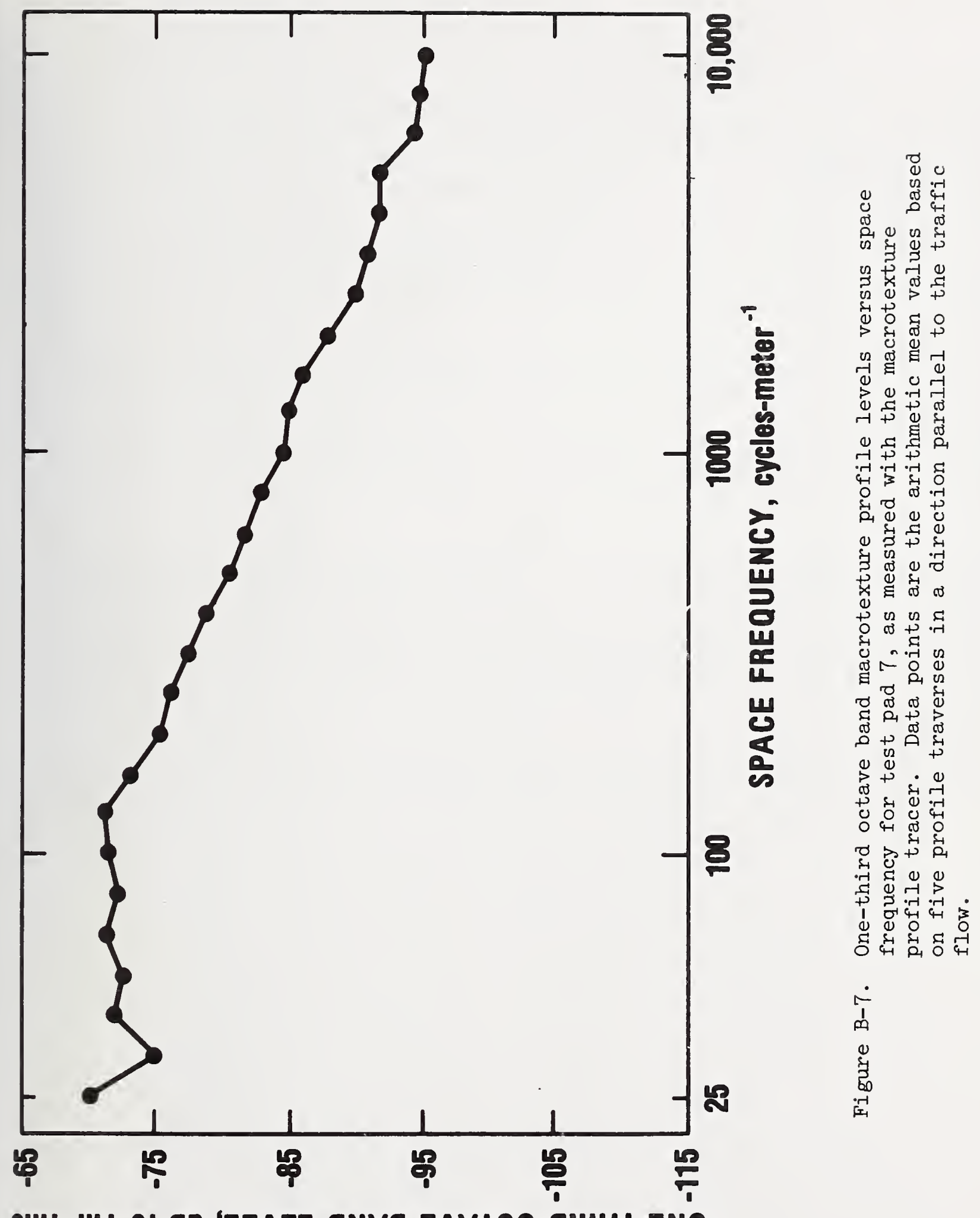

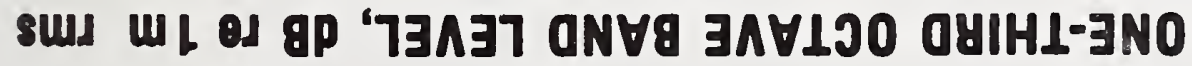


Table B-8. Mean and standard deviation of the profile band levels for test pad 8, as measured with the macrotexture profile tracer. Data are based on five profile traverses in a direction parallel to the traffic flow.

Mean and standard deviation of the profile band levels in $\mathrm{dB}$ re $I \mathrm{~m}$ ( $\mathrm{rms}$ )* for the one-third octave bands corresponding to the space frequency in cycles/meter.

\begin{tabular}{|l|ccccccccc|}
\hline $\begin{array}{l}\text { Band Center } \\
\text { Frequency }\end{array}$ & 25 & 31.5 & 40 & 50 & 63 & 80 & 100 & 125 & 160 \\
\hline Mean & 78.9 & 77.6 & 79.3 & 79.9 & 78.9 & 78.2 & 78.7 & 77.1 & 77.2 \\
$\begin{array}{l}\text { Standard } \\
\text { Deviation }\end{array}$ & 5.0 & 3.0 & 3.2 & 4.1 & 3.3 & 3.3 & 2.8 & 1.2 & 1.3 \\
\hline $\begin{array}{l}\text { Band Center } \\
\text { Frequency }\end{array}$ & 200 & 250 & 315 & 400 & 500 & 630 & 800 & 1000 & 1250 \\
\hline $\begin{array}{l}\text { Mean } \\
\text { Standard } \\
\text { Deviation }\end{array}$ & 18.5 & 80.3 & 81.0 & 81.5 & 83.0 & 84.3 & 85.6 & 87.5 & 88.0 \\
\hline $\begin{array}{l}\text { Band Center } \\
\text { Frequency }\end{array}$ & 1600 & 2000 & 2500 & 3150 & 4000 & 5000 & 6300 & 8000 & 10000 \\
\hline $\begin{array}{l}\text { Mean } \\
\text { Standard } \\
\text { Deviation }\end{array}$ & 89.2 & 92.1 & 92.9 & 93.7 & 94.0 & 94.7 & 94.7 & 94.3 & 95.3 \\
\hline
\end{tabular}

*All aB values are negative. 


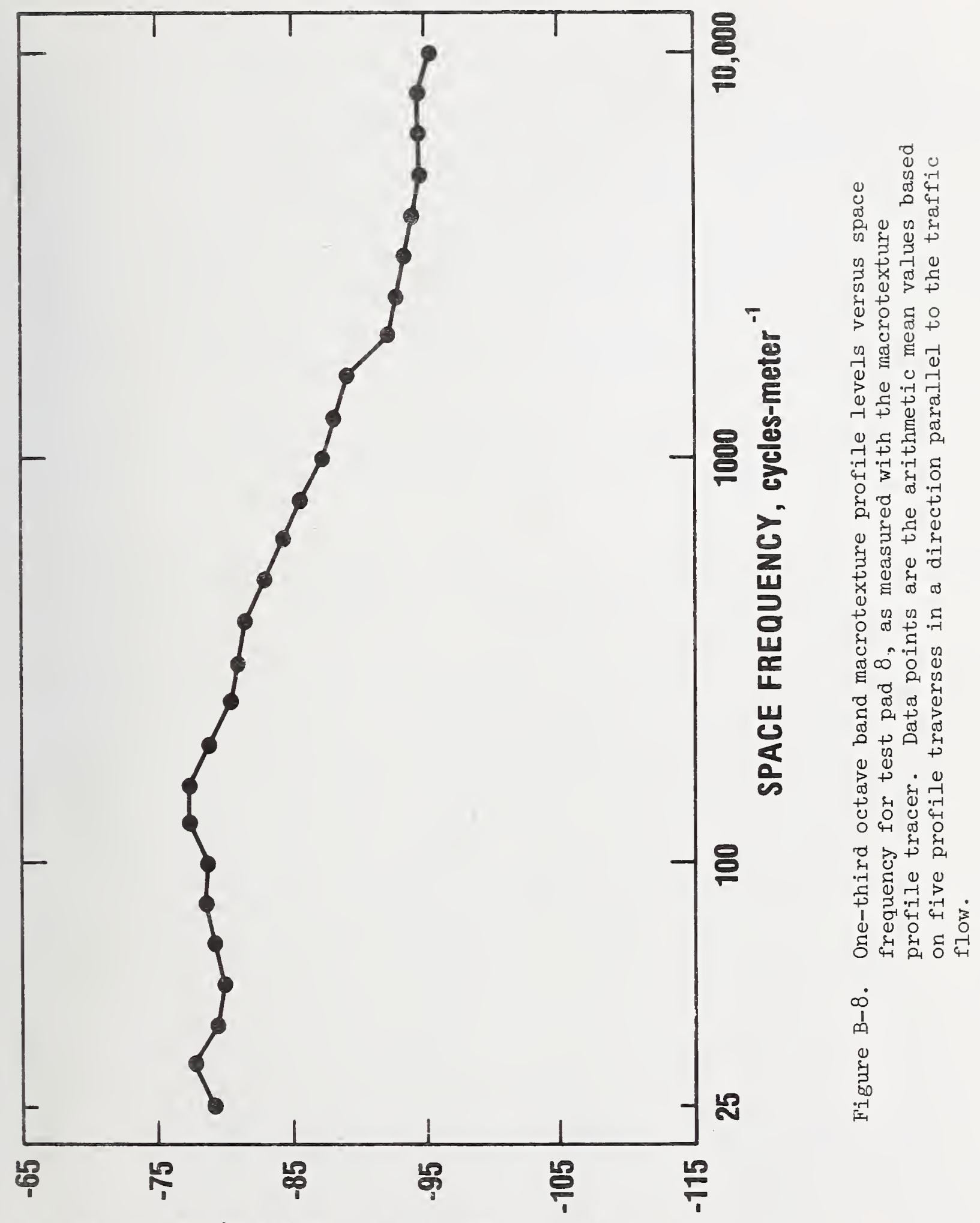

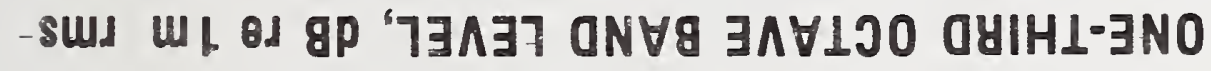




\section{Instrument Descriptions}

Unless otherwise stated, all instruments are Brliel and Kjaer $6 /$.

Type UA 0207 Windscreen: When a microphone is exposed to wind, and wind velocity variations, the turbulence created cause a noise to be generated due to a variation of air pressure on the diaphragm. To reduce this extraneous wind noise, a spherical windscreen constructed of specially prepared porous polyurethane sponge was utilized.

Type 4220 Pistonphone: This instrument is a small, battery-operated precision sound source which provides quick and accurate direct calibration of sound measuring equipment. When fitted to a B \& K microphone, the pistonphone produces a sound pressure level of $124 \pm 0.2 \mathrm{~dB}$, re $20 \mu \mathrm{Pa}$, at a frequency of $250 \mathrm{~Hz} \pm 1 \%$ (controlied by means of a transistor circuit). Maximum stability and a very low distortion (less than 3\% at $250 \mathrm{~Hz}$ ) result from the piston arrangement consisting of two pistons moving in opposite phase. The calibration of the pistonphone is performed at normal atmospheric pressure. Ambient pressure corrections are necessary for pressures other than $760 \mathrm{~mm} \mathrm{Hg}$. This calibration is not influenced by relative humidities up to $100 \%$ or temperatures within the range of $0-60^{\circ} \mathrm{C}\left(32-140^{\circ} \mathrm{F}\right)$.

Microphone: When one speaks of a microphone, a three part minimum system is implied: (1) a protecting grid; (2) a condenser microphone cartridge; and (3) a microphone preamplifier or cathode follower. For this testing the following components were utilized.

Type 4161 One-inch Condenser Microphones: The one-inch free-field condenser microphone is a type possessing relatively high sensitivity and covering a range of applicability from $2 \mathrm{~Hz}$ to $18 \mathrm{kHz}$ (frequency range) and $15 \mathrm{~dB}$ to $140 \mathrm{~dB}$ (dynamic range). A feature of these microphones is long-term stability under a variety of environmental conditions and insensitivity to temperature variations. Condenser microphones, in addition, were chosen because of their higher dynamic range, ease in calibration, and uniform frequency response. The cartridge which houses the microphone diaphragm is protected by the grid on one side and on the other is normally screwed onto the preamplifier. This particular microphone vents into a dehumidifier (which is located between the microphone and the preamplifier) rather than air. The silica gel drys the air used by the microphone for pressure equalization.

6/ Commercial instruments are identified in this report in order to adequately specify the experimental procedure. In no case does such identification imply recommendation or endorsement by the National Bureau of Standards, nor does it imply that the equipment identified is necessarily the best available for the purpose. 
Type UA 0310 Dehumidifier: The dehumidifier is designed to be mounted between the 4161 condenser microphone and its amplifier. It contains silica ge to dry the air used by thẹ microphone for pressure equalization. When used in 100\% relative humidity situations, the silica gel requires drying approximately once a month. The drying is accomplished by heating the silica gel for some hours at a temperature of $100^{\circ} \mathrm{C}$.

Type 2619 Half-inch FET Preamplifier: This preamplifier features a very high input impedance field-effect transistor, which represents virtually no load to the microphone cartridge. To mate the 2619 with the 4161 a suitable adapter must be utilized (model DB-0375).

Built into the preamplifier itself is a $6.3 \mathrm{~V}$ heating coil to prevent condensation when operation must be carried out in cold or humid environments.

The above described microphone subassembly provides reliable operation over a wide range of temperature, humidity, anc vibration and allows precision sound pressure measurements to be made over a wide frequency and dynamic range.

\section{Type 2804 Two Channel Power Supply: This unit is a portable, battery-} driven supply unit designed to provide the necessary polarization voltage for condenser microphones anä their accompanying preamplifiers.

NBS Field Instrumentation: To facilitate data acquisition in the field, this' battery-powered instrumentation system.was designed and fabricated by NPS specifically for application to passby noise measurements. The unit contains a $60 \mathrm{~dB}$ variable gain amplifier which provides the needed signal conditioning (amplification/attenuation) prior to recording. In adaition to recording the signal, weighting networks and hold circuitry are included to allow for direct reading of the linear and A-weighted fast response sound level observed during the passby. The hold circuitry and weighting networks meet the Type I requirements for the fast dynamic characteristic and the A-weighting response, respectively, of American National Standard Specification for Sound Level Meters, S1.4-1971. The flat frcquency response hold circuitry provides an indication as to whether or not a tape channel. had become saturated (i.e., the signal had exceeded tre dynamic range of the recorder) and thus the data were not acceptable. The A-weighted hold circuitry allowed for. direct reading of the A-weighted sound level observed during a passby without the necessity for returning the 'tape recordings to the laboratory for reduction and analysis.

Nagra Model SJ Tape Recorder: This unit is a portable 3-track (1/4 inch magnetic) tape recorder with two high quality amplitude modulated sound tracks ( $25 \mathrm{~Hz}$ to $35 \mathrm{kHz}$ ), plus a third FM track for recording very low frequencies (dc to $4 \mathrm{kHz}$ ), commentary, synchronization signals or timing 
information. The instrument records and reproduces at four speeds -- 15, $7-1 / 2,3-3 / 4$, and $1-1 / 2$ ips. The two-amplitude modulated channels can be fed from separate microphone inputs. The volume is controlled by separate step attenuators.

Type 3347 Real Time Analyzer: The real time analyzer is composed of two basic units: (1) type 2130 frequency analyzer and (2) type 4710 control and display unit.

The 2130 contains a measuring amplifier, filter channels with 1/3-octave bandwidth, a flat frequency response channel, weighting channels, true RMS detectors, and the synchronization system for scanning the channels.

The analyzer contains 38 parallel channels. 33 of these channels contain I/3-octave filters with center frequencies from $12.5 \mathrm{~Hz}$ to $20 \mathrm{kHz}$. The remaining five channels are reserved for the four weighting network filters -- A, 'B, C, and D -- and one flat frequency response channel.

The 4710 contains the circuitry for the 12-inch cathode ray tube (CRT), the Nixie displays, digital readout, and the logic control. The logic control section controls the analog/digital conversion and the communication sequence for external systems, as well as the internal synchronization in the 3347 during display or read-out modes.

The level in each channel can be read in $\mathrm{dB}$ directly on the screen, while a Nixie display shows the output level of any selected channel. This channel is indicated on the CRT as a brighter trace. The complete channel display is renewed every $20 \mathrm{msec}$.

Outputs are provided for both analog instruments ( $\mathrm{X}-\mathrm{Y}$ or level recorders) as well as digital (on-line computer or tape puncher). The digital output is in binary coded decimal (BCD) code.

Time constants may be selected from $20 \mathrm{msec}$ to $20 \mathrm{sec}$ so that confidence limits can be maintained throughout the frequency range.

Model 704 Raytheon Computer System: The Raytheon 704 computer system is a general purpose digital system that provides a 16-bit central processor unit with 900 nanosecond cycle time for on-line, real time applications.

The hardware configuration includes an $16 \mathrm{~K}$ (expandable to $32 \mathrm{~K}$ ) memory system, direct input/output bus, automatic priority interrupt, direct and indexed addressing, and byte and word addressing and instructions. Standard peripherals such as high speed paper tape, ASR-33 teletype, card equipment, and a magnetic tape unit are also included. 


\section{Appencix D}

Description of Nacrotexture Profile Mracer

The orofile tracer used in this study is shom in Figure 10 . The bed of the profile tracer consists of a plate on which the drive motor, limit switches, and cead weight tension restraint sustem are mounted. The bed is supported on the pavement by three adjustable legs so that it may de alignea parallel to the plane of the parement. The bea provides a reperence plane along wich a sled is drawn causing the stylus to traverse tre parement. The stylus is attached to the sled through a cantilerer spring which waintains a positive stylus pressure to ensure contact betreen the stulus and the parement surface. The core of a displacement urensacer ga Iinear variable differential transformer (IVDT) (H-P Sanborn Irodel TPCDT-500)ㅇ, also mounted on the slec, is spring-loaded against the stvlus holder so that the UVDI core follons the vertical motion of the stylus as it traverses the pavement. Feflon pacs on the sled provide smooth motion of the sled as it is dram along the bed. The draw wire for the sled is taken uo 97 a pulle: ariten at 3 rom by a sincironous motor (Bodine Wodel KC-22T5AI-). Tension in the araw wire is maintainea nearly constant by means of a restraining wire attached to the rear of the sled and Ioaded with a weight. The draw wire and restraining wire are attached in such a way that they provide a sitght domwara component to assure that the slea remains in contact with the bea Guring the treverse.

The total traverse length of the sled is 0.305 meters and the horizontal traverse rate is approximateiy 0.0039 meters/sec. The HDT contains an internal modulator-cemoäulator such that when exciteá by a DC roltage, ìt produces a DC analog signal proportional to the core displacement. The LVDT has a sensitivity of approximately 0.189 rolts/cm orer a total 0 ? the $2.5 \mathrm{~cm}$ linear range.

The styli usea in this project were turned from $0.16 \mathrm{~cm}$ diameter carbon steel with ar approximate $22^{\circ}$ cone angle anc a $0.13 \mathrm{~mm}$ tip radius. The styli were oil quench hardened to an estimatea Rockwell ho. C of apvroximately 60. Actual dimensions of two of the stuli used as measured with an optical comparator are shown in Figure D-I.

I/ Details of the operction and calibration of this device were taren from a report[I6] prepared for the liational Bureau of Standaras under sponsorship of the U. S. Department of Transportation by the Zennsvlvania Iransportation Institute (PTI), University Park, Pa.

8/ Comercial instruments are identifiea in this report in oräer to adequatelv specify the experimental procedure. In no case does such identification imply recomendation or endorsement by the liational Bureau of Stancarảs, nor does it imply that the equipment icentified is necessarily the best available for the purpose. 


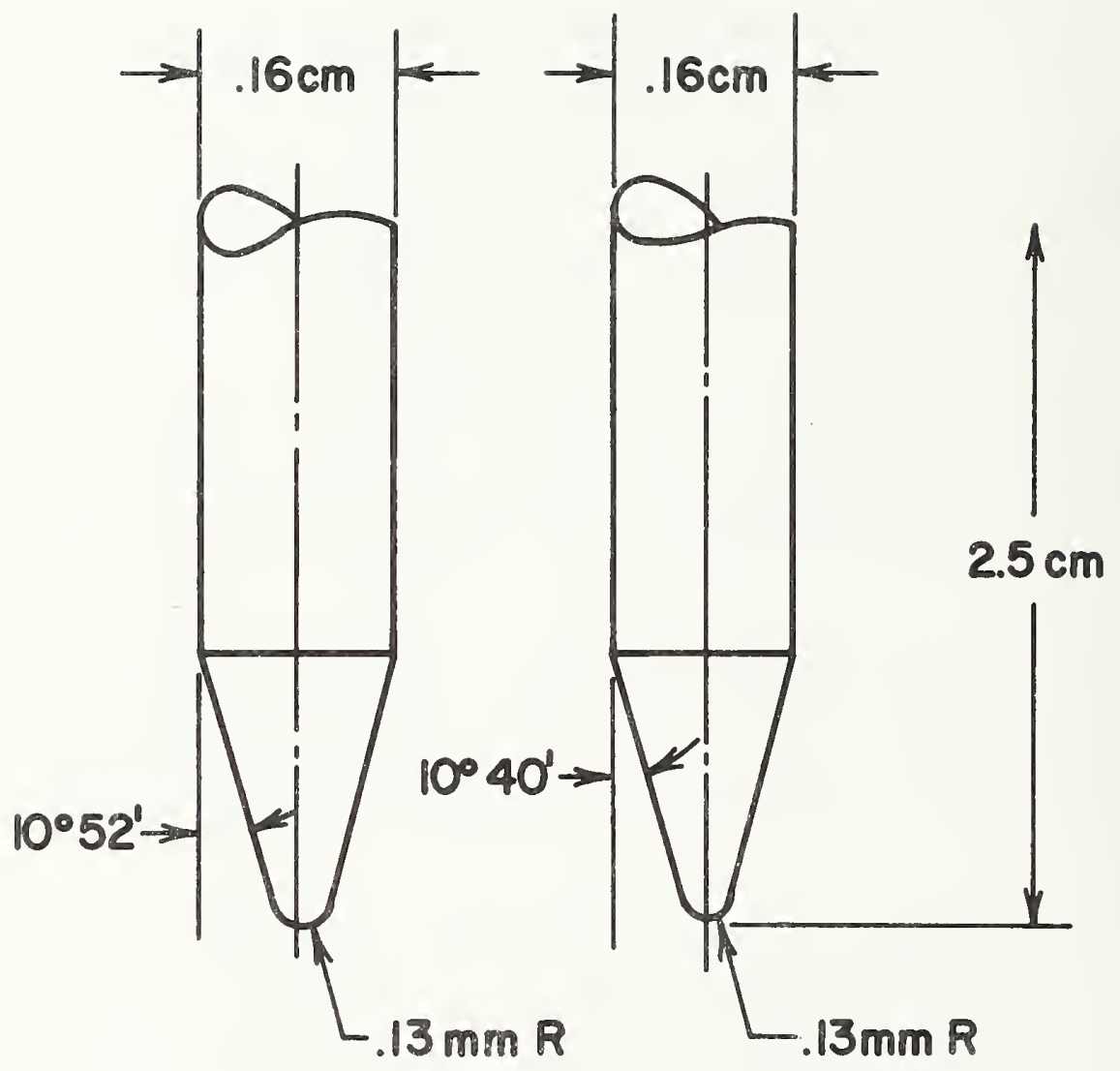

Figure D-1. Macrotexture profile tracer stylus configuration. 
Direct calibration of the profile tracer is performed by traversing carefully prepared sinusoidal calibration surfaces (Figures D-2 and D-3). These surfaces were manufactured by photographically reducing computer plotted sine functions and chemically etching stainless steel sheets having a thickness of $0.0127 \mathrm{~cm}$ (0.005 in.). Holes for locating pins were etched simultaneously so that the etched sheets could be assembled to provide a laminate approximately $1.3 \mathrm{~cm}$ thick. The calibration surfaces contained five sine functions with amplitudes and wavelengths as given in Table $D-1$.

Table D-1. Amplitudes and wavelengths of sinusoidal calibration surfaces.

\begin{tabular}{|cl|ll|}
\hline \multicolumn{2}{|c|}{ Amplitude } & \multicolumn{2}{c|}{ Wavelength } \\
\hline meters & \multicolumn{1}{c|}{ (in.) } & meters & (in.) \\
& & & \\
0.0127 & $(0.5)$ & 0.0254 & $(1.0)$ \\
0.00635 & $(0.25)$ & 0.0127 & $(0.5)$ \\
0.00318 & $(0.125)$ & 0.00635 & $(0.25)$ \\
0.00158 & $(0.0625)$ & 0.00318 & $(0.125)$ \\
0.000794 & $(0.03125)$ & 0.00158 & $(0.0625)$ \\
\hline
\end{tabular}

In addition to the sinusoidal calibration surfaces, a steel wedge having 1.25 $\mathrm{cm}$ high ramps with nominal $10^{\circ}$ and $45^{\circ}$ slopes from the horizontal (Figures D-4 and D-5) was also used. The actual angles were measured using an optical comparator. For all calibration surfaces and for some of the pavements a light coating of lubricating oil was found to be helpful in reducing chatter and reducing horizontal drag forces on the stylus on steep slopes. 


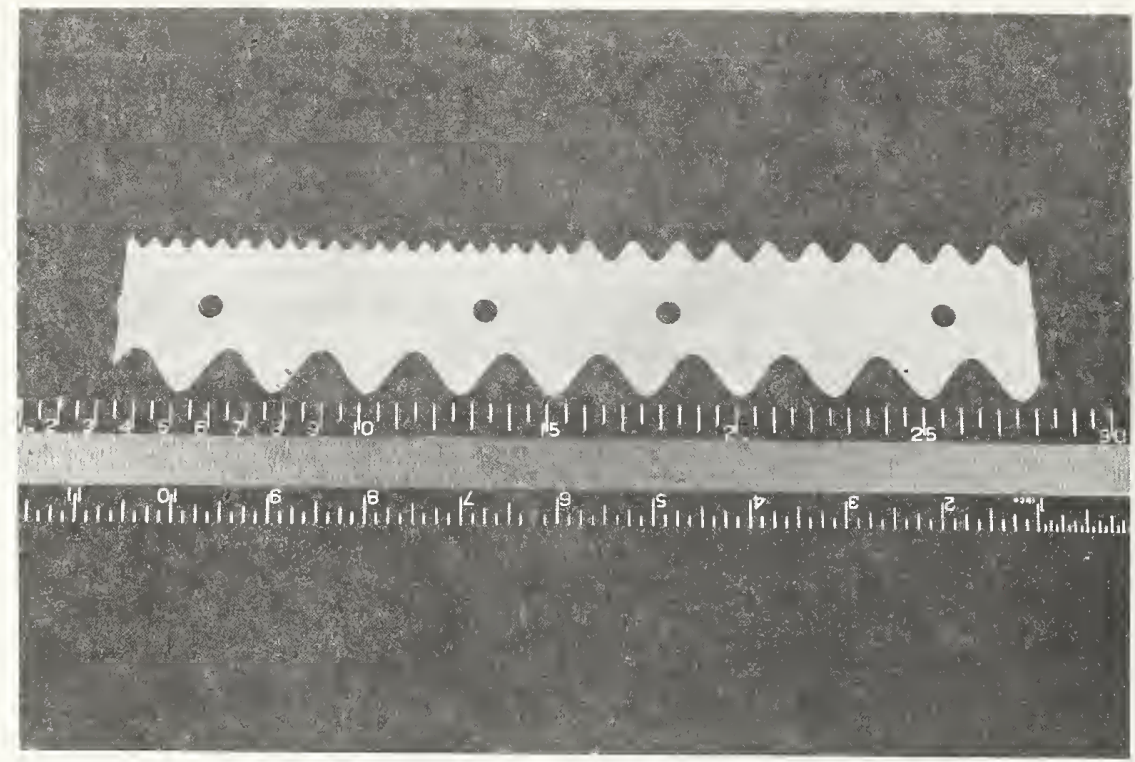

Figure D-2. Large sine wave calibration surfaces.

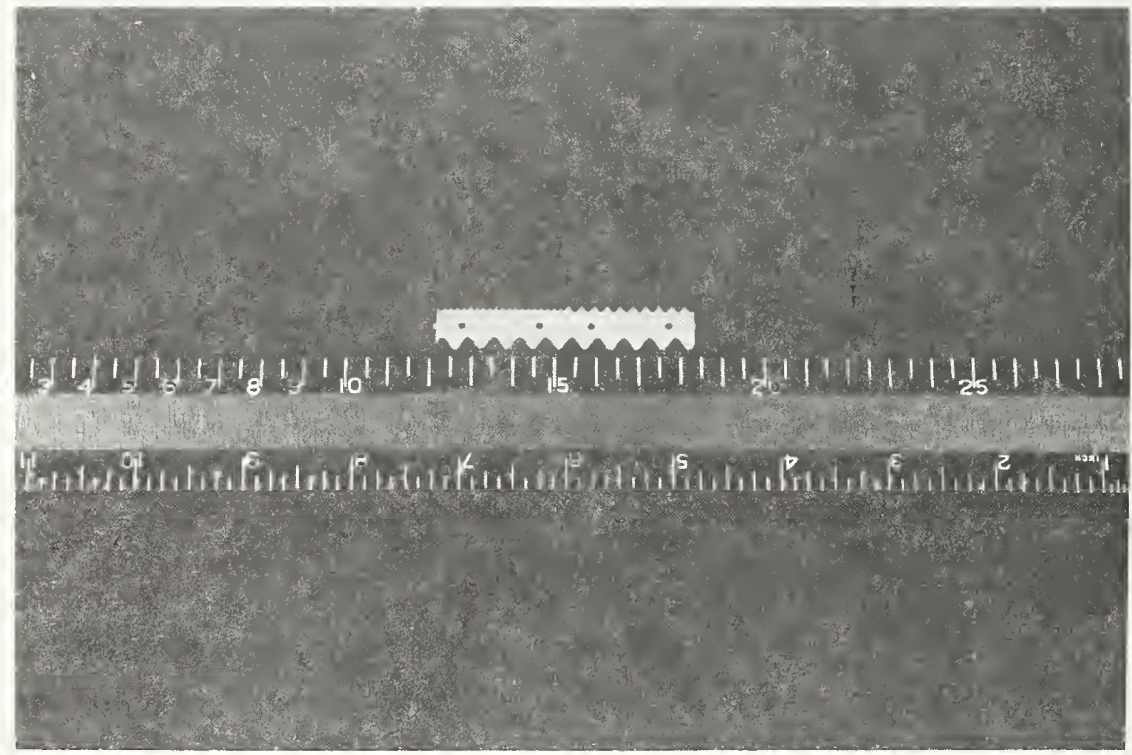

Fifure D-3. Small sine wave calibration surfaces. 


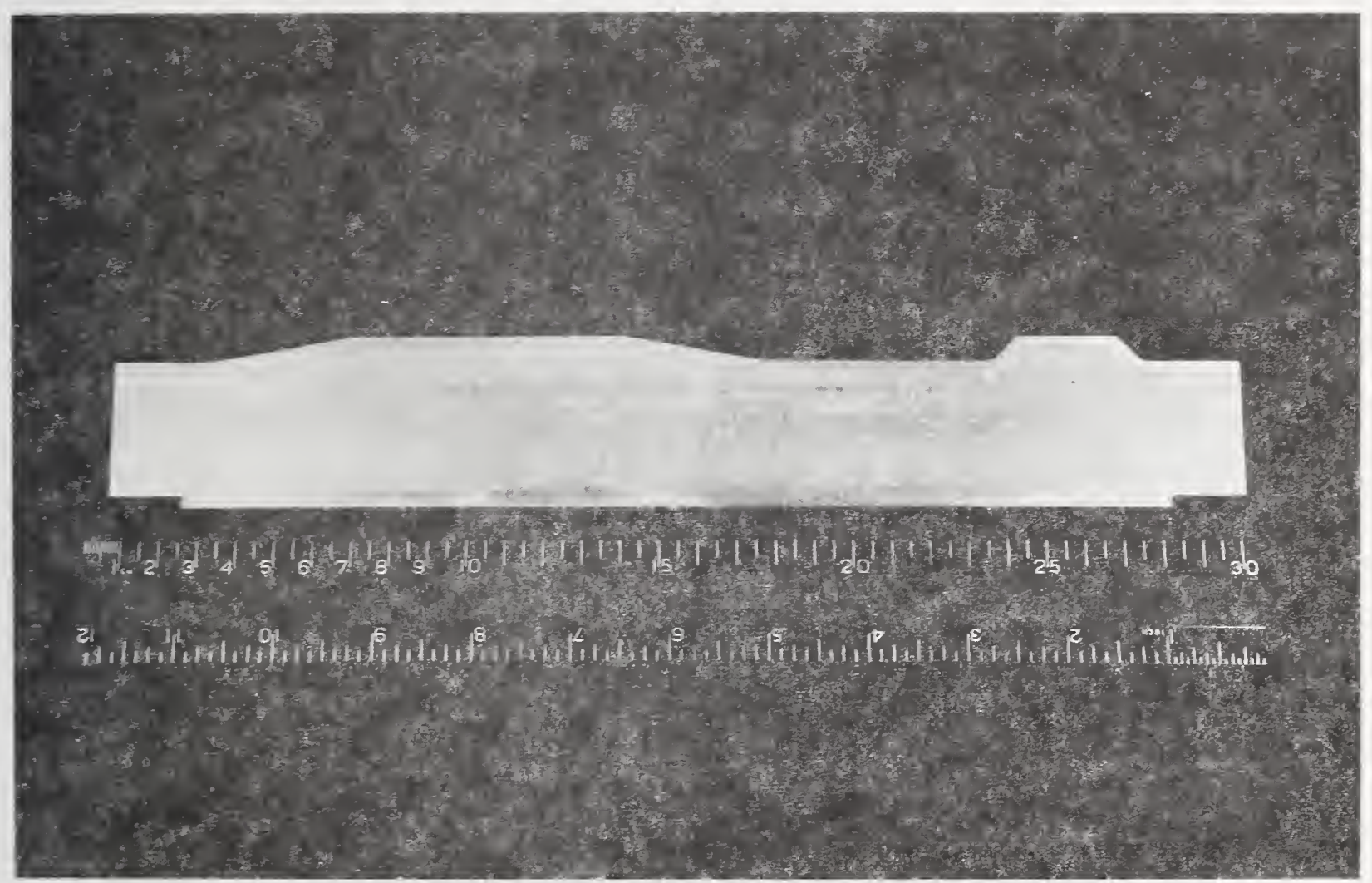

Figure D-4. Ramp calibration surfaces. 


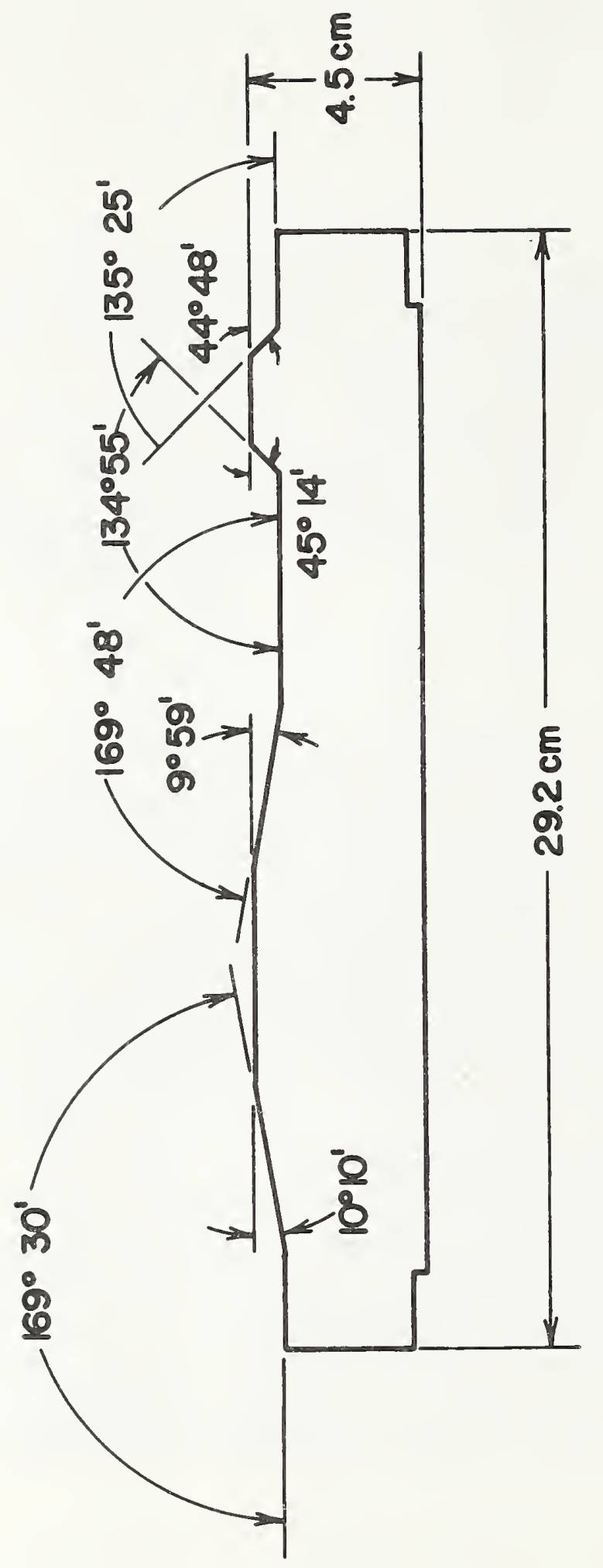

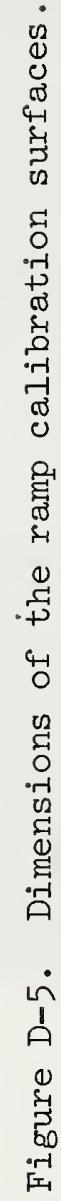




\section{Appendix E}

\section{Description of Test Pavements 9 /}

The TTI skid test pads were prepared by placing a controlled surface course on top of the existing pavement structure -- a well-constructed portland cement concrete runway of a former jet-training airfield (the one exception was pad 1 which was the original concrete runway). The surfaces, which represent a number of different construction methods and materials, were designed to have a range of skid numbers from 20 to 70 in several distinct steps.

Each of the eight test pads used in this study were 24 feet $(7.3 \mathrm{~m})$ in width and 600 feet $(182.9 \mathrm{~m})$ in length with a cross slope of approximately $1 / 8$ inch per foot $(1.04 \mathrm{~cm} / \mathrm{m})$. The pavement surfaces were chosen so as to exhibit widely different friction levels, friction-velocity gradients, drainage capabilities, mineralogical properties, and textural classifications. Based on the materials and methods of construction, these test pads can be categorized into three groups.

Group 1 (test pads 3, 4, 5 and 8) was comprised of hot-mixed asphaltic concrete courses which were surface finished by a variety of methods for developing a consistent macrotexture and microtexture. The asphaltic concrete used in these pads was produced in a commercial size hot-mix batch plant located at the Texas A \& M Research Annex. These paving mixtures were placed with a Bayber-Greene 4.A laydown machine, Barber-Greene Co., Aurora, Illinois=, in layers approximately $11 / 2$ inches $(3.8 \mathrm{~cm})$ thick. Compaction was accomplished by use of a twelve ton tandem steel roller using 8 passes, and by a light pneumatic roller using 15 passes. Asphalt contents in the paving mixtures used in the construction of these pads were held slightly above optimum to minimize stripping by the action of water. A single grade and source of asphalt cement was used. This material had a relatively flat viscosity-temperature curve and good durability predicted by laboratory oxidation and radiation tests (see Table E-1).

Group 2 (test pads 1 and 2) consisted of surfaces prepared by cleaning or surface coating previously constructed asphaltic concrete or portland cement courses.

9/Details of the composition of each test pad were taken from references [E1, E2, and E3] listed at the end of this appendix.

10/The commercial equipment utilized is identified in this report in order to adequately describe the method of construction of the test pads used throughout this program. In no case does such identification imply recommendation or endorsement by the National Bureau of Standards, nor does it imply that this equipment was necessarily the best available for the purpose. 


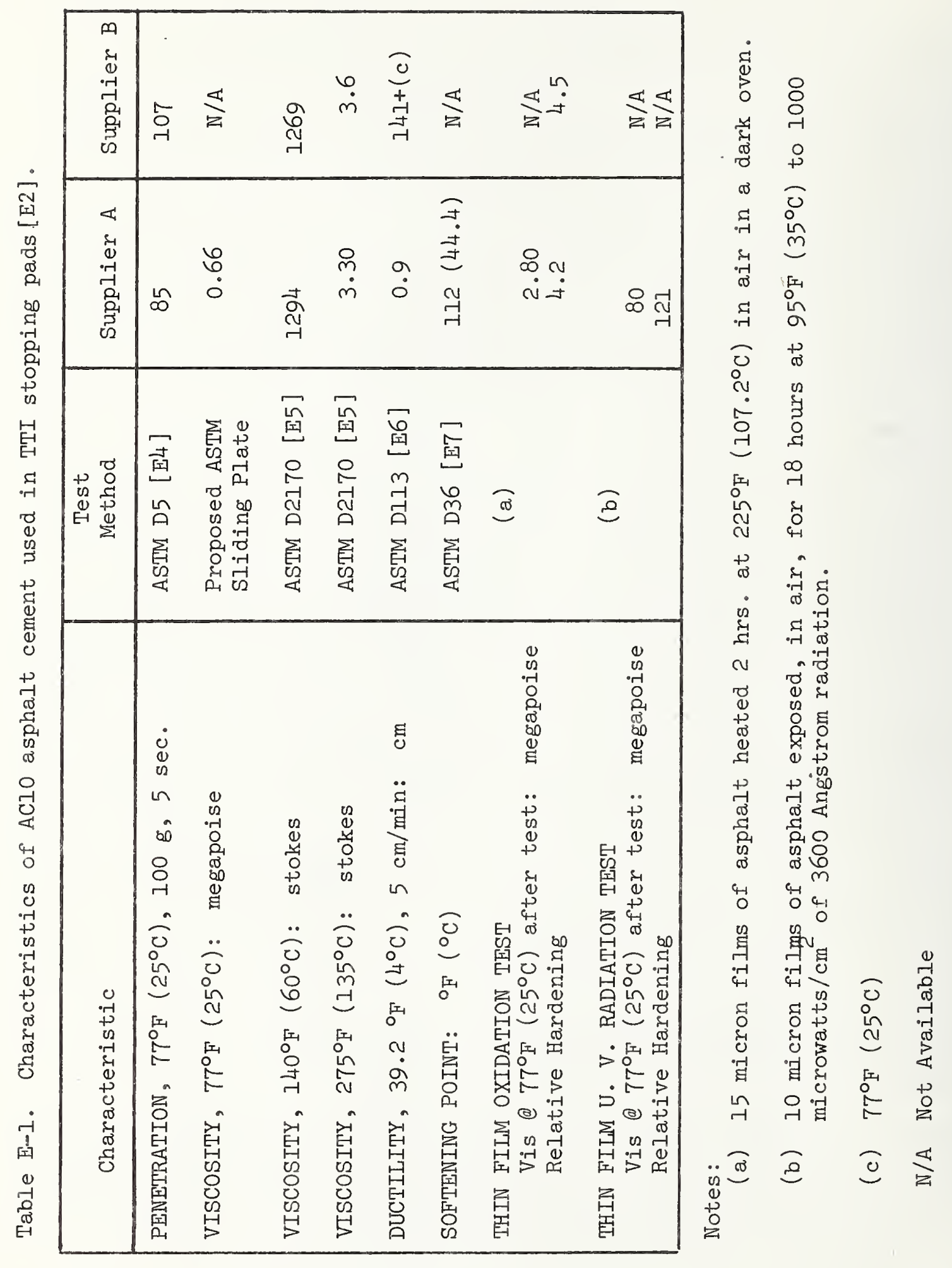


Q Group 3 (test pads 6 and 7) consịsted of asphalt chip seal surfaces. These test pads were constructed by first laying down a I inch $(2.54 \mathrm{~cm})$ layer of hot-mix asphaltic concrete (similar to Group 1). The asphaltic concrete was then hot covered with asphalt, followed by a layer of the chip aggregate. Final compaction was produced by a light pneumatic roller using 6 passes.

A discussion of the materials used and the techniques of surface finishing or coating of each of these test pads follows.

Pad 1: Portland cement concrete

Pad 1 consisted of a surface prepared by initially cleaning the existing runway using a high pressure spray, followed by periodic cleaning using a rotary broom and waten. The existing runway was constructed of portland cement concrete with a belt drag finish. A summary of the characteristics of pad $I$ is given in Table E-2.

Pad 2: Asphaltic concrete with Jennite 1 flush seal

Pad 2 consisted of a previously constructed asphaltic concrete course that was surface coated with a clay-filled tar emulsion available commercially under the tradename Jennite.

The asphaltic concrete course was oonstructed using the same methods as previously described for the Group 1 test pads, except that final compaction by the light pneumatic roller was increased from 15 to 30 passes.

The pavement was then thoroughly scrubbed using water and fine sand in a power driven rotary broom. Following the cleaning operation, four coats of Jennite were applied at an approximate application rate of $0.12 \mathrm{gal} / \mathrm{yd}^{2}\left(0.54\right.$ liters $\left./ \mathrm{m}^{2}\right)$. The completed surface was allowed to cure and harden three days and then was polished by a large rectangular sponge rubber float towed behind a truck at 8 to $10 \mathrm{mph}(12.9$ to $16.1 \mathrm{~km} / \mathrm{hr})$. During the polishing of the pavement, the surfaces were kept wet and fine sand and fly ash were used as polishing aids. A summary of the characteristics of pad 2 is given in Table E-3 (also Figure E-1).

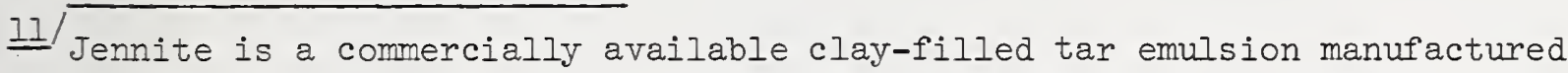
by the Jennite Company, Houston, Texas. This material is identified in this report in order to adequately describe the method of construction of one of the test pads used in this program. In no case does such identification imply recommendation or endorsement by the National Bureau of Standards, nor does it imply that this material was necessarily the best available for the purpose. 


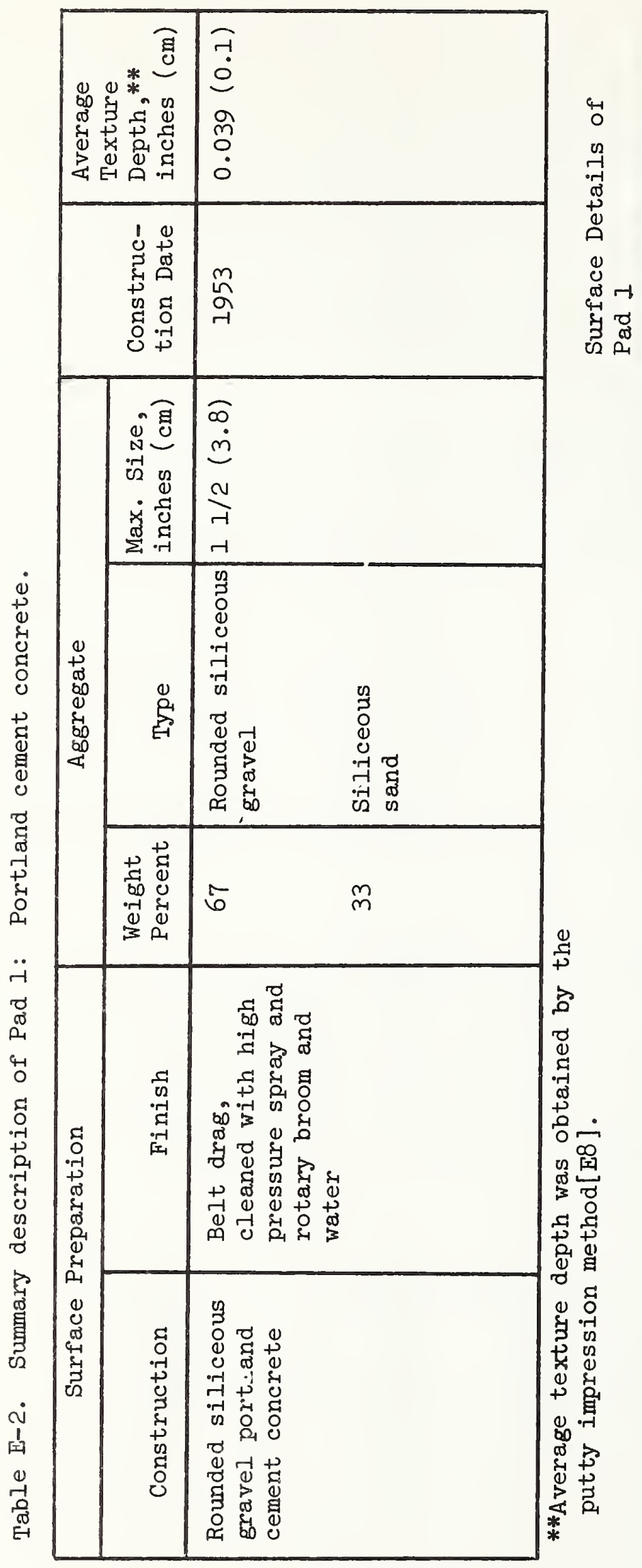




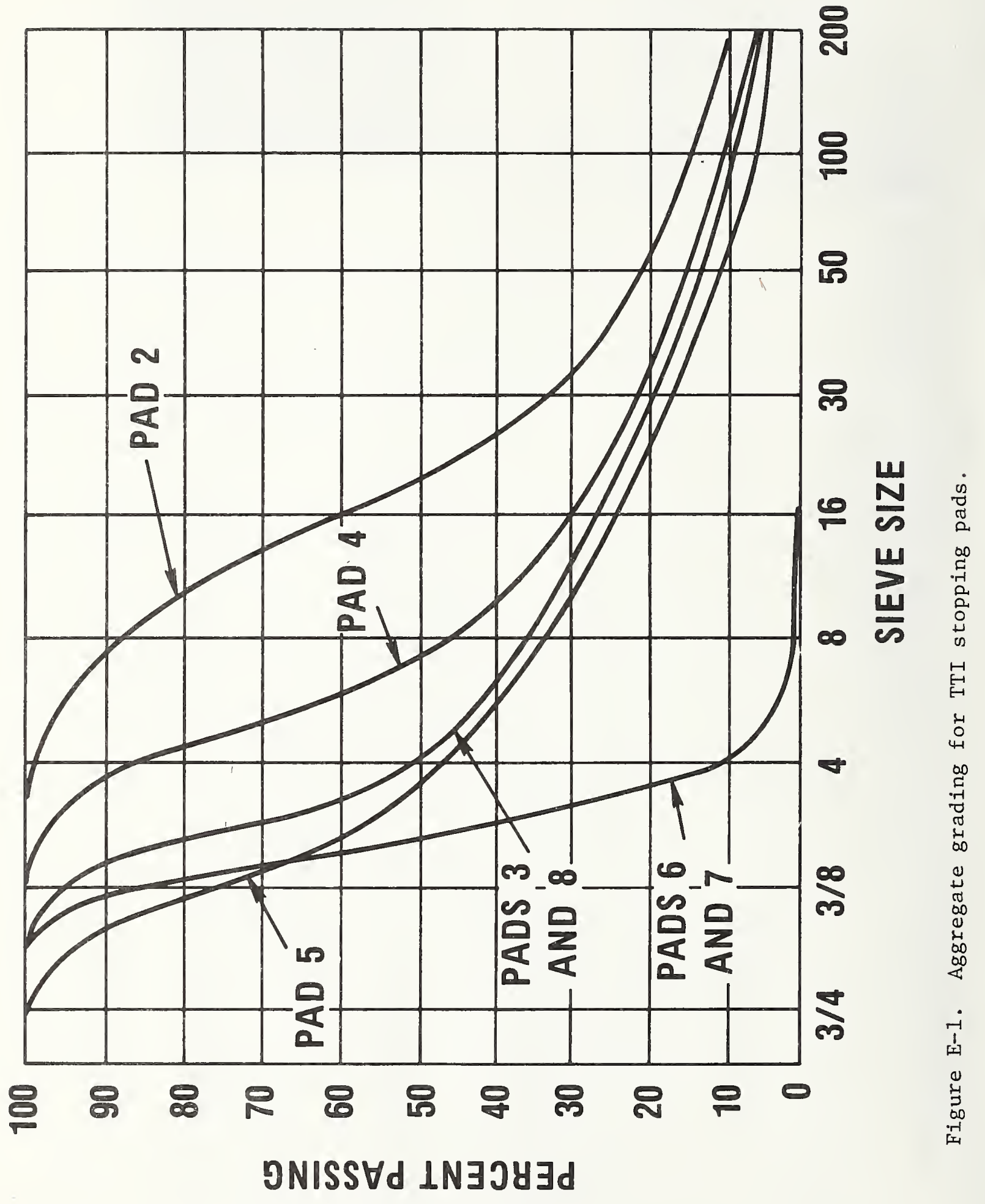


Pad 3: Limestone hot-mix asphaltic concrete with a terrazo finish

Pad 3 consisted of a hot-mixed asphaltic concrete course that had been specially surface finished. The asphaltic concrete course, which used limestone as the major aggregate, was produced, layed down and compacted as described previously for Group 1 test pads. The pavement was then ground using a gasoline powered terrazo grinding machine equipped with No. 80 grit carborundum stones. Grinding was continued until all the pavement surface texture presented by the crushed stone was essentially eliminated. The result was similar to a terrazo floor. After this grinding operation, the pavement was polished by the same method as pad 2 using the sponge rubber float and water. Again, fine sand and fly ash were used as polishing aids. A summary. of the characteristics of pad 3 is given in Table E-4 (also Figure E-1).

\section{Pad 4: Crushed gravel hot-mix asphaltic concrete}

Pad 4 consisted of a hot-mixed asphaltic concrete course using crushed gravel as the major aggregate. The asphaltic concrete course was produced, layed down, and compacted as described previously for Group 1 test pads. Following this, the pavement was polished by the same method as pad 2. A summary of the characteristics of pad 4 is given in Table E-5 (also Figure E-1).

Pad 5: Rounded gravel hot-mix asphaltic concrete

Pad 5 consisted of a hot-mixed asphaltic conćrete course simjlar to pad 4 except that rounded gravel was used as the major aggregate. The asphaltic concrete course was produced, layed down, and compacted as described previously for Group 1 test pads. Following this, the pavement was polished using the same procedure as described for pad 2. A summary of the characteristics of pad 5 is given in Table E-6 (also Figure E-l).

\section{Pad 6: Rounded gravel asphalt chip seal}

Pad 6 consisted of an asphalt chip seal surface, which used rounded gravel as the chip aggregate. This test pad was constructed by first laying down a 1 inch $(2.54 \mathrm{~cm})$ layer of hot-mix asphaltic concrete using methods similar to that used to construct the Group 1 test pads. This hot-mixed asphaltic concrete was then hot covered with asphalt with an approximate application rate of $0.33 \mathrm{gal} / \mathrm{yd}^{2}$ $\left(1.5\right.$ liters $\left./ \mathrm{m}^{2}\right)$. This was followed by a layer of rounded gravel aggregate with a coverage of approximately $171 \mathrm{~b} / \mathrm{yd}\left(9.24 \mathrm{~kg} / \mathrm{m}^{2}\right)$. Compaction was produced by a light pneumatic roller using 6 passes . The pad was allowed to set for 24 hours, and then was broom cleaned. This was followed by 2 hours of rerolling with a light pneumatic roller. A summary of the characteristics of pad 6 is given in Table E-7 (also Figure E-1). 


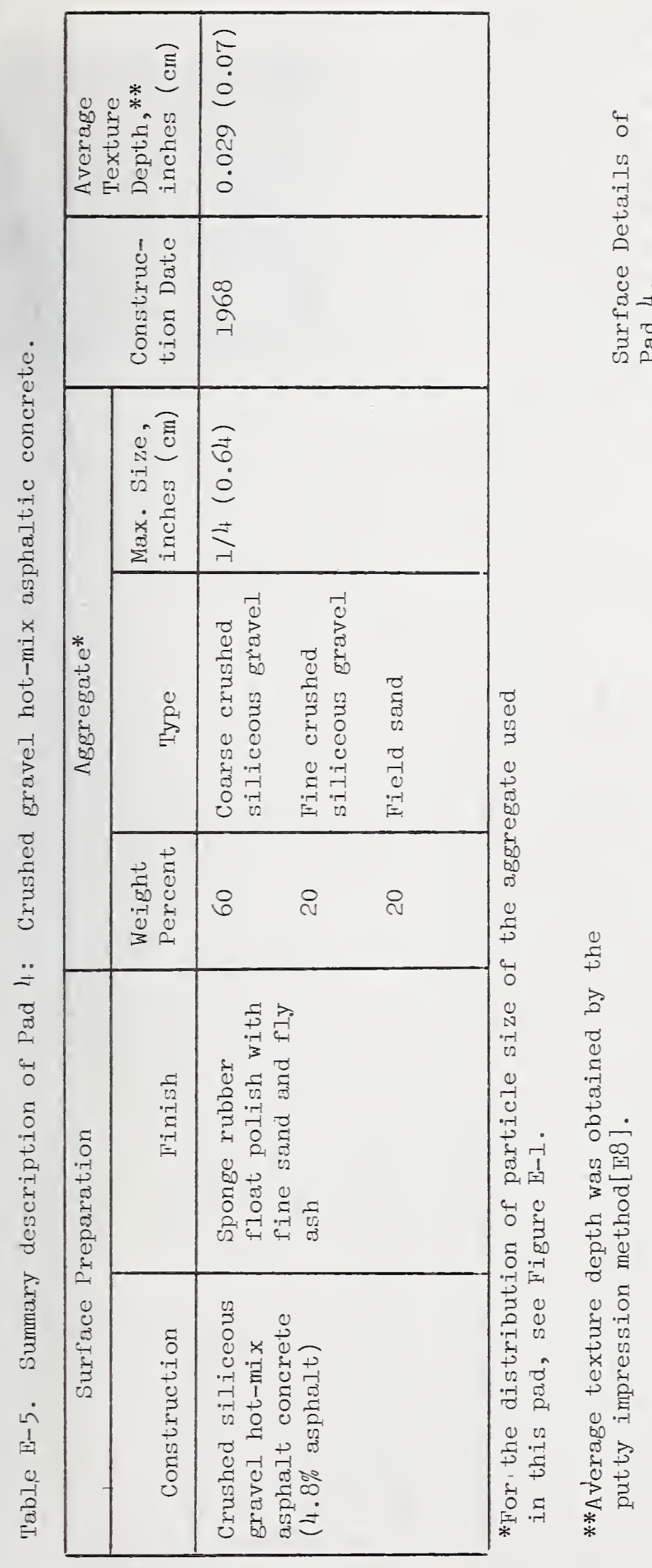




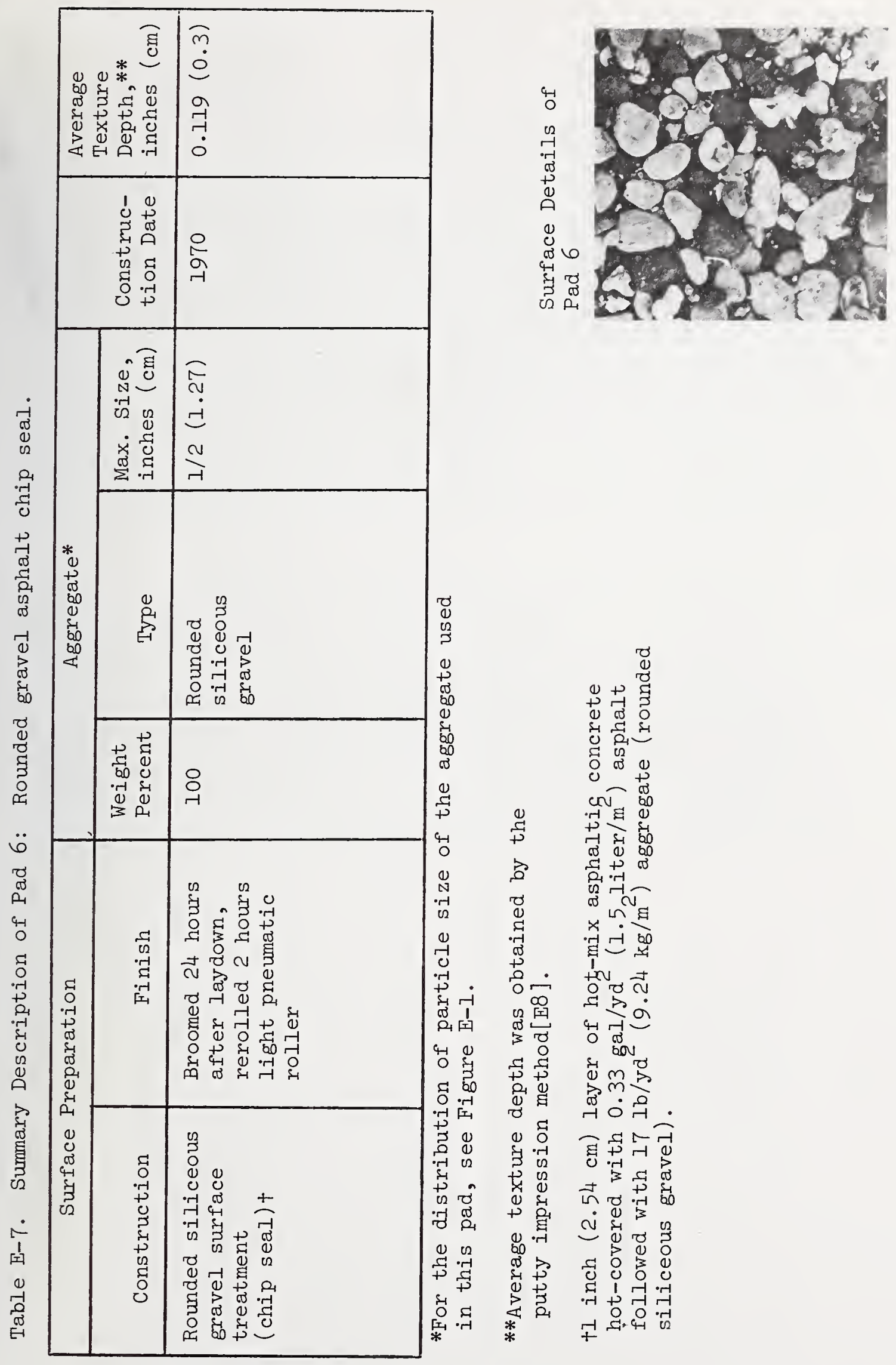


Pad 7: Lightweight aggregate asphalt chip seal

Pad 7 consisted of an asphalt chip seal surface similar to pad 6 except that instead of rounded gravel, a synthetic lightweight material (fired clay) was used as the chip aggregate. Again, the test construction consisted of first laying down a 1 inch $(2.54 \mathrm{~cm})$ layer of hot-mix asphaltic concrete using methods similar to that used to construct the Group 1 test pads. This hot-mixed asphaltic concrete was then hot covered with asphalt with an approximate application rate of $0.35 \mathrm{gal} / \mathrm{yd}^{2}\left(1.58 \mathrm{liters} / \mathrm{m}^{2}\right)$. This was followed by a layer of synthetic lightweight aggregate (fired clay) with a coverage of approximately $10 \mathrm{lb} / \mathrm{yd}^{2}\left(5.4 \mathrm{~kg} / \mathrm{m}^{2}\right)$. Compaction was produced by a light pneumatic roller using 6 passes. The pad was allowed to set for 24 hours, and then was broom cleaned. This was followed by 2 hours of rerolling with a light pneumatic roller. A summary of the characteristics of pad 7 is given in Table $E-8$ (also Figure E-I).

Pad 8: Lightweight aggregate hot-mix asphaltic concrete

Pad 8 consisted of a hot-mixed asphaltic concrete course using a synthetic lightweight material (fired clay) as the major aggregate. The asphaltic concrete course was produced, layed down, and compacted as described previously for Group 1 test pads. The pavement was then thoroughly scrubbed with a broom using water and detergent. After this scrubbing, the pavement was polished using the sponge rubber float and water as described for pad 2. Again fine sand was used as a polishing aid. A summary of the characteristics of pad 8 is given in Table E-9 (also Figure E-1). 


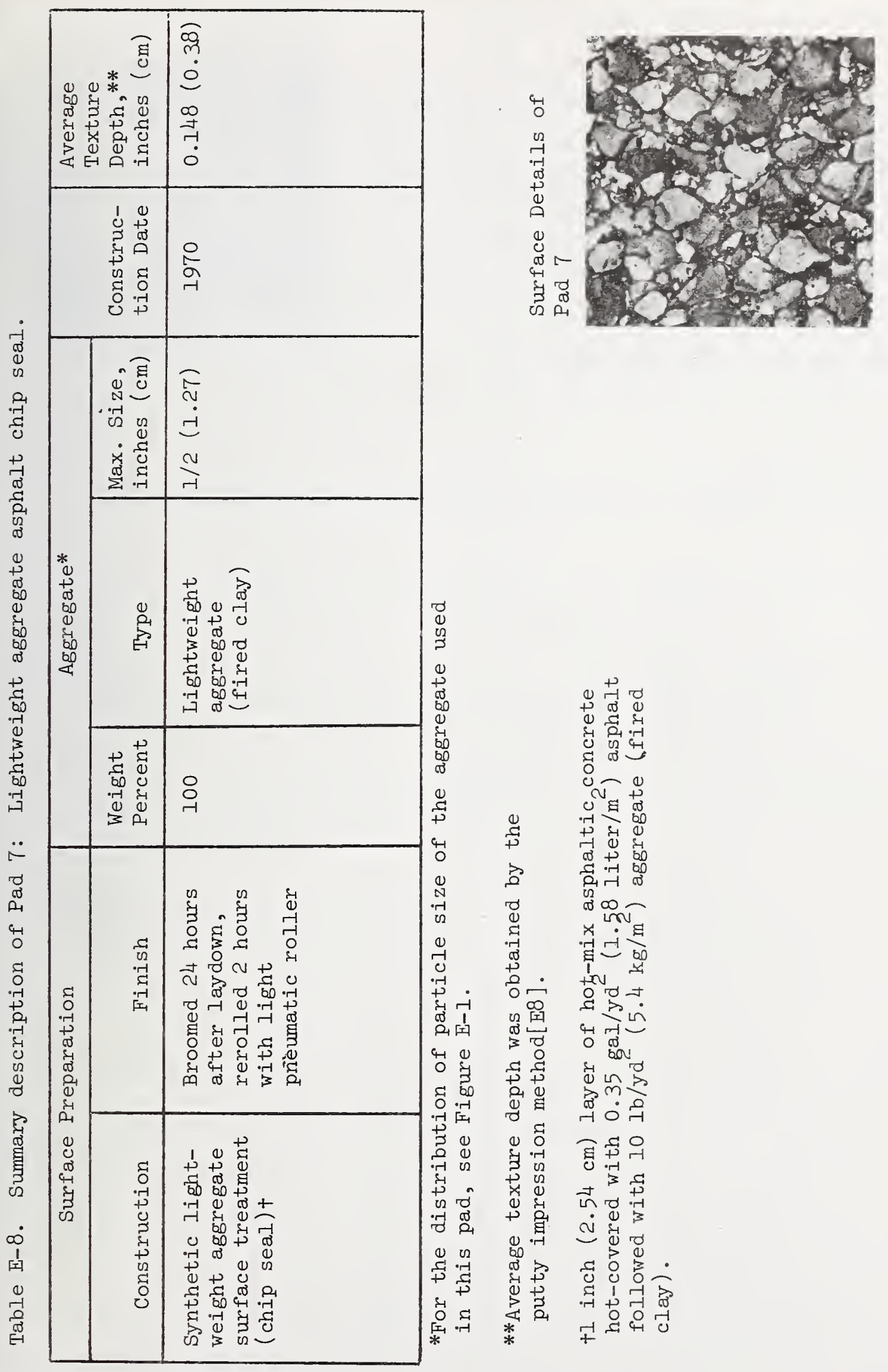




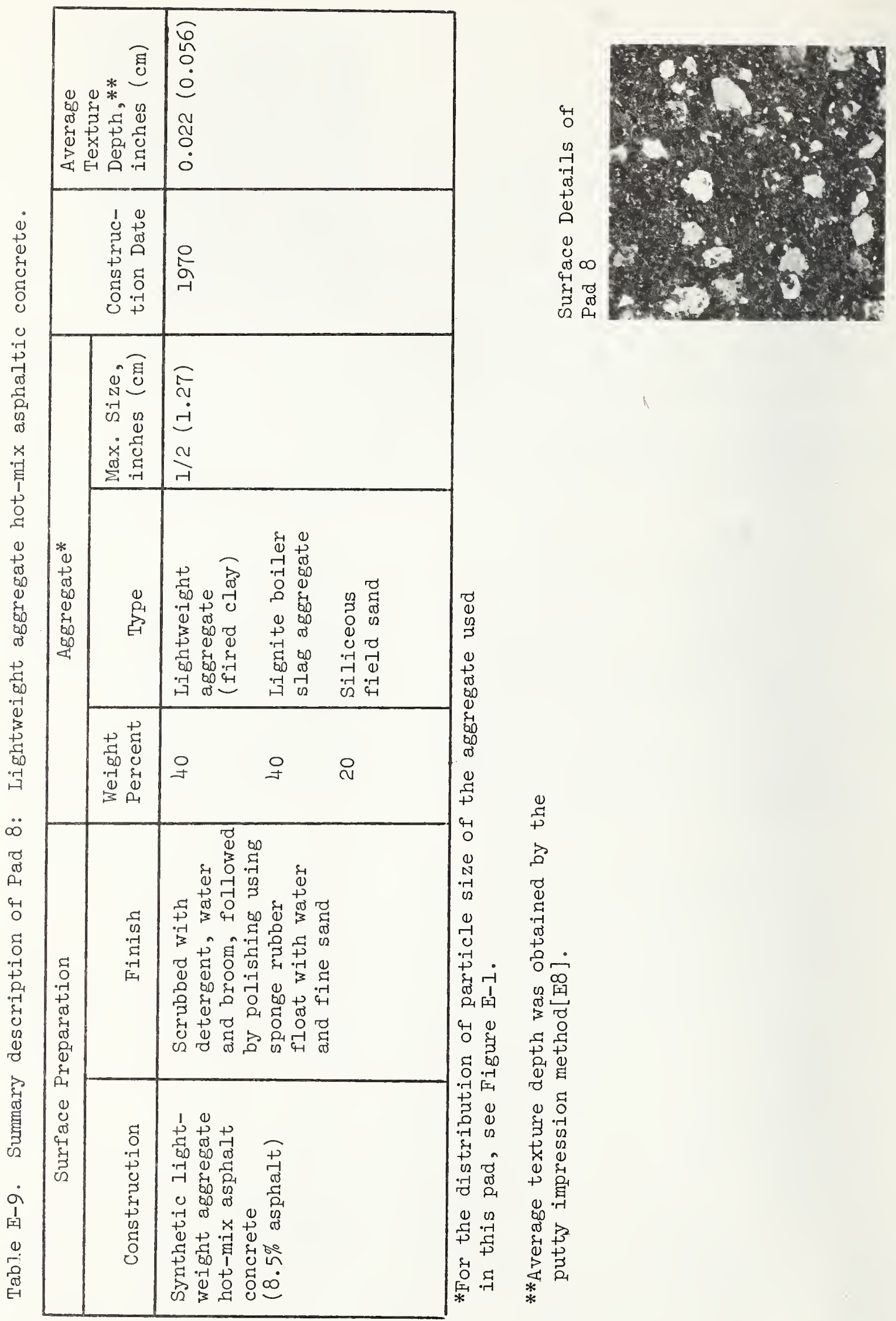


[EI] Gallaway, B. M., Epps, J. A., and Hargett, E. R., Design and construction of full-scale stopping pads and spin-out curves to predetermine friction values, Journal of Naterials 5 (2), 303-322 (1970).

[E2] Irey, D. I., Stocker, A. J., et al., Pilot field test and evaluation center (Technical Report 797-3, Texas Transportation Institute, Texas A \& University, College Station, Texas, 1972).

[E3] Gallaway, B. M., Rose, J. G., Scott, Jr., W. W., and Schiller, R. E., Influence of water depths on friction properties of various paverent types (Research Report 138-6, Texas Transportation Institute, Texas \& \& $H$ University, College Station, Texas, 1974).

[E4] American Society for Testing and Waterials, D 5-71, Standard Method of Test for Penetration of Bituminous Materials in Part 15, 3ook of ASTM Standards, 1974 (ASTr, Philadelphia, Pennsylvania) (Revised 1973).

[E5] American Society for Testing and Materials, D 2170-67, Standard Method of Test for Kinematic Viscosity of Asphalt in Part 15, Book of ASTr Standards 1974 (ASTM, Philadelphia, Pernsylvania) (Revisec 1974).

[E6] American Society for Testing and Naterials, D 113-69, Standard Method of Test for Ductility of 3ituminous Waterials in Part 15, 300k of ASTM Standards, 1974 (ASTr, Philadelphia. Pennsylvania).

[E7] American Society for Testing and Materials, D 36-70, Standard Method of Test for Softening Point of Asphaits and Tar Pitches (Ring-and-Ball Aoparatus) in Part 15, Book of AST! Standards, 1974 (ASTr, Philadelohia, Pennsylvania).

[E8] Gallaway, B. M., and Rose, J. G., Macrotexture, friction, cross slope, and wheeltrack depression measurements on 4 l tyoical Texas highway pavezents (Research Report 138-2, Texas Transportation Institute, Texas A \& M University, Colleze Station, Texas, 1970). 


\section{References}

[1] Anon., Truck noise-I, peak A-weighted sound levels due to truck tires, U. S. Department of Transportation Report OST-ONA-71-9 (National Bureau of Standards, Washington, D. C., 1970).

[2] Leasure, Jr., W. A., Corley, D. M., Flynn, D. R., and Forrer, J. S., Addendum to truck noise-I, peak A-weighted sound levels due to truck tires, U. S. Department of Transportation Report OST/TST-72-1 (National Bureau of Standards, Washington, D. C., 1972).

[3] Leasure, Jr., W. A., and Corley, D. M., Truck noise-1B, spectral and directional characteristics of noise generated by truck tires, U. S. Department of Transportation Report DOT-TST-75-71 (National Bureau of Standards, Washington, D. C., 1974).

[4] Leasure, Jr., W. A., and Mathews, D. E., Pecos truck tire noise study: summary of results, NBS Report NBSIR 74-446 (National Bureau of Standards, Washington, D. C., January 1974).

[5] Leasure, Jr., W. A., Mathews, D. E., and Rinkinen, W. J., Truck noise I-A, noise evaluation tests of military truck tires, U. S. Department of Transportation Report DOT-TST-74-21 (National Bureau of Standards, Washington, D. C., February 1974).

[6] Tetlow, D., Truck tire noise, S)V Sound and Vibration 5 (8), 17-23 (1971).

[7] Hayden, R. E., Roadside noise from the interaction of a rolling tire with the road surface (Proceedings of the Purdue Noise Control Conference, Purdue University, West Lafayette, Indiana, July 14-16, 1971).

[8] Wik, T. R., and Miller, R. F., Mechanisms of tire sound generation, published in SAE Report SP-373: Truck Tire Noise (Society of Automotive Engineers, Inc., New York, N. Y., 1972).

[9] Corcoran, D. A., Effects of operating parameters on truck tire sounds, published in SAE Report SP-373: Truck tire noise (Society of Automotive Engineers, Inc., New York, N. Y., 1972).

[10] Hillquist, R. K. and Carpenter, P. C., A basic study of automobile tire noise, presented at the 85th meeting of the Acoustical Society of America, Boston, Mass. (April 1973). 
[1I] Thurman, G. R., Effect of road surface and bed clearance on truck tire noise, SAE Report 740607 (Society of Automotive Engineers, New York, New York, 1974).

[12] Gallaway, B. M., Epps, J. A., and Hargett, E. R., Design and construction of full-scale stopping pads and spin-out curves to predetermine friction values, Journal of Materials 5 (2), 303-322 (1970).

[13] Ivey, D. L., Stocker, A. J., et al., Pilot field test and evaluation center, TTI Technical Report 797-3 (Texas Transportation Institute, Texas A \& M University, College Station, Texas, 1972).

[14] Gallaway, B. M., Rose, J. G., Scott, Jr., W. W., and Schiller, R. E., Influence of water depths on friction properties of various pavement types, TTI Research Report 138-6 (Texas Transportation Institute, Texas A \& M University, College Station, Texas, 1974).

[15] Hudson, W. R., High-speed road profile equipment evaluation, published in Design, Performance and Surface Properties of Pavement, Highway Research Record, Number 189, 150-165 (Highway Research Board, Washington, D. C., 1967).

[16] Lawther, J. M., and Henry, J. J., Characterization of pavement macrotexture by profile spectral analysis, National Bureau of Standards Report NBSGCR 75-35 (The Pennsylvania Transportation Institute, University Park, Pa., 1974).

[17] Leasure, Jr., W. A., and Bender, E. K., Tire-road interaction noise, J. Acoust. Soc. Am. 58 (1), 39-50 (1975).

[18] Siddon, T. E., Noise generation mechanisms for passenger car tires, presented at the 84th meeting of the Acoustical Society of America, Miami, Florida (1972).

[19] Clark, S. K. (Ed.), Mechanics of pneumatic tires, NBS Monograph No. 122 (National Bureau of Standards, Washington, D. C. 1971).

[20] Chiesa, A., Oberto, L. and Tamburini, L., Transmission of tyre vibrations, Automobile Engineer 54, 520-530 (December 1964).

[2I] Reiter, Jr., W. F., Resonant sound and vibration characteristics of a truck tire, Tire Science and Technology, TSTCA, 2 (2), 130-141 (May 1974).

[22] Reiter, Jr., W. F., Eberhardt, A. C., Harper, L. J., and Atkinson, T. I., Truck noise VII-A, experimental investigation of truck tire sound and vibration, U. S. Department of Transportation Report DOT-TST-75-60 (Center for Acoustical Studies, North Carolina State University, Raleigh, North Carolina, December 1974). 
[23] Thurman, G. R., Characteristics of truck tire sound, published in SAE Report SP-373: Truck Tixe Noise (Society of Automotive Engineers, Inc., New York, N. Y., 1972).

[24] Wisleder, D. E., and Johns, J., Traffic noise versus roadway surfaces, presented at the 89th meeting of the Acoustical Society of America, Austin, Texas (April 1975).

[25] Kay, R. A., and Stephens, J. K., Porous friction courses and roadway surface noise, U. S. Department of 'Transportation Implementation Package 74-II (U. S. Department of Transportation, Federal Highway Administration, Washington, D. C., September 1974).

[26] Rose, J. G., Hutchinson, J. W., and Gallaway, B. M., Summary and analysis of the attributes of methods of surface texture measurement, published in Skid Resistance of Highway Pavements, ASTM STP530, 60-77 (Arnerican Society for Testing and Materials, Philadelphia, Pa., 1973).

[27] American Society for Testing and Materials, E274-70, Standard Method of Test for Skid Resistance of Paved Surfaces Using a Full-Scale Tire in Part 15, Book of ASTM Standards, 1974 (ASTM, Philadelphia, Pennsylvania).

[28] Close, W. H., Regulatory implications of truck tire noise studies, SAE Report 740606 (Society of Automotive Engineers, Inc., New York, N. Y., 197,4).

[29] Leasure, Jr., W. A., Mathews, D. E., and Cadoff, M. A., Automobile tire noise: results of a pilot study and review of the open literature, U. S. Department of Transportation Report No. DOT-TST-76-4 (National Bureau of Standards, Washington, D. C., August 1975). 


\section{Acknowledgements}

The authors would like to recognize the contributions made by the following organizations which have greatly aided this program: the staff of the Pennsylvania Transportation Institute especially Dr. James M. Lawther and Dr. John J. Henry; the Texas Transportation Institute in particular Mr. A. J. Stocker and the staff of the Texas A\&M University Research Annex; and the tire companies which loaned the government the test tires used in this study.

The authors also express appreciation to Mr. W. J. Rinkinen for his assistance in data acquisition and reduction, to Mrs. J. Russell for the typing and preparation of the manuscript, and to $\mathrm{Mr}$. W. H. Close (Office of Noise Abatement, U. S. Department of Transportation) for his review and comments. 
